\title{
Impact Assessment of Electric Vehicle Charging on Power Distribution Systems
}

by

Jian Xiong, B. Eng.

A thesis submitted to the Faculty of Graduate and Postdoctoral Affairs in partial fulfillment of the requirements for the degree of Master of Applied of Science in

Electrical and Computer Engineering

Ottawa-Carleton Institute for Electrical and Computer Engineering Carleton University Ottawa, Ontario

(C) 2014, Jian Xiong 


\begin{abstract}
This thesis investigates the impact of electric vehicle (EV) charging on distribution power systems through the following two tasks. The first task is to build the model of EVs connecting to the grid. Based on this model, the impact of EV charging on the distributed system at the neighborhood level is analyzed on both summer and winter peak days. These impacts are evaluated by taking into account the limitations of the rated transformer capacity and secondary drop lead current. In addition, as a practical concern for the power grid, the transformer ageing cycle is also investigated when EVs are penetrated into the grid. The other task is to investigate the impact of EV penetration across the entire distribution system. The EV charging impact on a feeder of the distribution system of Hydro Ottawa is assessed by considering the feeder unbalance and energy loss.
\end{abstract}




\section{Acknowledgements}

I would like to extend my appreciations and gratitude to my supervisor, Professor Xiaoyu Wang, for his suggestion, instruction, and guidance while I was carrying out this research. He provided persistent sources of support and encouragement when I was troubled with hesitations and uncertainties. This thesis would not have been possible completed without his irreplaceable care and support.

This thesis was conducted under the Electric Mobility Adoption and Prediction (EMAP) project lead by Pollution Probe and Hydro Ottawa. I appreciate Margaret Flores, Raed Abdullah from Hydro Ottawa and Melissa DeYoung from Pollution Probe for their generous support on the data and tools utilized in the thesis and valuable comments and suggestions on the research results.

The significant thanks must go to my research collaborators: Shichao Liu from Department of Systems and Computer Engineering, Rahul Kosuru and Akshay Kashyap from my research group, Di Wu from McGill University, Professor Haibo Zeng from Virginia Polytechnic Institute and State University, and Professor Paul D. H. Hines from University of Vermont have all supplemented my understanding and my work.

I would like to thank Sylvie Beekmans, Anna Lee, Blazenka Power, Scott Bruce, and Stephen MacLaurin from the Department of Electronics, for their help during the whole research. I also want to thank my classmates Alasdair Rankin and Ryan Griffin, for their tireless devotion of time and intellect toward the research. 
Finally, I am particularly appreciative to my family and my relatives, for their unselfish love and support. 


\section{Table of Contents}

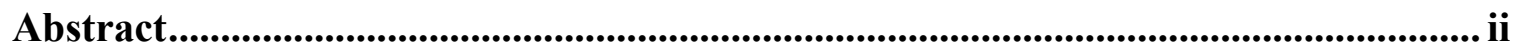

Acknowledgements ...........................................................................................................................iii

Table of Contents ....................................................................................................................... v

List of Tables ............................................................................................................................... vii

List of Figures................................................................................................................................... $\mathrm{x}$

1 Chapter: Introduction ......................................................................................................... 1

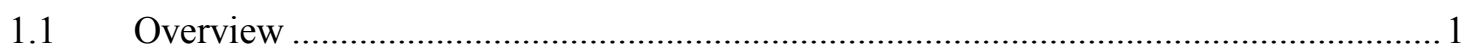

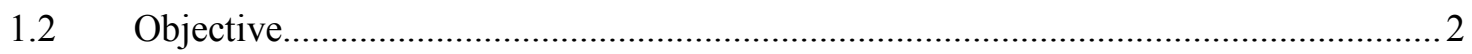

$1.3 \quad$ Literature Review ..................................................................................

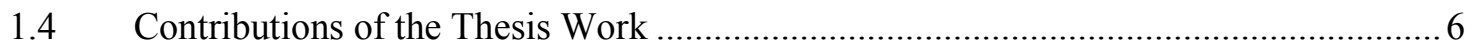

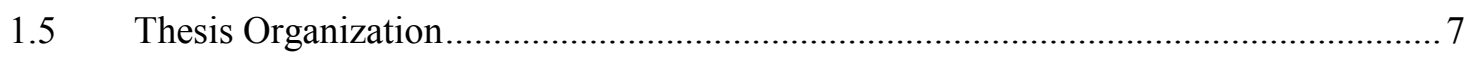

2 Chapter: Characteristics of Grid-Connected EV Charging ..................................... 8

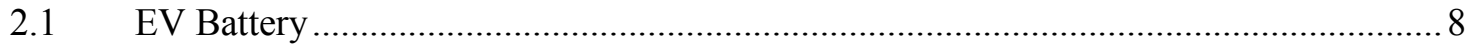

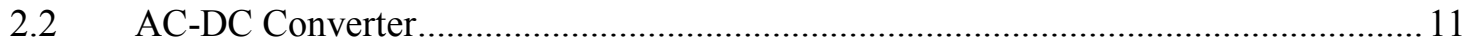

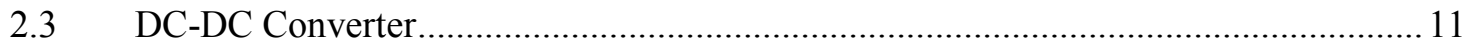

2.4 EV Charging Power Levels ................................................................................... 14

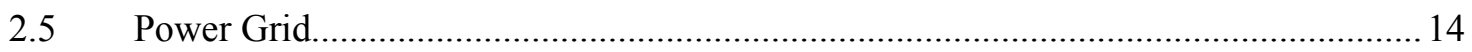

3 Chapter: Assessment of EV Charging at the Neighborhood Level........................ 16

3.1 EV Charging at the Neighborhood Level .................................................................. 16

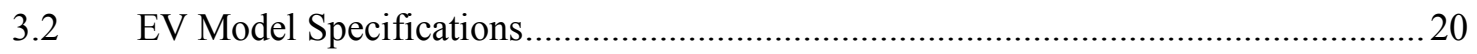

3.3 EV Charging Affected by Transformer Capacity and Secondary Current Limit .........21

3.3.1 Warmest Day ……………………………………………………………… 21

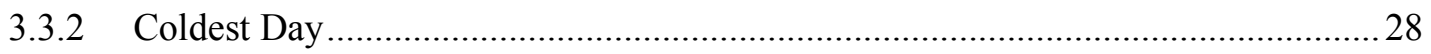


3.4 EV Charging Affected by Transformer Ageing ................................................... 32

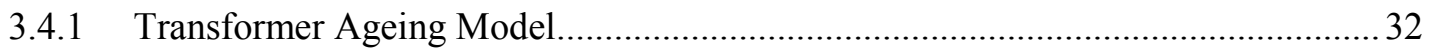

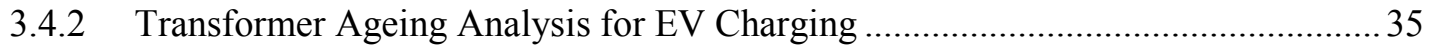

3.4.3 Transformer Ageing Analysis on the Warmest Day ................................................ 38

3.4.4 Transformer Ageing Analysis on the Coldest Day ................................................ 43

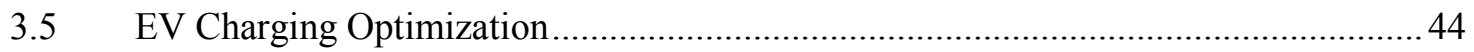

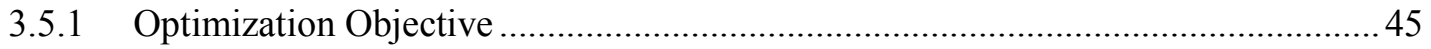

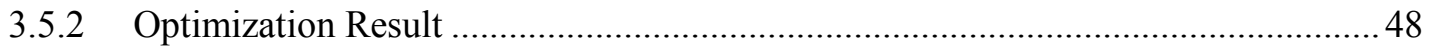

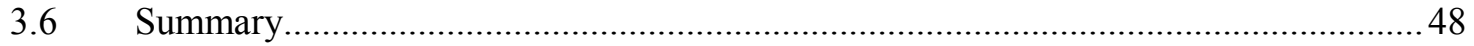

4 Chapter: Assessment of EV Charging at the Feeder Level.................................. 50

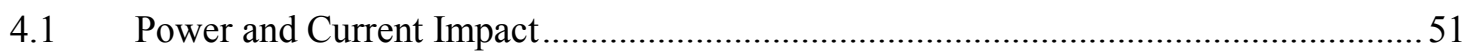

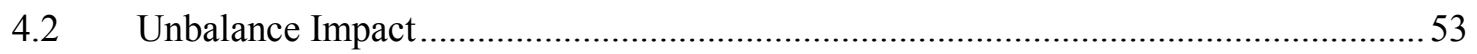

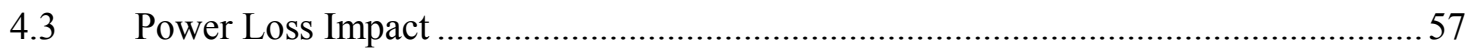

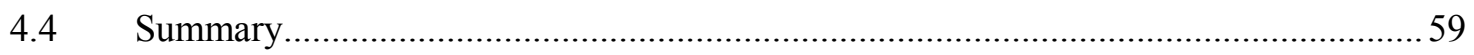

5 Chapter: Conclusions and Future Work ......................................................6 60

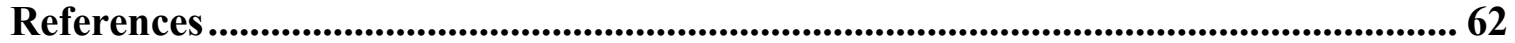




\section{List of Tables}

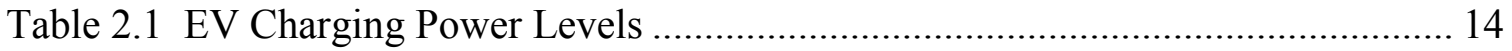

Table 3.1 EV Model Specifications ....................................................................... 20

Table 3.2 EV Penetration Limit on the Warmest Day-Power Limit 50kW (Peak Load

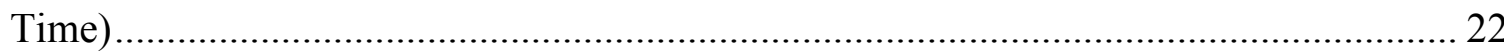

Table 3.3 EV Penetration Limit on the Warmest Day-Current Limit 185A (Peak Load

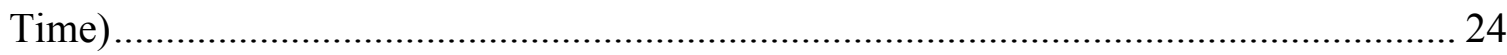

Table 3.4 EV Penetration Limit on the Warmest Day-Current Limit 325A (Peak Load Time)

Table 3.5 Verified EV Penetration Limit on the Warmest Day-Current Limit 185A

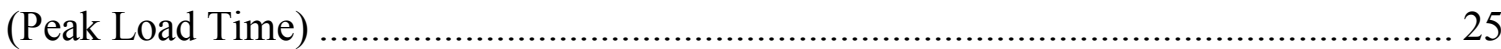

Table 3.6 Verified EV Penetration Limit on the Warmest Day-Current Limit 325A

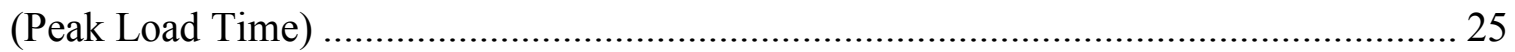

Table 3.7 EV Penetration Limit on the Warmest Day-Power Limit 50kW (Valley Load

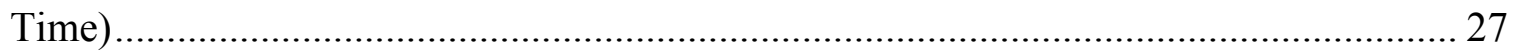

Table 3.8 EV Penetration Limit on the Warmest Day-Current Limit 185A (Valley Load

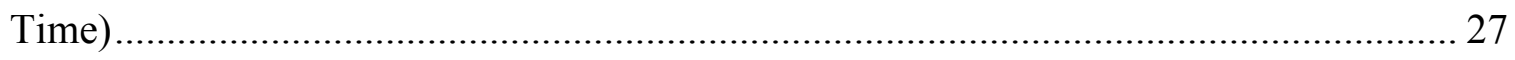

Table 3.9 EV Penetration Limit on the Warmest Day-Current Limit 325A (Valley Load Time)

Table 3.10 EV Penetration Limit on the Coldest Day-Power Limit 50kW (Peak Load

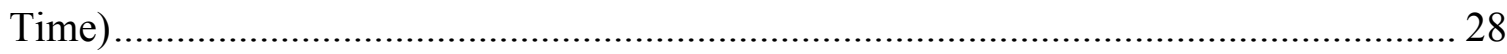


Table 3.11 EV Penetration Limit on the Coldest Day-Current Limit 185A (Peak Load

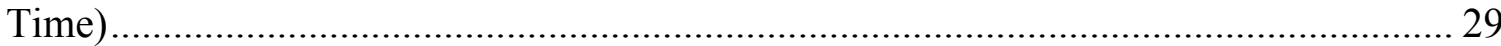

Table 3.12 EV Penetration Limit on the Coldest Day-Current Limit 325A (Peak Load Time) 30

Table 3.13 EV Penetration Limit on the Coldest Day-Power Limit 50kW (Valley Load

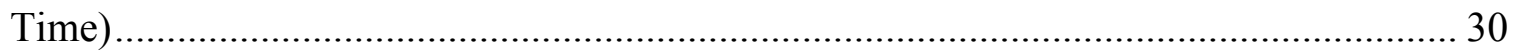

Table 3.14 EV Penetration Limit on the Coldest Day-Current Limit 185A (Valley Load

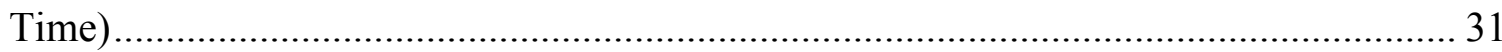

Table 3.15 EV Penetration Limit on the Coldest Day-Current Limit 325A (Valley Load

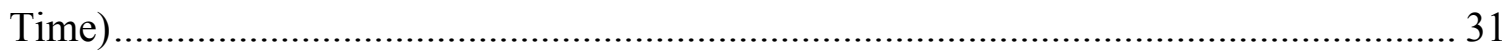

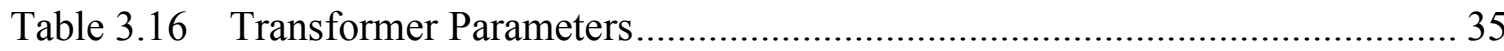

Table 3.17 Summary of Transformer Ageing Analysis on the Warmest Day (Peak Load

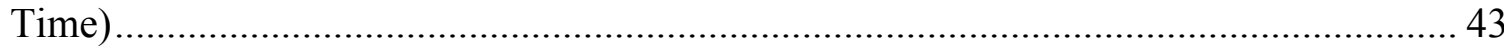

Table 3.18 Summary of Transformer Ageing Analysis on the Coldest Day (Peak Load

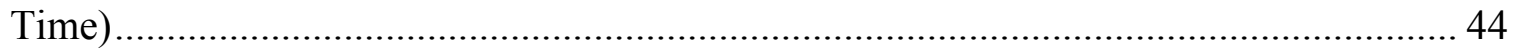

Table 3.19 EV Charging Optimization Nomenclature .......................................... 45

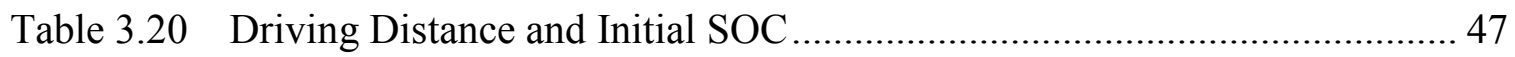

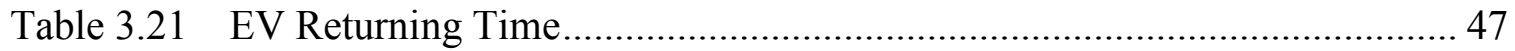

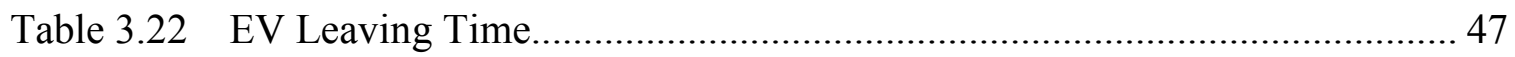

Table 4.1 Transformer Connection Distribution.................................................. 51

Table 4.2 New Transformer Connection Distribution .............................................. 51

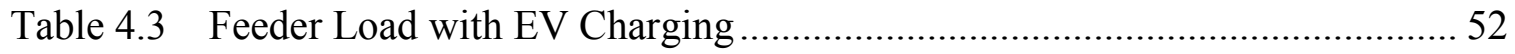

Table 4.4 Feeder Current with EV Charging .......................................................... 53 
Table 4.5 Basic Electric Power Generation and Losses ...

Table 4.6 Electric Power Generation and Losses with EV Charging .......................... 58 


\section{List of Figures}

Figure 2.1 Schematic diagram of grid-connected EV charging system......................... 8

Figure 2.2 Charging and discharging principle of lithium ion battery .......................... 9

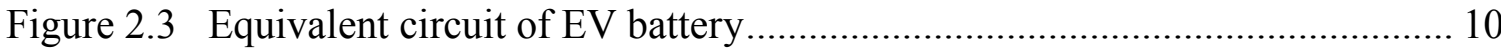

Figure 2.4 Single-phase unidirectional AC-DC conversion circuit of EV charger ........ 11

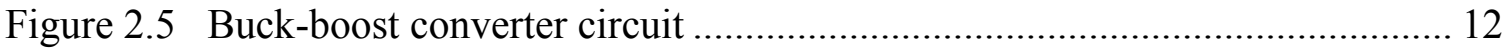

Figure 2.6 Charging power curves of 3 types of battery......................................... 13

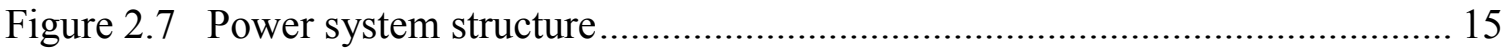

Figure 3.1 Load connection at the neighborhood level for pole-mounted transformer .. 18

Figure 3.2 Load profile by hour on the warmest day (July 17, 2013) .......................... 19

Figure 3.3 Load profile by hour on the coldest day (January 23, 2013)...................... 19

Figure 3.4 Constant charging power curve used in grid assessment of EV charging.... 21

Figure 3.5 Comparison of EV penetration levels on the warmest day (peak load time) 23

Figure 3.6 Relationship between secondary current limit and 6.6kW charger number. 26

Figure 3.7 Comparison of EV Table 3.12penetration levels on the coldest day (peak

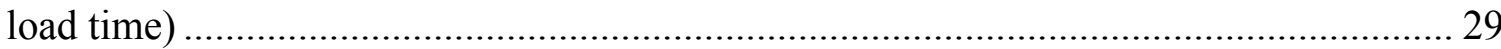

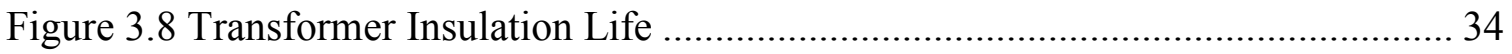

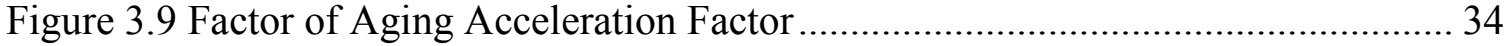

Figure 3.10 Transformer temperature without EV charging (warmest day) ............... 35

Figure 3.11 Transformer FAA without EV charging (warmest day).......................... 36

Figure 3.12 Transformer $F_{A A}$ with EV charging $(6.6 \mathrm{~kW}$ charger, warmest day) ......... 37

Figure 3.13 Transformer $F_{E Q A}$ with EV charging (6.6kW charger, warmest day) ........ 37 
Figure 3.14 Transformer $F_{A A}$ with EV charging (1.0kW charger, warmest day) ......... 38

Figure 3.15 Transformer $F_{E Q A}$ with EV charging (1.0kW charger, warmest day) ........ 38

Figure 3.16 Transformer $F_{A A}$ with EV charging (3.3kW charger, warmest day) ......... 39

Figure 3.17 Transformer $F_{E Q A}$ with EV charging (3.3kW charger, warmest day) ........ 39

Figure 3.18 Transformer $F_{A A}$ with EV charging (6.6kW charger, warmest day) ......... 40

Figure 3.19 Transformer $F_{E Q A}$ with EV charging (6.6kW charger, warmest day) ....... 40

Figure 3.20 Transformer $F_{A A}$ with EV charging (20kW charger, warmest day) .......... 41

Figure 3.21 Transformer $F_{A A}$ with EV charging and threshold limit (20kW charger,

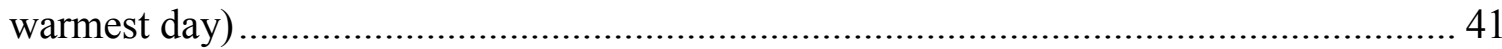

Figure 3.22 Transformer $F_{E Q A}$ with EV charging (20kW charger, warmest day) ........ 42

Figure 3.23 Transformer $F_{E Q A}$ with EV charging and threshold limit (20kW charger,

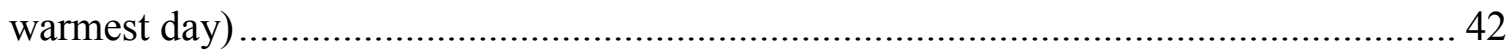

Figure 3.24 Optimal EV charging result ....................................................... 48

Figure 4.1 Schematic diagram of the investigated residential feeder for EV charging

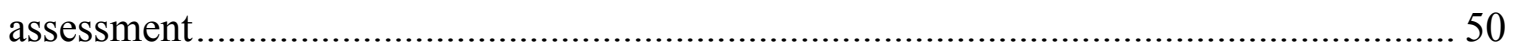

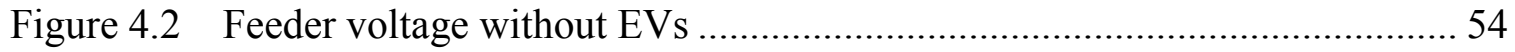

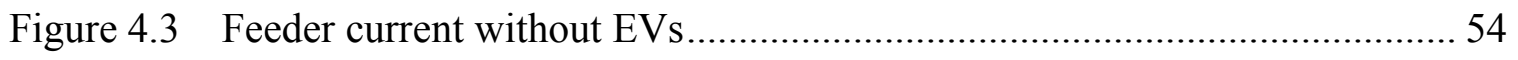

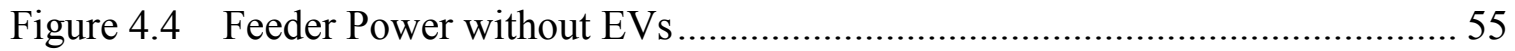

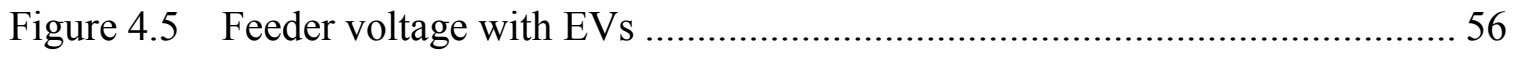

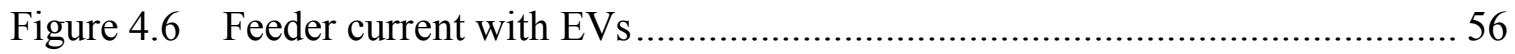

Figure 4.7 Percent of feeder voltage unbalance.................................................. 57

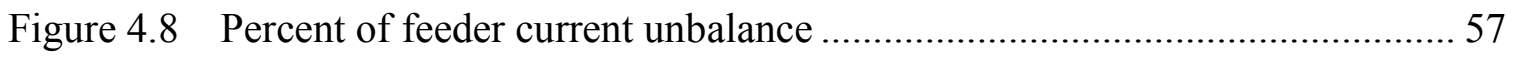




\section{Chapter: Introduction}

This chapter introduces the background and objective of the thesis work and presents the literature review on grid assessment of electric vehicle (EV) charging.

\subsection{Overview}

With the development of clean energy and smart grid, EV adoption in Canada is widely spread in recent years. There will be more than 500,000 EVs on Canadian roads by 2018 [1]. In the major Canadian cities, EVs are anticipated to be increasingly used over the next five years. However, the capacity of the local distribution systems to deliver power to EV end-users may be constrained under certain conditions. Thus, it is very important to enhance the electricity distribution system's ability to respond to the power demand for EV charging. EV load ( $2 \mathrm{~kW}$ at Level 1 and $7.2 \mathrm{~kW}$ at Level 2) is substantial compared with other residential load (a typical gas heated residential home represents a load of $4 \mathrm{~kW}$ ) [2]. High concentrating of EV charging may overload existing transformers in the distribution systems. Consequently, it is essential for electric utilities to assess the grid capacity considering the EV load characteristics at the planning stage of large-scale EV application. Since the load features of EVs are mainly influenced by the charging characteristics of the EV batteries and the time of EV switching on and off, the studies on EV load have been increasingly focused on these two aspects. The aggregated charging features of large number of EV batteries are usually investigated in the scale of hours and the accurate equivalent battery models for the grid assessment studies are necessary. In comparison with the battery charging, the distributed feature of EV plugin/off time has more significant effect on the aggregation load characteristic when the number of EV is large. Depending on timing and duration of the EV connection to the 
grid, there could be a wide variety of impact on grid constraints and capacity requirements. The other factors such as initial battery charging status and ambient temperature will also affect the EV load profile.

\subsection{Objective}

The objective of this thesis is to assess the penetration effect of EV batteries on the distribution system of Hydro Ottawa in the City of Ottawa. The thesis mainly focuses on proposing a methodology to model and analyze the network potential for EV charging at the neighborhood level and the feeder level in distribution power systems. The investigated distribution system data including the information of distribution substations,

feeders, transformers, and load profiles are provided by Hydro Ottawa. Several criteria are introduced to conduct the assessment at the neighborhood level including transformer capacity limit, secondary drop lead current limit, factor of transformed accelerated aging and factor of transformer equivalent aging. At the feeder level, the voltage and current unbalance and the energy loss caused by high penetration EVs are investigated for Hydro Ottawa's distribution system.

\subsection{Literature Review}

Based on different concerns, including EV penetration levels, EV charging characteristic, EV charging times and measurement metrics of the distribution system performance, many valuable works have been reported in terms of the effects of EV charging on distribution systems in the literature.

The penetration rates of EVs into distribution systems of different countries around the world have been used to more accurately assess the potential impact of the EV 
charging on the distribution systems. In North America, a constant 25\% Plug-in Hybrid Electric Vehicles (PHEV) market share starting in 2020 is estimated in [3]. In Japan, 20\% of new car sales by 2020 are expected to be EVs [4]. In Norway, 50,000 EVs are expected to be sold by 2018 [5]. 30\% PHEV market penetration by 2030 is the objective of Belgium [6]. When a large number of EVs are integrating into the current distribution systems, capacities of these distribution systems may be not sufficient to support the EV charging. Therefore the distribution systems may be overloaded without assessing the effects of the EV charging situations. For example, to meet the added power demand brought by PHEV charging in the evening, most regions in North America may need to build additional generation capacity [7]. When a very large number of PHEVs are penetrating into the distribution systems, it would place great pressure on peak units if the charging of these PHEVs are not properly controlled [8].

Meanwhile, different EV load characteristics have been considered when EVs are charging from distribution systems. Since the load features of EVs are mainly influenced by the charging characteristics of the EV batteries and the time of EV switching on and off, the studies on EV load have been increasingly focused on these two aspects. The charging characteristics have been defined by the battery size, charger efficiency, miles driven, and charger type [9]. For instance, four EV charging cases have been investigated, including uncontrolled domestic charging, uncontrolled domestic off-peak charging, smart domestic charging and uncontrolled public charging [10]. In [11], normal PHEV charging and quick PHEV charging have been studied on a regular weekday and off-peak days in summer and winter. This work has noticed that all PHEV charging strategies will create new load peaks. It will result in a slight decrease in operating 
efficiency of distribution transformers and even overloaded the distribution transformer in some cases. In [12]-[14], PHEVs charging at multiple levels of the grid have been suggested, including $1.4 \mathrm{~kW} \mathrm{EV} \mathrm{load} \mathrm{at} \mathrm{Level} 1$ of $120 \mathrm{~V} / 15 \mathrm{~A}, 2 \mathrm{~kW}$ EV load at Level 2 of $120 \mathrm{~V} / 20 \mathrm{~A}$ and $6 \mathrm{~kW}$ EV load at Level 2 of $240 \mathrm{~V} / 30 \mathrm{~A}$. Under the assumption of high PHEV penetration in the market, uniform charging, home-based charging and off-peak charging have been studied in [15]. According to [16], the authors have noticed that people would like charge their PEVs as soon as they arrive home, which probably results in a daily charging peak around $6 \mathrm{pm}-8 \mathrm{pm}$. They have suggested that proposing effective ways to manage EV charging is indispensable. In terms of EV charging in a macro-scale time domain, different seasons of a year have been considered in [17]-[19]. In [17], the authors have pointed out that the per-vehicle peak charging rate varies with different seasons and it is generally shorter in the summer and longer in the spring.

Besides EV charging characteristics, a variety of aspects of the distribution systems have been studied in terms of the effects of EV charging on the distribution systems. These aspects include phase imbalance, power quality, transformer lifespan and capacity limit [20]. In [21], the relationships between the number of active EV chargers and the levels of voltage and current imbalances have been investigated. It has been found that fewer active EV chargers result in larger current imbalance and lower voltage imbalance. When the power quality issue is taken into account, it mainly refers to harmonic distortion in the distribution systems. In [22], the authors have pointed out EV chargers from a large class of harmonic-producing load and these chargers become widespread in the residential distribution systems. When a large number of EVs are connected to the distribution system, it may cause the degradation of its transformer 
performance such as reducing the transformer's lifespan [23]. In [24], the impacts of the PHEV charging on Pacific Northwest distribution systems have been specifically investigated by researchers from Pacific Northwest National Laboratory (PNNL) in Richland, Washington. The test results with different residential feeder load profiles have shown that the distribution system could support the additional power demand for the $120 \mathrm{~V}$ smart charging profiles and it may be overloaded by the $240 \mathrm{~V}$ rapid charging profiles.

In view of the potential adverse impacts of the EV charging on the distribution systems, several optimal EV charging management strategies have also been developed in the literature. In [25], the authors have found that a large number of instant EV chargers will overload the distribution system. They used the electrolyte refilling technology to increase the allowable number of instant EV chargers. In [26], linear programming methods have been used for developing optimal EV charging strategies. The authors of this work have seen that these optimal EV charging methods could improve the three-phase voltage drop performance of the distribution system. In [27], the authors have developed an optimal charging strategy to maximize the EV chargers number under the power deliver limit of a distribution system. In [28], central control methods and distributed methods have been compared for the optimal EV charging issue. It has been observed that the full network state information is needed to centrally control the EV charging, while only the local information is used to make individual EV charging decisions. 
Although these work are very valuable and promising, detailed assessments of the effects of the EV charging are still necessary when a particular distribution system is considered in practice. This thesis aims to assess the penetration effect of EV batteries on the distribution system of Hydro Ottawa in the City of Ottawa. While a lot of the existing works use assumed load profiles, the investigated distribution system data in this work including the information of distribution substations, feeders, transformers, and load profiles are provided by Hydro Ottawa. With these real-world data, we model and evaluate the network potential for EV charging at the neighborhood level and the feeder level in distribution power systems. In addition, this research builds on the methodology from the Toronto Electric Mobility Adoption and Prediction (EMAP) study [29] and the findings inform the subsequent Ottawa EMAP study [30]. This work will help Hydro Ottawa to understand the effects of the EV charging on the power demand profile of Hydro Ottawa's distribution system. The investigation results are necessary to make informed, strategic and effective investments in EV charging technology and infrastructure in the next few years.

\subsection{Contributions of the Thesis Work}

The main contributions of the thesis are as follows:

1. This thesis proposes a methodology to assess the potential capacities of the power distribution systems for EV charging at the neighborhood level and the feeder level. Particularly, the transformer ageing model is investigated to quantify the relationship between EV load and transformer life cycle. 
2. An optimal EV charging strategy is designed to increase the penetration level of the EV charging power at the neighborhood level.

3. The conducted EV charging assessment and the designed optimal EV charging strategy in this thesis are based on the data obtained from the distribution systems of Hydro Ottawa. The research results provide insightful reference for the EV employment in the City of Ottawa.

\subsection{Thesis Organization}

A range of scenarios were investigated in this thesis to better understand the extent to which a number of key variables could impact the capacity of the electricity distribution system at the neighborhood level and the feeder level to accommodate EV charging at home. The thesis is organized as follows: Chapter 2 introduces the characteristics of grid-connected EV charging. Chapter 3 presents the grid assessment results at the neighborhood level considering the factor of transformer ageing. Chapter 4 analyzes the EV charging impact at the feeder level. Chapter 5 gives out the conclusions and discusses the future work. 


\section{Chapter: Characteristics of Grid-Connected EV Charging}

In order to analyze the impact of EV charging on the power grid, the characteristics of the EV charging process need to be understood. Figure 2.1 shows the generalized scheme of a grid-connected EV charging system where AC-DC and DC-DC converters are utilized for EV battery charging from the main grid [31]. Usually there is AC load connected at the grid side. This chapter will introduce each component of the EV system shown in this figure.

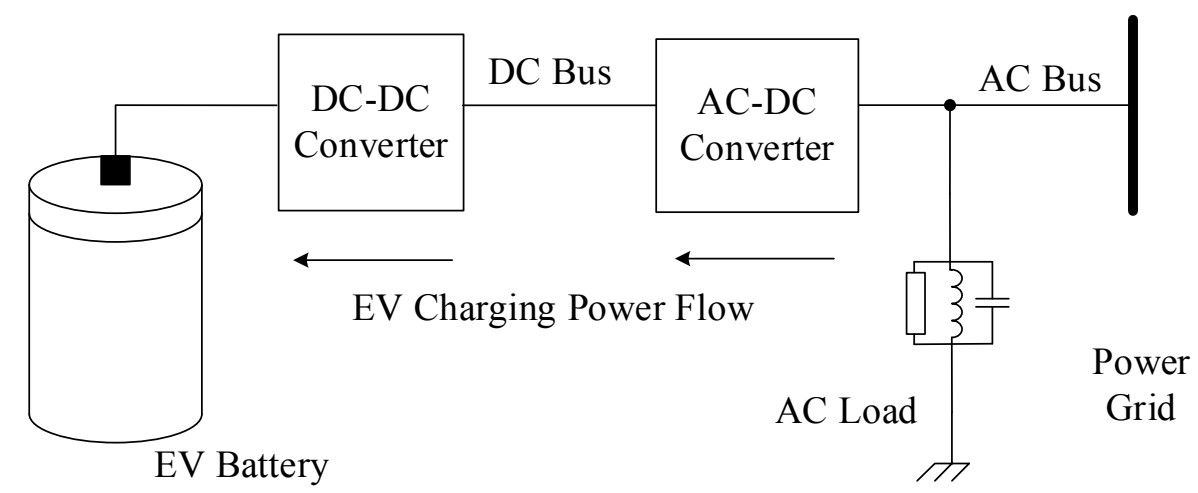

Figure 2.1 Schematic diagram of grid-connected EV charging system

\subsection{EV Battery}

High energy density batteries are preferred in EV applications due to the space limitation and the driving distance requirement of EV. There are different types of EV batteries including lead-acid, nickel metal hydride, and lithium ion battery. At the current stage, lithium ion battery is the most commonly used EV battery. The charging and discharging principle of lithium ion battery is shown in Figure 2.2 [32]. 


\section{Charging and discharging mechanism of}

lithium ion battery

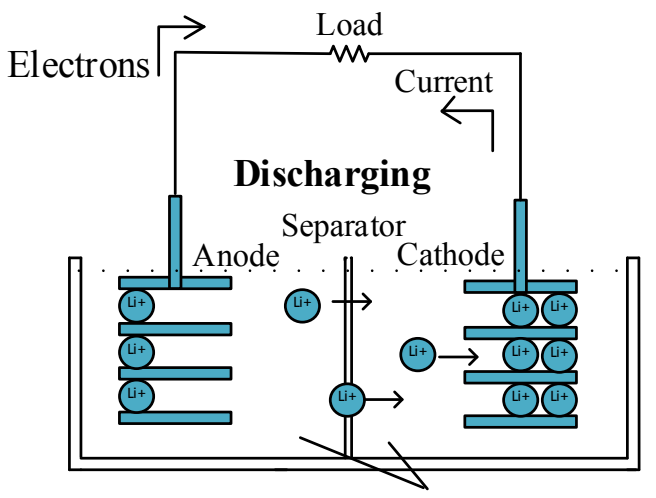

Electrolyte

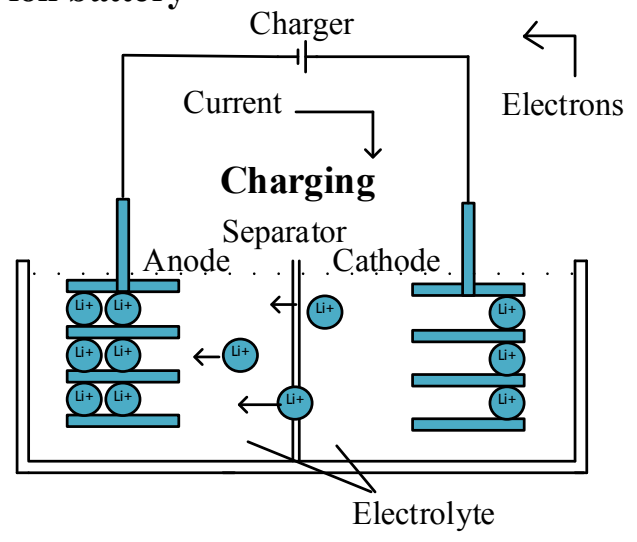

Figure 2.2 Charging and discharging principle of lithium ion battery

Lithium battery consists of anode, cathode, and electrolyte. During the discharging period, the electrons flow from anode to cathode through wire and load, which means the current flows in opposite direction from cathode to anode. The metal ions $\mathrm{Li}^{+}$flow from the anode to the cathode through the electrolyte. During the charging period, the electrons flow from cathode to anode through wire and load, and the current flows in opposite direction from anode to cathode. The metal ions $\mathrm{Li}^{+}$flow from the cathode to the anode through the electrolyte.

The equivalent electric circuit of lithum EV battery can be represented by a controlled DC voltage source $\left(E_{\text {batt }}\right)$ with an internal series resistance $(R)$ shown in Figure 2.3. The details of the equivalent model are described as follows [33], [34]:

$$
V_{\text {batt }}=E_{0}+\frac{K Q}{0.1 Q+I t} \cdot i-\frac{K Q}{Q-I t} \cdot I t+A e^{-B \cdot I t}+R \cdot i
$$




$$
I t=\left[1-S O C_{0}\right] \cdot Q-\int_{0}^{t} i d t, \quad 0 \leq I t \leq Q
$$

where $V_{\text {batt }}$ is the terminal voltage of the battery; $i$ is the discharging current; $Q$ is the nominal capacity of the battery; $K$ is a polarization constant of battery; $E_{0}$ is the constant electric potential of the battery; $A$ and $B$ are the constants of the exponential section of the battery charging; It is the extracted capacity of the battery; $S O C_{0}$ is the initial battery state-of-charge (SOC) - the percentage of charge left in the battery.

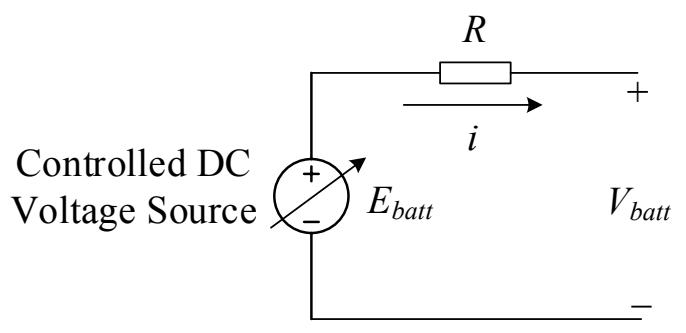

\section{Figure 2.3 Equivalent circuit of EV battery}

The meanings of the right part items in (1) are explained as follows [33], [34]. $E_{0}$ is the constant electric potential of the battery. The second item represents the impact of the polarization resistance. The third item is a non-linear voltage concerning the polarization voltage that changes with the actual charge of the battery in the initial rise part of battery charging. The fourth item represents the end part in the exponential section of the end battery charging term. The fifth item is the voltage loss on the internal resistance of the battery. 


\subsection{AC-DC Converter}

AC-DC converter is used to converter grid AC voltage into DC voltage to be applied to EV battery. Depending on different purpose of grid connection of EV, AC-DC converter can be unidirectional or bi-directional. Unidirectional AC-DC part consists of diode rectifier and power factor correction (PFC) circuit as shown in Figure 2.4 [35]. With this type of AC-DC converter, power can only flow from the grid to EV battery. PFC circuit is employed here to remove the DC bus voltage ripple caused by diode rectifier. Bidirectional AC-DC converter or inverter will be used if EV battery is designed to discharge power into the grid for vehicle-to-grid (V2G) operation. This thesis mainly investigates the unidirectional EV charging scenario.

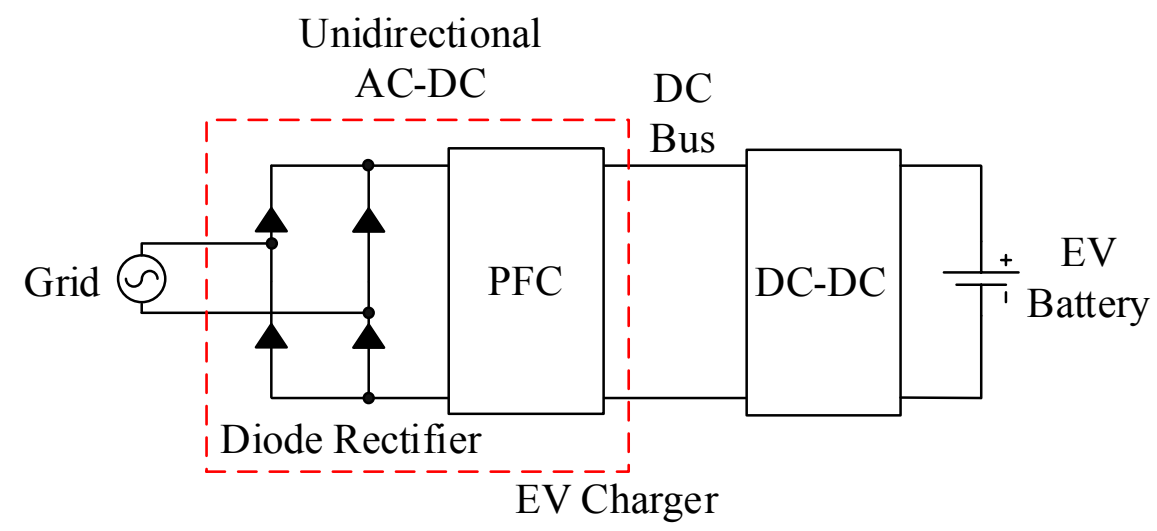

Figure 2.4 Single-phase unidirectional AC-DC conversion circuit of EV charger

\subsection{DC-DC Converter}

DC-DC stage is mainly used to modulate the battery DC voltage and the battery charging current. Similar with AC-DC converter, DC-DC converter can also be unidirectional and bidirectional based on different grid connection applications. DC-DC converter of unidirectional charging systems generally consists of a traditional DC-DC 
circuit which could be buck converter, boost converter, buck-booster converter, flyback converter, Cuk converter, and so on [36]. The DC-DC converter is used to converter the DC bus voltage to different EV battery EV battery voltages. As the grid voltages are standard, we need different voltage levels for different types of batteries.

Figure 2.5 shows the circuit topology of a buck-booster converter. The insulatedgate bipolar transistor (IGBT) acts as a switch to control the charging voltage $V_{\text {batt }}$ and the charging current $I_{\text {batt }}$. A constant voltage controller or a constant current controller can be designed to alter the switching status of the IGBT through the pulse generator.

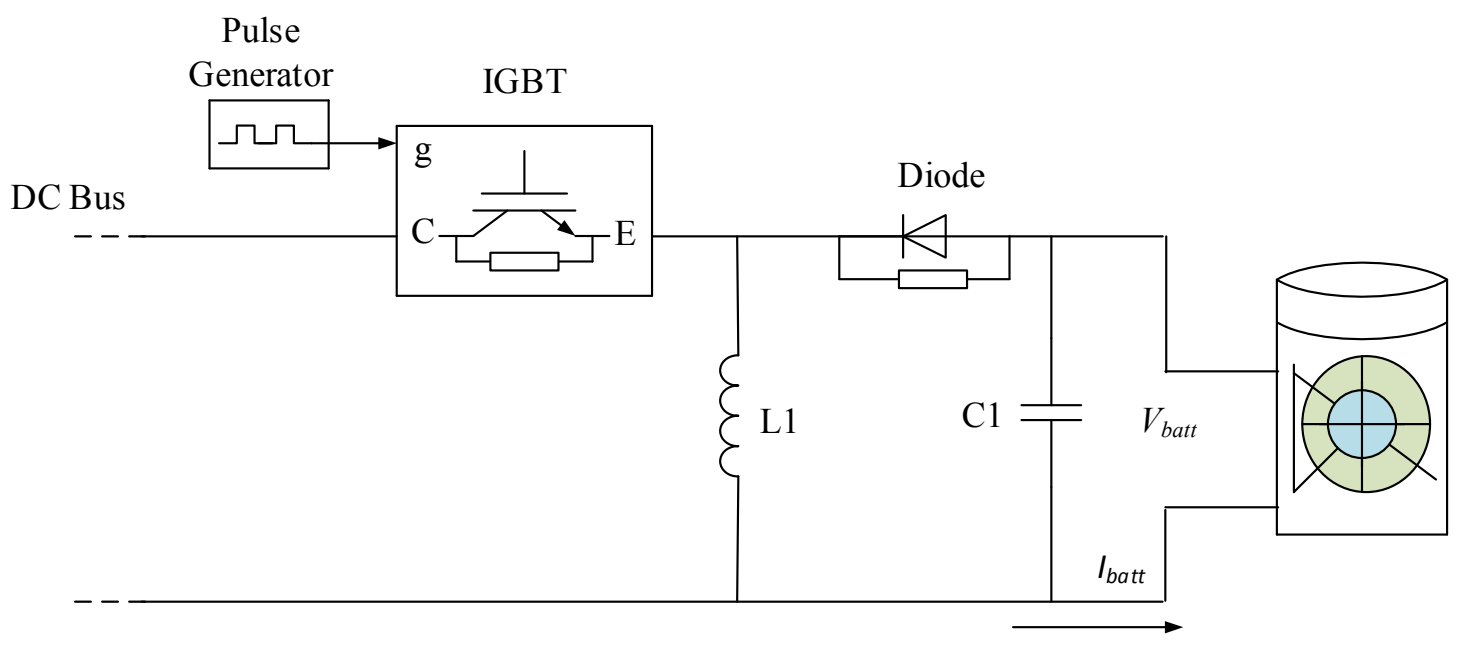

Figure 2.5 Buck-boost converter circuit

The two-stage charging of constant-current and constant-voltage is a common approach to extend battery service life. This charging approach starts to charge a low SOC battery by using constant current control with a relatively large reference charging current (rated battery current). The charging strategy is changed to the constant voltage control when the battery voltage reaches its rated value. Based on (1), the charging 
current indicates the charging speed and the charging voltage exhibits the SOC level of EV battery. When the large charging current is applied, the SOC value will increase fast and it will reach a high SOC level after the charging voltage hits the maximum value. Figure 2.6 shows the charging power curves of three different types of EV battery with the above two-stage charging approach.

In Figure 2.6, the constant voltage charging stage of lithium battery lasts a very short time with respect to the constant current-charging stage and charging current decays to 0 sharply. However, the constant voltage charging stages of the other two types of batteries are much longer remarkably. Therefore, to concentrate on the main characteristics of the EV charging and simplify the calculation, the constant voltage charging process could be ignored in the study of lithium battery charging characteristics and modeling. Furthermore, based on this figure a constant charging power curve can be used as good approximation for grid assessment of EV charging.

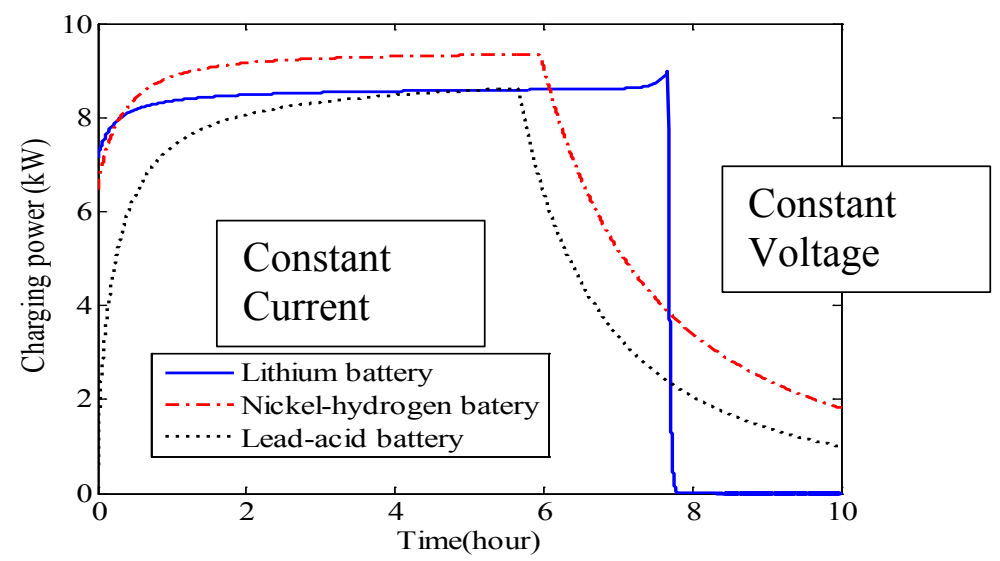

Figure 2.6 Charging power curves of 3 types of battery 


\subsection{EV Charging Power Levels}

Based on charging power levels, EV battery chargers can be classified as Level 1, Level 2 and Level 3 in North America. Typically, Level 1 charging is described as portability and used as an on-board charger. It has characteristics of long charging time and low cost. Level 2 charging has a balanced performance that volume and charging time are moderate. Its cost is higher than Level 1 charging. People describe Level 2 charging as the primary method for both private and public facilities. It can be used in V2G systems. Level 3 charging is mostly used in large power systems and fast charging systems. It is intended for commercial and public applications, operating like a filling station but has a large cost. Table 2.1 lists different EV charging power levels defined by Society of Automotive Engineers (SAE) [37].

Table 2.1 EV Charging Power Levels

\begin{tabular}{|c|c|c|c|c|}
\hline Charge level & Maximum Voltage & Maximum Current & Maximum Power & Phase \\
\hline AC level 1 & $120 \mathrm{~V} \mathrm{AC}$ & $16 \mathrm{~A}$ & $1.9 \mathrm{~kW}$ & single \\
\hline AC level 2 & $240 \mathrm{~V} \mathrm{AC}$ & $80 \mathrm{~A}$ & $19.2 \mathrm{~kW}$ & split \\
\hline AC level 3 & $480 \mathrm{~V} \mathrm{AC}$ & $330 \mathrm{~A}$ & $158.4 \mathrm{~kW}$ & three \\
\hline DC level 1 & $200-450 \mathrm{~V} \mathrm{DC}$ & $180 \mathrm{~A}$ & $19.2 \mathrm{~kW}$ & \\
\hline DC level 2 & $200-450 \mathrm{~V}$ DC & $200 \mathrm{~A}$ & $90 \mathrm{~kW}$ & \\
\hline DC level 3 & $200-600 \mathrm{~V} \mathrm{DC}$ & $240 \mathrm{~A}$ & $240 \mathrm{~kW}$ & \\
\hline
\end{tabular}

\subsection{Power Grid}

EVs are connected to distribution power systems during their charging. Figure 2.7 shows a simplified power system structure where electricity is generated at central power 
plant and delivered to load side through transmission system, substation and distribution system. Usually, large industrial and commercial load are directly connected to distribution system feeders and small residential load are connected to the branches (laterals) of feeders. When EVs are charged at industrial and commercial sites, the aggregated charging impact on the grid could be assessed at the feeder level directly. When EVs are charged at home, the aggregated impact on the grid will be assessed at the neighborhood level at first and then at the feeder level.

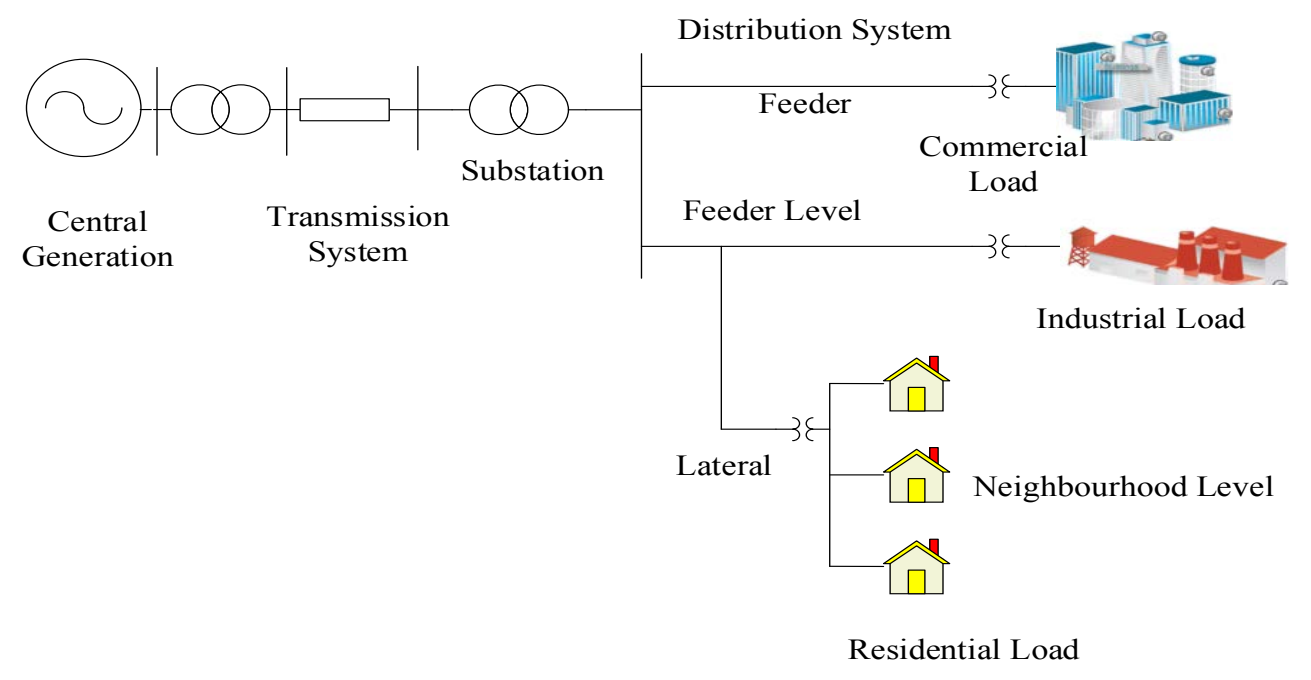

Figure 2.7 Power system structure 


\section{Chapter: Assessment of EV Charging at the Neighborhood Level}

This chapter presents the grid assessment results of EV charging for a representative neighborhood in Ottawa. Several factors including transformer capacity, secondary current limit, and transformer ageing are considered to find the maximum number of different types of EV that can be connected to the grid in this neighborhood. An optimal charging strategy is also designed and tested in this chapter.

\subsection{EV Charging at the Neighborhood Level}

At the neighborhood level, a pole-mounted or pad-mounted transformer supplies power to several households, which is illustrated in Figure 3.1 where two neighborhoods served by Hydro Ottawa's distribution system are plotted. When distribution feeders are located overhead, the transformer is usually mounted on a utility pole and is referred to as pole-mounted. When the distribution feeders run underground, the transformer is mounted on a concrete pad (pad-mounted) or installed in an underground vault [30]. Figure 3.1(a) shows a neighborhood with pole-mounted transformer and Figure 3.1(b) shows a neighborhood with pad-mounted transformer. The primary side of the transformers in this figure is connected to the $27.6 \mathrm{kV}$ feeder of the investigated distribution system. The secondary side of the transformers is connected to the household load which has the phase to phase voltage $240 \mathrm{~V}$. The secondary connection system consists of the following [30]:

- Secondary drop lead is a conductor connecting the transformer to a secondary bus. 
- Secondary bus is a bus provides a common electrical connection between multiple electrical devices. It is a common connection point for the individual service cables running directly to each household serviced by the transformer.

- Service cables connect the secondary bus to the end-user. Service cables are the last stage of the distribution system.

If the transformer is pole-mounted then there are secondary bus and secondary drop lead between the household load and the transformer, as shown in Figure 3.1(a). If the transformer is pad-mounted, the secondary side of the transformer will be directly connected the household load without secondary bus and secondary drop lead, as shown in Figure 3.1(b). In this figure, each household in one neighborhood has its basic load power level and the total load power level of this neighborhood is the sum of all the households. The total load power delivered by the feeder will flow through the polemounted or pad-mounted transformer without being over the capacity of the transformer, i.e., 50kVA. For the neighborhood with pole-mounted transformer, there is current limit for the secondary bus and the secondary drop lead. As a result, the total load current of the neighborhood cannot be over this limit. In the service area of Hydro Ottawa, the old current limit is defined as $185 \mathrm{~A}$ whereas the new standard increases the current limit to $325 \mathrm{~A}$ by upgrading the cables used for the secondary drop lead and secondary bus.

EV will be connected to individual household when EV charging impact is considered. At this time, the total load power flowing through the transformer will be the sum of the total basic household load power and the aggregated EV load power. The total EV load power depends on the number of EV connected to the households in the 
neighborhood at the same time and the plug in/off time of each EV. In this thesis, four Ottawa neighborhoods either with pole-mounted transformer or with pad-mounted transformer are investigated. Similar grid assessment results are obtained for these neighborhoods and only the results for the neighborhood shown in Figure 3.1(a) are presented and discussed.

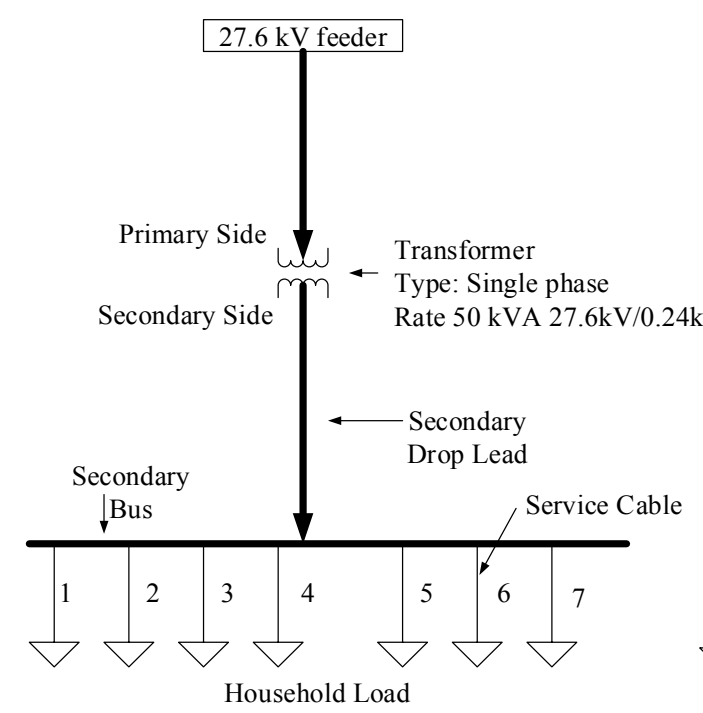

(a) Pole-mounted transformer

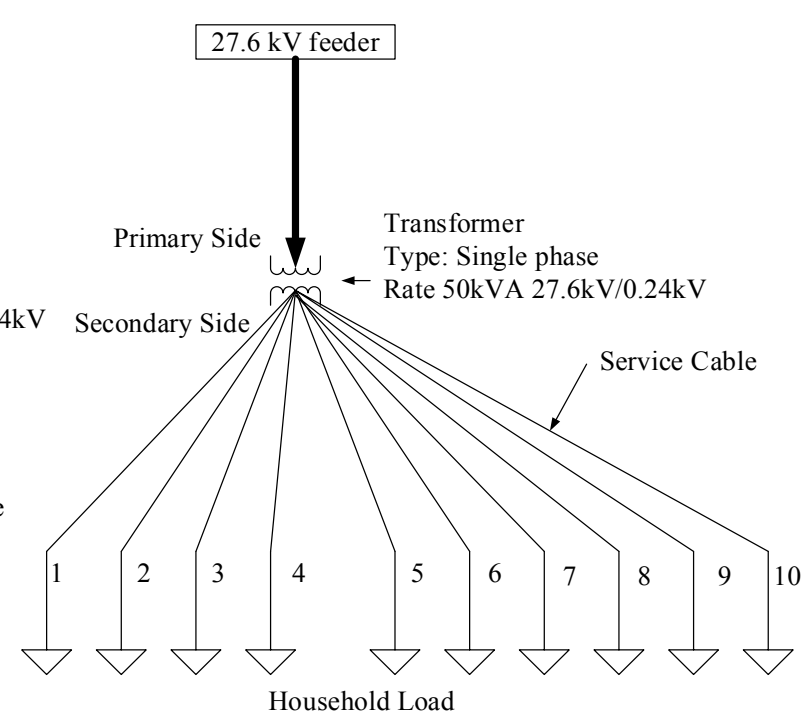

(b) Pad-mounted transformer

Figure 3.1 Load connection at the neighborhood level for pole-mounted transformer

Figure 3.2 and Figure 3.3 show the total transformer load and the individual household load for the summer peak day (highest temperature of $33.2^{\circ} \mathrm{C}$ at $1.00 \mathrm{pm}$ $(13: 00)$ on $17^{\text {th }}$ July 2013) and the winter peak day (lowest temperature of $-28.5^{\circ} \mathrm{C}$ at 08:00am on $23^{\text {rd }}$ January 2013) [38] without EV charging for the neighborhood shown in Figure 3.1(a), respectively. Those two days are the representative highest load power days in one year due to the highest temperature Figure 3.3 (maximum cooling load will be picked up) and the lowest temperature (maximum heating load will be picked up). 
There are seven households in this neighborhood and it can be seen that the maximum power of the neighborhood is less than $20 \mathrm{~kW}$ on the summer peak day and $16 \mathrm{~kW}$ on the winter peak days, which means the total neighborhood load is well below the transformer capacity 50kVA. Also it is not difficult to calculate that the maximum total load current of the neighborhood is below the current limit of the secondary drop lead and the secondary bus.

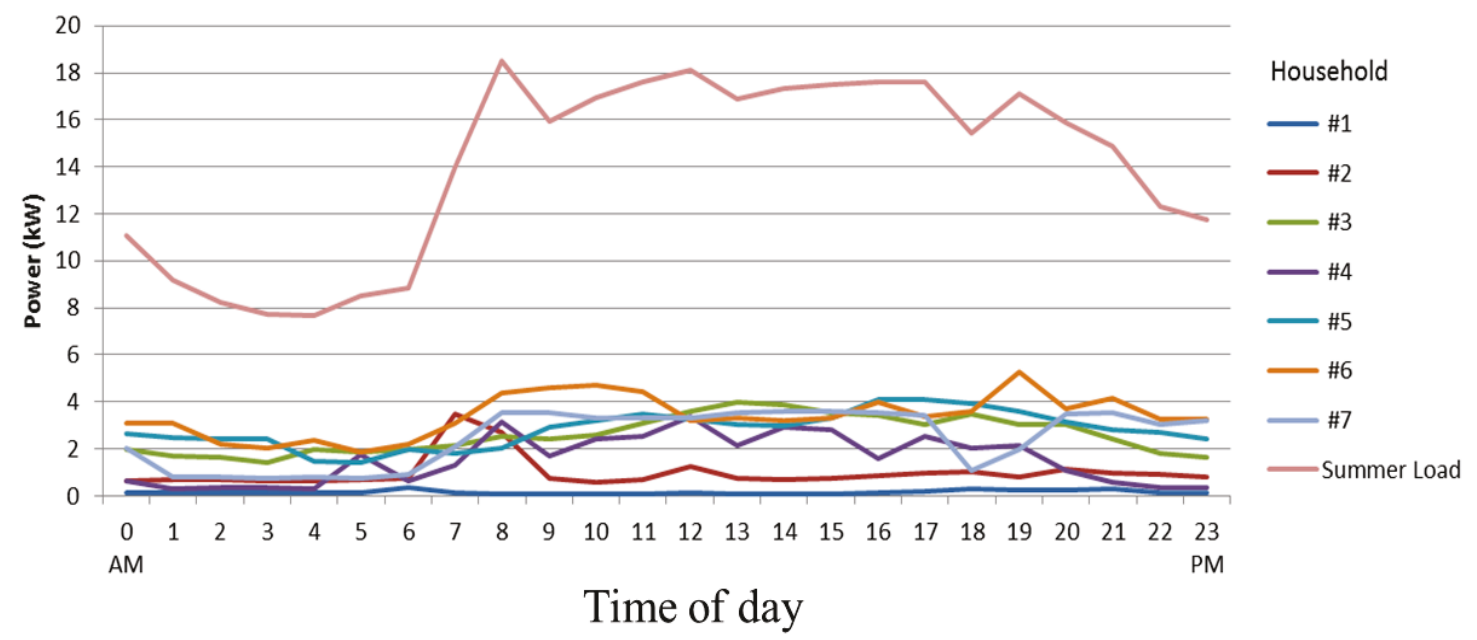

Figure 3.2 Load profile by hour on the warmest day (July 17, 2013)

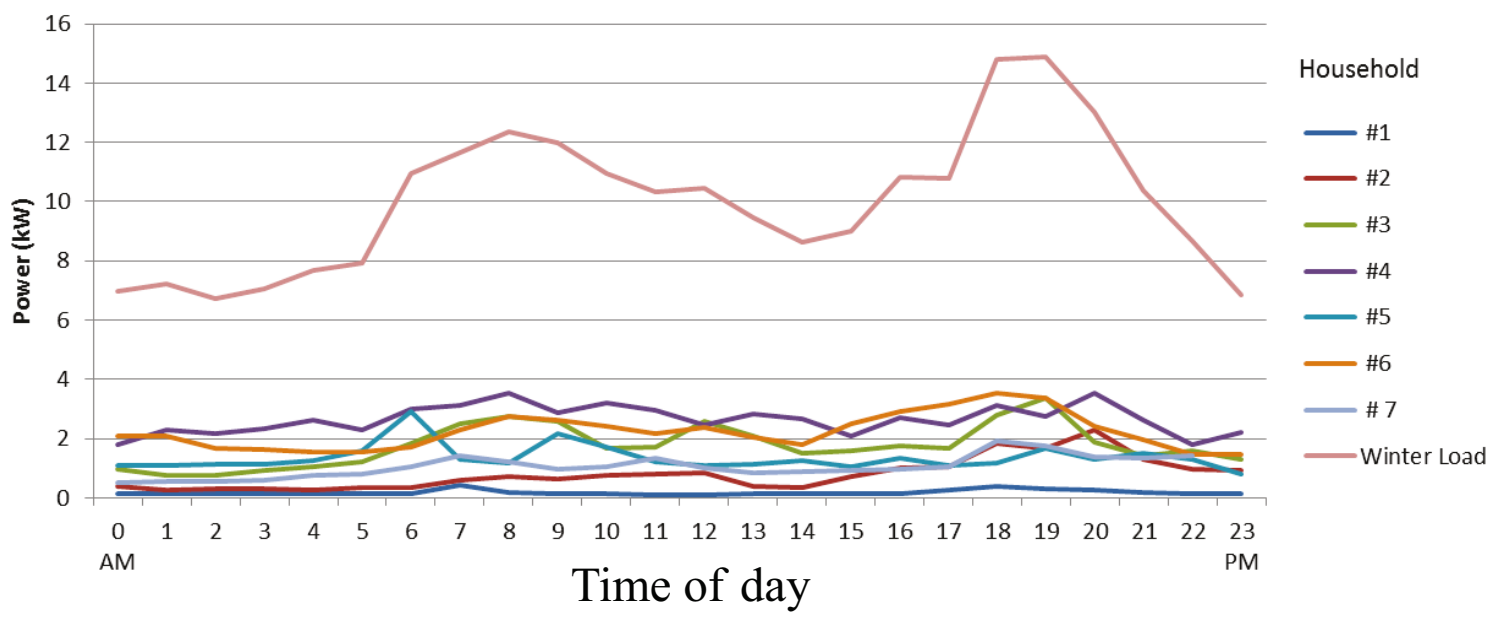

Figure 3.3 Load profile by hour on the coldest day (January 23, 2013) 


\subsection{EV Model Specifications}

Currently there are different types of EV on market. Several popular EVs are selected to be studied in this grid assessment work. The specifications of the investigated EVs are shown in Table 3.1. Here, "charging hours" means how long it will take an EV to be fully charged with empty battery. "Per hour charge" means how many kilometers an EV can drive with one-hour charging. In this thesis, it is assumed that each EV has an empty battery when it is connected to the grid for charging. As a result, "charging hours" will be the total connected time for each EV. Figure 3.4 illustrates the charging power of Honda Fit EV. It takes 3 hours to charge this EV from empty to full. During this threehour period, the charging power of $\mathrm{EV}$ or the power contribution from $\mathrm{EV}$ to the total transformer load is always $6.6 \mathrm{~kW}$. When the $\mathrm{EV}$ is full, it will be disconnected from the grid and no more power will be delivered to it. Additionally, the EV penetration rate used in this thesis is calculated by using the total load profile for the transformer and adding the additional load for one EV per household served by the transformer.

Table 3.1 EV Model Specifications

\begin{tabular}{|c|c|c|c|c|}
\hline EV Model & $\begin{array}{c}2013 \text { Fiat 500e } \\
120 \mathrm{~V}[39]\end{array}$ & $\begin{array}{c}\text { Nissan Leaf } \\
240 \mathrm{~V}[40][41]\end{array}$ & $\begin{array}{c}2014 \text { Honda Fit } \\
\text { EV 240V [42] }\end{array}$ & $\begin{array}{c}\text { TESLA Model } \\
\text { S 240V [43] }\end{array}$ \\
\hline Charging power & $1.0 \mathrm{~kW}$ & $3.3 \mathrm{~kW}$ & $6.6 \mathrm{~kW}$ & $20 \mathrm{~kW}$ \\
\hline Battery size & $24 \mathrm{kWh}$ & $24 \mathrm{kWh}$ & $20 \mathrm{kWh}$ & $85 \mathrm{kWh}$ \\
\hline Charging hours & 22 hours & 8 hours & 3 hours & 5 hours \\
\hline Per hour charge & $7 \mathrm{~km}$ & $14 \mathrm{~km}$ & $43 \mathrm{~km}$ & $100 \mathrm{~km}$ \\
\hline
\end{tabular}




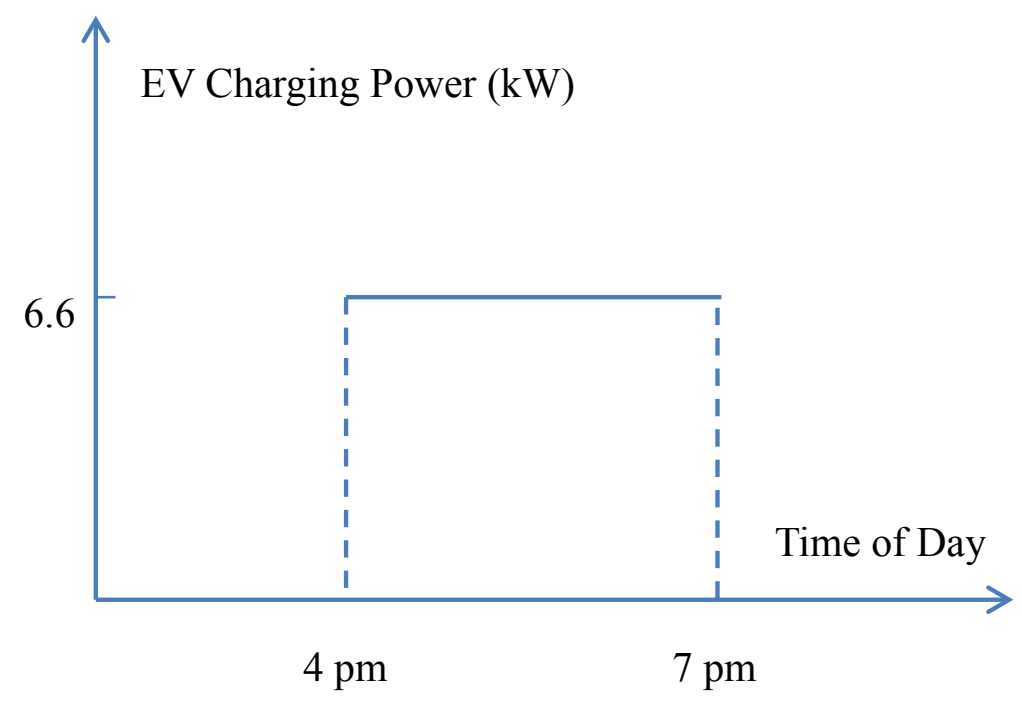

Figure 3.4 Constant charging power curve used in grid assessment of EV charging

\subsection{EV Charging Affected by Transformer Capacity and Secondary Current}

\section{Limit}

The neighborhood shown in Figure 3.1(a) is used to investigate the key variables limiting EV charging in this section. Two main factors, the transformer capacity and the secondary drop lead current limit, are studied. A set of scenarios are developed based on the neighborhood load profiles shown in Figure 3.2 and Figure 3.3 and the EV chargers shown in Table 3.1. It is assumed that maximum number of EVs could charge at the highest load point on the load profiles simultaneously. While this condition is not likely to occur in actual applications, this investigation allows for a better understanding of possible worst-case scenarios and key factors that could limit the number of EVs that can be accommodated by the electricity distribution system.

\subsubsection{Warmest Day}

In Figure 3.2, the transformer load on the warmest day of 2013 is the sum of the individual house load. The maximum (i.e., peak) transformer load is $18.48 \mathrm{~kW}$ occurring 
at 8:00am. The minimum (i.e. valley) transformer load is $7.69 \mathrm{~kW}$ occurring at 4:00am. In this assessment, the "worst charging scenario" and the "minimum load charging scenario" are corresponding to the peak load time and the valley load time of the investigated day, respectively. The two scenarios form the base load situations and different number and type of EVs are tested on these base load situations.

Table 3.2 shows the EV penetration level for the "worst charging scenario" based on the rated transformer capacity $(50 \mathrm{kVA})$. EVs are connected to the grid at 8:00am which is the peak load time. The highlighted parts in the table mean the total load is over the rated transformer capacity $50 \mathrm{kVA}$, i.e., overload. Here we assume the load power factor is 1 . As a result, the load level $50 \mathrm{~kW}$ will be equivalent to the transformer capacity $50 \mathrm{kVA}$. From this table it can be observed that the $1.0 \mathrm{~kW}$ and $3.3 \mathrm{~kW}$ chargers will not cause overload. The $6.6 \mathrm{~kW}$ charger will allow $4 \mathrm{EVs}$ and the $20 \mathrm{~kW}$ charger will allow only one EV to be connected. After these EVs numbers, the power consumer is over 50 $\mathrm{kW}$.

Table 3.2 EV Penetration Limit on the Warmest Day-Power Limit 50kW (Peak Load Time)

\begin{tabular}{|c|c|c|c|c|}
\hline \multirow{2}{*}{$\begin{array}{c}\text { Number of } \\
\text { EVs in } \\
\text { addition to } \\
\text { house load }\end{array}$} & \multicolumn{4}{|c|}{ Transformer Load (kW) } \\
\cline { 2 - 5 } & $\mathbf{1 . 0 k W}$ & $\mathbf{3 . 3 k W}$ & $\mathbf{6 . 6 k W}$ & $\mathbf{2 0 k W}$ \\
\hline $\mathbf{1}$ & 19.48 & 21.78 & 25.08 & 38.48 \\
\hline $\mathbf{2}$ & 20.48 & 25.08 & 31.68 & 58.48 \\
\hline $\mathbf{3}$ & 21.48 & 28.38 & 38.28 & 78.48 \\
\hline $\mathbf{4}$ & 22.48 & 31.68 & 44.88 & 98.48 \\
\hline $\mathbf{5}$ & 23.48 & 34.98 & 51.48 & 118.48 \\
\hline $\mathbf{6}$ & 24.48 & 38.28 & 58.08 & 138.48 \\
\hline $\mathbf{7}$ & 25.48 & 41.58 & 64.68 & 158.48 \\
\hline
\end{tabular}


Figure 3.5 considers the charging hours of each type of EV. The maximum EV number 7 is used to illustrate the charging impact. It displays that the transformer will be overloaded if all the $7 \mathrm{EVs}$ of $6.6 \mathrm{~kW}$ or $20 \mathrm{~kW}$ are connected to the grid. It is worth to note different EV may charge at different time and the total transformer load for the $6.6 \mathrm{~kW}$ charger could be under the rated transformer capacity if an optimal charging strategy is arranged for the EVs.

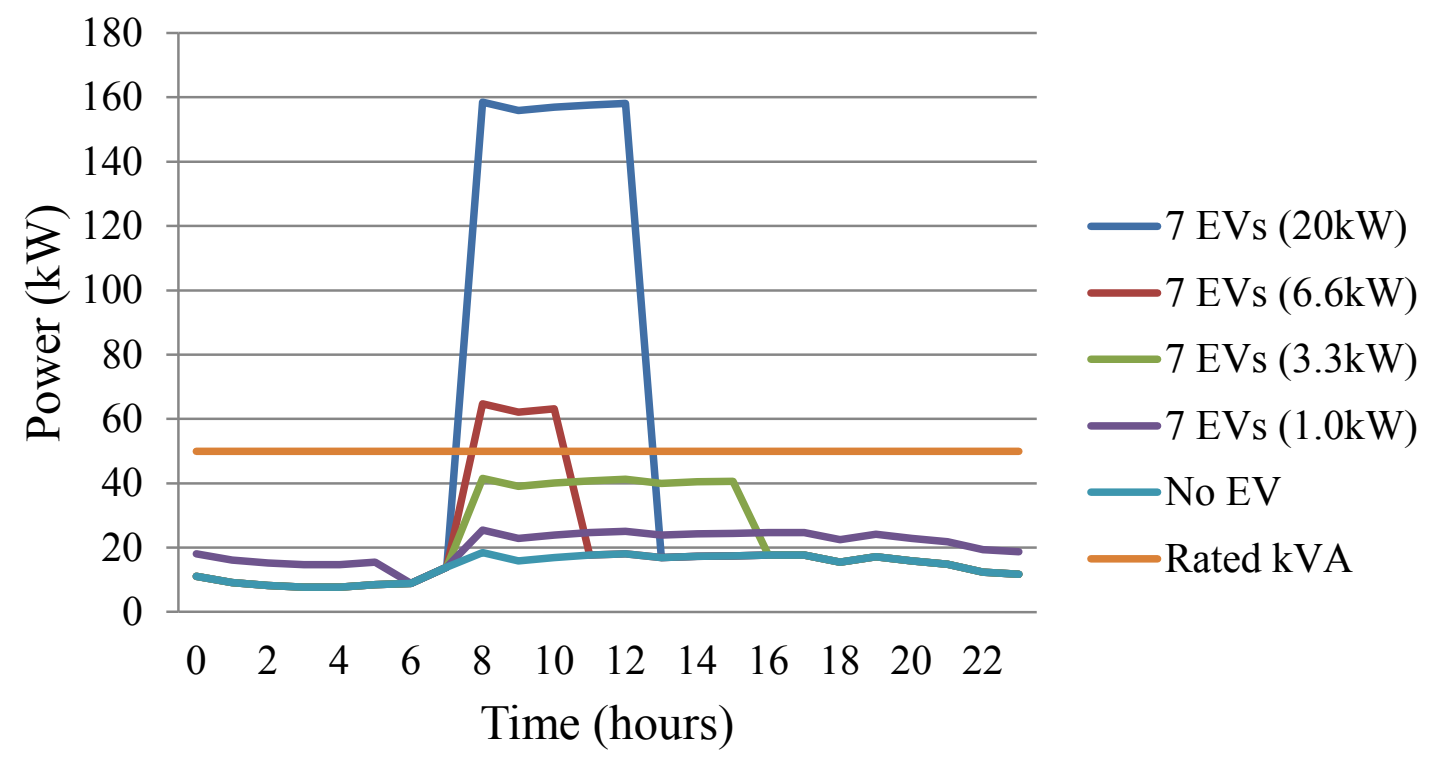

Figure 3.5 Comparison of EV penetration levels on the warmest day (peak load time)

As we mentioned before, there are two standards for the secondary drop lead current limit in Ottawa. The old limit is $185 \mathrm{~A}$, and the new limit is $325 \mathrm{~A}$. Table 3.3 shows the EV penetration limit when the 185A limit is used to assess the charging effect. EVs are connected to the grid at 8:00am which is the peak load time. The highlighted parts mean the second drop lead is overloaded. Using the old standard (185A), the $6.6 \mathrm{~kW}$ charger will allow $3 \mathrm{EVs}$ and the $20 \mathrm{~kW}$ charger will allow only one EV to be connected. 
The new standard current limit (325A) shown in Table 3.4 will allow the $6.6 \mathrm{~kW}$ charger to connect $7 \mathrm{EVs}$ and the $20 \mathrm{~kW}$ charger to connect $2 \mathrm{EVs}$. In this situation, the secondary drop lead can connect more EVs.

Table 3.3 EV Penetration Limit on the Warmest Day-Current Limit 185A (Peak Load Time)

\begin{tabular}{|c|c|c|c|c|}
\hline \multirow{2}{*}{$\begin{array}{c}\text { Number of } \\
\text { EVs in } \\
\text { addition to } \\
\text { house load }\end{array}$} & \multicolumn{4}{|c|}{ Current on Secondary Drop Lead (A) } \\
\cline { 2 - 5 } & $\mathbf{1 . 0} \mathbf{~ k W}$ & $\mathbf{3 . 3} \mathbf{~ k W}$ & $\mathbf{6 . 6} \mathbf{~ k W}$ & $\mathbf{2 0} \mathbf{~ k W}$ \\
\hline $\mathbf{1}$ & 81.17 & 90.75 & 104.50 & 160.33 \\
\hline $\mathbf{2}$ & 85.33 & 104.50 & 132.00 & 243.67 \\
\hline $\mathbf{3}$ & 89.50 & 118.25 & 159.50 & 327.00 \\
\hline $\mathbf{4}$ & 93.67 & 132.00 & 187.00 & 410.33 \\
\hline $\mathbf{5}$ & 97.83 & 145.75 & 214.50 & 493.67 \\
\hline $\mathbf{6}$ & 102.00 & 159.50 & 242.00 & 577.00 \\
\hline $\mathbf{7}$ & 106.17 & 173.25 & 269.50 & 660.33 \\
\hline
\end{tabular}

Table 3.4 EV Penetration Limit on the Warmest Day-Current Limit 325A (Peak Load Time)

\begin{tabular}{|c|c|c|c|c|}
\hline \multirow{2}{*}{\begin{tabular}{c} 
Number of $\begin{array}{c}\text { EVs in } \\
\text { addition to } \\
\text { house load }\end{array}$ \\
\cline { 2 - 5 }
\end{tabular}} & \multicolumn{4}{|c|}{ Current on Secondary Drop Lead (A) } \\
\cline { 2 - 5 } EV Charger Capacity \\
\hline $\mathbf{1}$ & $\mathbf{1 . 0} \mathbf{~ k W}$ & $\mathbf{3 . 3} \mathbf{~ k W}$ & $\mathbf{6 . 6} \mathbf{~ k W}$ & $\mathbf{2 0} \mathbf{~ k W}$ \\
\hline $\mathbf{2}$ & 81.17 & 90.75 & 104.50 & 160.33 \\
\hline $\mathbf{3}$ & 85.33 & 104.50 & 132.00 & 243.67 \\
\hline $\mathbf{4}$ & 93.50 & 118.25 & 159.50 & 327.00 \\
\hline $\mathbf{5}$ & 97.83 & 132.00 & 187.00 & 410.33 \\
\hline $\mathbf{6}$ & 102.00 & 145.75 & 214.50 & 493.67 \\
\hline $\mathbf{7}$ & 106.17 & 173.50 & 242.00 & 577.00 \\
\hline
\end{tabular}

The professional simulation software CYMEDist is utilized to verify the calculation results listed in Table 3.2, Table 3.3 and Table 3.4. The verification results are shown in Table 3.5 and Table 3.6, respectively. 
Table 3.5 Verified EV Penetration Limit on the Warmest Day-Current Limit 185A (Peak Load Time)

\begin{tabular}{|c|c|c|c|}
\hline EV \# (6.6kW) & Current (A) & Voltage (V) & Load (kW) \\
\hline $\mathbf{0}$ & 77.48041 & 238.4 & 18.47133 \\
\hline $\mathbf{1}$ & 105.3664 & 238 & 25.07721 \\
\hline $\mathbf{2}$ & 133.3102 & 237.6 & 31.6745 \\
\hline $\mathbf{3}$ & 161.3117 & 237.2 & 38.26313 \\
\hline $\mathbf{4}$ & 189.4864 & 236.8 & 44.87037 \\
\hline $\mathbf{5}$ & 217.7188 & 236.4 & 51.46872 \\
\hline $\mathbf{6}$ & 246.0667 & 236 & 58.07174 \\
\hline $\mathbf{7}$ & 274.5878 & 235.6 & 64.69288 \\
\hline
\end{tabular}

Table 3.6 Verified EV Penetration Limit on the Warmest Day-Current Limit 325A (Peak Load Time)

\begin{tabular}{|c|c|c|c|}
\hline EV \# (6.6kW) & Current (A) & Voltage (V) & Load (kW) \\
\hline $\mathbf{0}$ & 77.48041 & 238.4 & 18.47133 \\
\hline $\mathbf{1}$ & 105.3664 & 238 & 25.07721 \\
\hline $\mathbf{2}$ & 133.3102 & 237.6 & 31.6745 \\
\hline $\mathbf{3}$ & 161.3117 & 237.2 & 38.26313 \\
\hline $\mathbf{4}$ & 189.4864 & 236.8 & 44.87037 \\
\hline $\mathbf{5}$ & 217.7188 & 236.4 & 51.46872 \\
\hline $\mathbf{6}$ & 246.0667 & 236 & 58.07174 \\
\hline $\mathbf{7}$ & 274.5878 & 235.6 & 64.69288 \\
\hline
\end{tabular}

From Table 3.5, the current results match the analytical method. The $6.6 \mathrm{~kW}$ charger will allow 3 EVs which match with the value of the $6.6 \mathrm{~kW}$ charger in Table 3.3 according to the old secondary drop lead current capacity 185A. Also from Table 3.5, the load results match the analytical method. The $6.6 \mathrm{~kW}$ charger will allow 4 EVs which match the value of the $6.6 \mathrm{~kW}$ charger in Table 3.2 according to the transformer capacity $50 \mathrm{kVA}$. 
In Table 3.6, the $6.6 \mathrm{~kW}$ charger will allow 7 EVs which with the value of the $6.6 \mathrm{~kW}$ charger in Table 3.4 according to the new secondary drop lead current capacity 325A. Figure 3.6 summaries the secondary drop lead current versus the allowed $6.6 \mathrm{~kW}$ EV charger number.

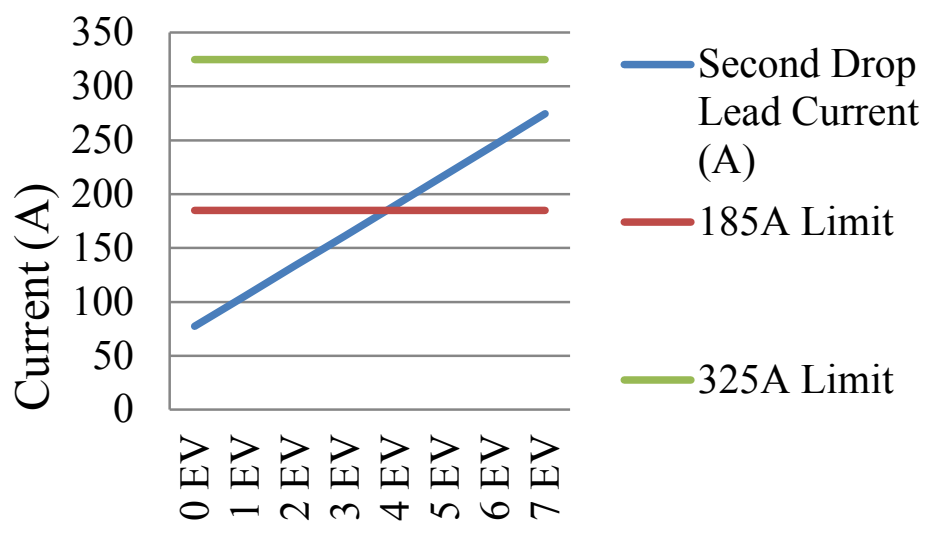

Figure 3.6 Relationship between secondary current limit and 6.6kW charger number

Table 3.7 shows the EV penetration level for the "minimum load charging scenario" based on the rated transformer capacity (50kVA). EVs are connected to the grid at 4:00am which is the valley load time. The highlighted parts in the table mean the total load is over the rated transformer capacity $50 \mathrm{kVA}$, i.e., overload. In this scenario, 6 EVs can be allowed for the $6.6 \mathrm{~kW}$ charger and $2 \mathrm{EVs}$ are allowed for the $20 \mathrm{~kW}$ charger. It is obvious that more EVs charging at the valley load time can be allowed than those charging at the peak load time. The same conclusion can be drawn from the comparison of the results shown in Table 3.8 and Table 3.9 based on the secondary current limit. 
Table 3.7 EV Penetration Limit on the Warmest Day-Power Limit 50kW (Valley Load Time)

\begin{tabular}{|c|c|c|c|c|}
\hline \multirow{2}{*}{$\begin{array}{c}\text { Number of } \\
\text { EVs in } \\
\text { addition to } \\
\text { house load }\end{array}$} & \multicolumn{4}{|c|}{ Transformer Load (kW) } \\
\cline { 2 - 5 } & $\mathbf{1 . 0} \mathbf{~ k W}$ & $\mathbf{3 . 3} \mathbf{~ k W}$ & $\mathbf{6 . 6} \mathbf{~ k W}$ & $\mathbf{2 0} \mathbf{~ k W}$ \\
\hline $\mathbf{1}$ & 8.69 & 10.99 & 14.29 & 27.69 \\
\hline $\mathbf{2}$ & 9.69 & 14.29 & 20.89 & 47.69 \\
\hline $\mathbf{3}$ & 10.69 & 17.59 & 27.49 & 67.69 \\
\hline $\mathbf{4}$ & 11.69 & 20.89 & 34.09 & 87.69 \\
\hline $\mathbf{5}$ & 12.69 & 24.19 & 40.69 & 107.69 \\
\hline $\mathbf{6}$ & 13.69 & 27.49 & 47.29 & 127.69 \\
\hline $\mathbf{7}$ & 14.69 & 30.79 & 53.89 & 147.69 \\
\hline
\end{tabular}

Table 3.8 EV Penetration Limit on the Warmest Day-Current Limit 185A (Valley Load Time)

\begin{tabular}{|c|c|c|c|c|}
\hline \multirow{2}{*}{$\begin{array}{c}\text { Number of } \\
\text { EVs in } \\
\text { addition to } \\
\text { house load }\end{array}$} & \multicolumn{4}{|c|}{ Old Standard Current on Secondary Drop Lead (A) } \\
\cline { 2 - 5 } & $\mathbf{1 . 0} \mathbf{~ k W}$ & $\mathbf{3 . 3} \mathbf{~ k W}$ & $\mathbf{6 . 6} \mathbf{~ k W}$ & $\mathbf{2 0} \mathbf{~ k W}$ \\
\hline $\mathbf{1}$ & 36.21 & 45.79 & 59.54 & 115.38 \\
\hline $\mathbf{2}$ & 40.38 & 59.54 & 87.04 & 198.71 \\
\hline $\mathbf{3}$ & 44.54 & 73.29 & 114.54 & 282.04 \\
\hline $\mathbf{4}$ & 48.71 & 87.04 & 142.04 & 365.38 \\
\hline $\mathbf{5}$ & 52.88 & 100.79 & 169.54 & 448.71 \\
\hline $\mathbf{6}$ & 57.04 & 114.54 & 197.04 & 532.04 \\
\hline $\mathbf{7}$ & 61.21 & 128.29 & 224.54 & 615.38 \\
\hline
\end{tabular}

Table 3.9 EV Penetration Limit on the Warmest Day-Current Limit 325A (Valley Load Time)

\begin{tabular}{|c|c|c|c|c|}
\hline \multirow{2}{*}{$\begin{array}{c}\text { Number of } \\
\text { EVs in } \\
\text { addition to } \\
\text { house load }\end{array}$} & \multicolumn{4}{|c|}{ New Standard Current on Secondary Drop Lead (A) } \\
\cline { 2 - 5 } & $\mathbf{1 . 0} \mathbf{~ k W}$ & $\mathbf{3 . 3} \mathbf{~ k W}$ & $\mathbf{6 . 6} \mathbf{~ k W}$ & $\mathbf{2 0 ~ k W}$ \\
\hline $\mathbf{1}$ & 36.21 & 45.79 & 59.54 & 115.38 \\
\hline $\mathbf{2}$ & 40.38 & 59.54 & 87.04 & 198.71 \\
\hline $\mathbf{3}$ & 44.54 & 73.29 & 114.54 & 282.04 \\
\hline $\mathbf{4}$ & 48.71 & 87.04 & 142.04 & 365.38 \\
\hline $\mathbf{5}$ & 52.88 & 100.79 & 169.54 & 448.71 \\
\hline $\mathbf{6}$ & 57.04 & 114.54 & 197.04 & 532.04 \\
\hline $\mathbf{7}$ & 61.21 & 128.29 & 224.54 & 615.38 \\
\hline
\end{tabular}




\subsubsection{Coldest Day}

Similar analysis for the warmest day has been done for the coldest day load profile shown in Figure 3.3. Table 3.10 shows the EV penetration level for the "worst charging scenario" based on the rated transformer capacity (50kVA). EVs are connected to the grid at 7:00pm (19:00) which is the peak load time. The highlighted parts mean the total load is over the rated transformer capacity $50 \mathrm{kVA}$, i.e., overload. Here we assume the load power factor is 1 . As a result, the load level $50 \mathrm{~kW}$ will be equivalent to the transformer capacity $50 \mathrm{kVA}$.

Table 3.10 EV Penetration Limit on the Coldest Day-Power Limit 50kW (Peak Load Time)

\begin{tabular}{|c|c|c|c|c|}
\hline \multirow{2}{*}{$\begin{array}{c}\text { Number of } \\
\text { EVs in } \\
\text { addition to } \\
\text { house load }\end{array}$} & \multicolumn{4}{|c|}{ Transformer Load (kW) } \\
\cline { 2 - 5 } & $\mathbf{1 . 0} \mathbf{~ k W}$ & $\mathbf{3 . 3} \mathbf{~ k W}$ & $\mathbf{6 . 6} \mathbf{~ k W}$ & $\mathbf{2 0} \mathbf{~ k W}$ \\
\hline $\mathbf{1}$ & 15.9 & 18.2 & 21.5 & 34.9 \\
\hline $\mathbf{2}$ & 16.9 & 21.5 & 28.1 & 54.9 \\
\hline $\mathbf{3}$ & 17.9 & 24.8 & 34.7 & 74.9 \\
\hline $\mathbf{4}$ & 18.9 & 28.1 & 41.3 & 94.9 \\
\hline $\mathbf{5}$ & 19.9 & 31.4 & 47.9 & 114.9 \\
\hline $\mathbf{6}$ & 20.9 & 34.7 & 54.5 & 134.9 \\
\hline $\mathbf{7}$ & 21.9 & 38 & 61.1 & 154.9 \\
\hline
\end{tabular}

From Table 3.10 it is observed that the $1.0 \mathrm{~kW}$ and $3.3 \mathrm{~kW}$ chargers will not cause overload. The $6.6 \mathrm{~kW}$ charger will allow $5 \mathrm{EVs}$ and the $20 \mathrm{~kW}$ charger will allow only one $\mathrm{EV}$ to be connected. The assessment results are further displayed in Figure 3.7 considering the charging hours of each type of EV. The maximum EV number, seven is used to illustrate the charging impact. This figure displays that the transformer will be overloaded if all the houses have the $6.6 \mathrm{~kW}$ or the $20 \mathrm{~kW}$ charger. 


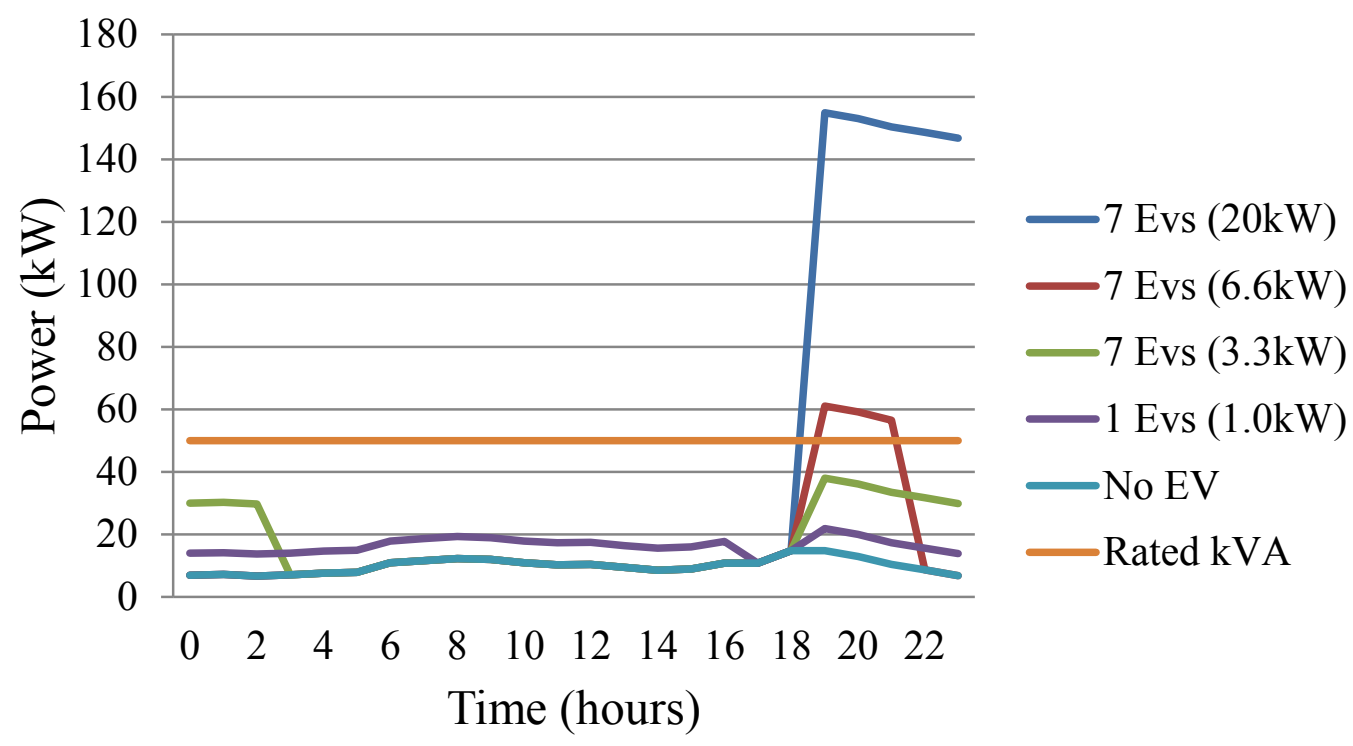

Figure 3.7 Comparison of EV Table 3.12penetration levels on the coldest day (peak load time)

Table 3.11 shows the EV penetration level for the "worst charging scenario" based on the old secondary current limit (185A). EVs are connected to the grid at 7:00pm (19:00) which is the peak load time. The highlighted parts mean the secondary drop lead is overloaded. Similarly, 4 EVs are allowed for the $6.6 \mathrm{~kW}$ charger and $1 \mathrm{EV}$ is allowed for the $20 \mathrm{~kW}$ charger to be connected.

Table 3.11 EV Penetration Limit on the Coldest Day-Current Limit 185A (Peak Load Time)

\begin{tabular}{|c|c|c|c|c|}
\hline \multirow{2}{*}{\begin{tabular}{c} 
Number of $\begin{array}{c}\text { EVs in } \\
\text { addition to } \\
\text { house load }\end{array}$ \\
\cline { 2 - 5 }
\end{tabular}} & \multicolumn{4}{|c|}{ Current on Secondary Drop Lead (A) } \\
\cline { 2 - 5 } EV Charger Capacity \\
\hline $\mathbf{1}$ & $\mathbf{1 . 0} \mathbf{~ k W}$ & $\mathbf{3 . 3} \mathbf{~ k W}$ & $\mathbf{6 . 6} \mathbf{~ k W}$ & $\mathbf{2 0} \mathbf{~ k W}$ \\
\hline $\mathbf{2}$ & 76.25 & 75.83 & 89.58 & 145.42 \\
\hline $\mathbf{3}$ & 74.42 & 89.58 & 117.08 & 228.75 \\
\hline $\mathbf{4}$ & 78.75 & 103.33 & 144.58 & 312.08 \\
\hline $\mathbf{5}$ & 82.92 & 117.08 & 172.08 & 395.42 \\
\hline $\mathbf{6}$ & 87.08 & 130.83 & 199.58 & 478.75 \\
\hline $\mathbf{7}$ & 91.25 & 144.58 & 227.08 & 562.08 \\
\hline & & 158.33 & 254.58 & 645.42 \\
\hline
\end{tabular}


Table 3.12 shows the EV penetration level for the "worst charging scenario" based on the new standard secondary drop lead current (325A). EVs are connected to the grid at 19:00pm which is the peak load time. The highlighted parts in Table 13 mean the second drop lead is overcurrent. Similarly, $7 \mathrm{EVs}$ are allowed for the $6.6 \mathrm{~kW}$ charger and 3 EVs are allowed for the $20 \mathrm{~kW}$ charger.

Table 3.12 EV Penetration Limit on the Coldest Day-Current Limit 325A (Peak Load Time)

\begin{tabular}{|c|c|c|c|c|}
\hline \multirow{2}{*}{$\begin{array}{c}\text { Number of } \\
\text { EVs in } \\
\text { addition to } \\
\text { house load }\end{array}$} & \multicolumn{4}{|c|}{ Current on Secondary Drop Lead (A) } \\
\cline { 2 - 5 } & $\mathbf{1 . 0} \mathbf{~ k W}$ & $\mathbf{3 . 3} \mathbf{~ k W}$ & $\mathbf{6 . 6} \mathbf{~ k W}$ & $\mathbf{2 0} \mathbf{~ k W}$ \\
\hline $\mathbf{1}$ & 66.25 & 75.83 & 89.58 & 145.42 \\
\hline $\mathbf{2}$ & 70.42 & 89.58 & 117.08 & 228.75 \\
\hline $\mathbf{3}$ & 74.58 & 103.33 & 144.58 & 312.08 \\
\hline $\mathbf{4}$ & 78.75 & 117.08 & 172.08 & 395.42 \\
\hline $\mathbf{5}$ & 82.92 & 130.83 & 199.58 & 478.75 \\
\hline $\mathbf{6}$ & 87.08 & 144.58 & 227.08 & 562.08 \\
\hline $\mathbf{7}$ & 91.25 & 158.33 & 254.58 & 645.42 \\
\hline
\end{tabular}

Table 3.13 EV Penetration Limit on the Coldest Day-Power Limit 50kW (Valley Load Time)

\begin{tabular}{|c|c|c|c|c|}
\hline \multirow{3}{*}{$\begin{array}{l}\text { Number of } \\
\text { EVs in } \\
\text { addition to } \\
\text { house load }\end{array}$} & \multicolumn{4}{|c|}{ Transformer Load (kW) } \\
\hline & \multicolumn{4}{|c|}{ EV Charger Capacity } \\
\hline & $1.0 \mathrm{~kW}$ & $3.3 \mathrm{~kW}$ & $6.6 \mathrm{~kW}$ & $20 \mathrm{~kW}$ \\
\hline 1 & 7.73 & 10.03 & 13.33 & 26.73 \\
\hline 2 & 8.73 & 13.33 & 19.93 & 46.73 \\
\hline 3 & 9.73 & 16.63 & 26.53 & 66.73 \\
\hline 4 & 10.73 & 19.93 & 33.13 & 86.73 \\
\hline 5 & 11.73 & 23.23 & 39.73 & 106.73 \\
\hline 6 & 12.73 & 26.53 & 46.33 & 126.73 \\
\hline 7 & 13.73 & 29.83 & 52.93 & 146.73 \\
\hline
\end{tabular}


Table 3.13, Table 3.14, and Table 3.15 show the EV penetration limits when EVs are charging at the valley load time $(2: 00 \mathrm{pm})$ on the coldest day. Similar conclusion from the warmest day can also be obtained here. 6 EVs can be allowed for the $6.6 \mathrm{~kW}$ charger and $2 \mathrm{EVs}$ are allowed for the $20 \mathrm{~kW}$ charger when the transformer capacity is used as the criterion. $5 \mathrm{EVs}$ can be connected to the grid with $6.6 \mathrm{~kW}$ charger and $1 \mathrm{EV}$ with $20 \mathrm{~kW}$ charger when the old secondary current limit is applied. 7 EVs are allowed for the $6.6 \mathrm{~kW}$ charger and $3 \mathrm{EVs}$ are allowed for the $20 \mathrm{~kW}$ charger when the new secondary current limit is applied.

Table 3.14 EV Penetration Limit on the Coldest Day-Current Limit 185A (Valley Load Time)

\begin{tabular}{|c|c|c|c|c|}
\hline \multirow{2}{*}{$\begin{array}{c}\text { Number of } \\
\text { EVs in } \\
\text { addition to } \\
\text { house load }\end{array}$} & \multicolumn{4}{|c|}{ Old Standard Current on Secondary Drop Lead (A) } \\
\cline { 2 - 5 } & $\mathbf{1 . 0} \mathbf{~ k W}$ & $\mathbf{3 . 3} \mathbf{~ k W}$ & $\mathbf{6 . 6} \mathbf{~ k W}$ & $\mathbf{2 0} \mathbf{~ k W}$ \\
\hline $\mathbf{1}$ & 32.21 & 41.79 & 55.54 & 111.38 \\
\hline $\mathbf{2}$ & 36.38 & 55.54 & 83.04 & 194.71 \\
\hline $\mathbf{3}$ & 40.54 & 69.29 & 110.54 & 278.04 \\
\hline $\mathbf{4}$ & 44.71 & 83.04 & 138.04 & 361.38 \\
\hline $\mathbf{5}$ & 48.88 & 96.79 & 165.54 & 444.71 \\
\hline $\mathbf{6}$ & 53.04 & 110.54 & 193.04 & 528.04 \\
\hline $\mathbf{7}$ & 57.21 & 124.29 & 220.54 & 611.38 \\
\hline
\end{tabular}

Table 3.15 EV Penetration Limit on the Coldest Day-Current Limit 325A (Valley Load Time)

\begin{tabular}{|c|c|c|c|c|}
\hline \multirow{2}{*}{$\begin{array}{c}\text { Number of } \\
\text { EVs in } \\
\text { addition to } \\
\text { house load }\end{array}$} & \multicolumn{4}{|c|}{ New Standard Current on Secondary Drop Lead (A) } \\
\cline { 2 - 5 } & $\mathbf{1 . 0} \mathbf{k W}$ & $\mathbf{3 . 3} \mathbf{~ k W}$ & $\mathbf{6 . 6} \mathbf{~} \mathbf{W}$ & $\mathbf{2 0} \mathbf{~ k W}$ \\
\hline $\mathbf{1}$ & 32.21 & 41.79 & 55.54 & 111.38 \\
\hline $\mathbf{2}$ & 36.38 & 55.54 & 83.04 & 194.71 \\
\hline $\mathbf{3}$ & 40.54 & 69.29 & 110.54 & 278.04 \\
\hline $\mathbf{4}$ & 44.71 & 83.04 & 138.04 & 361.38 \\
\hline $\mathbf{5}$ & 48.88 & 96.79 & 165.54 & 444.71 \\
\hline $\mathbf{6}$ & 53.04 & 110.54 & 193.04 & 528.04 \\
\hline $\mathbf{7}$ & 57.21 & 124.29 & 220.54 & 611.38 \\
\hline
\end{tabular}




\subsection{EV Charging Affected by Transformer Ageing}

In Section 3.3, the impact of EV charging on the grid is evaluated based on the limitation of rated transformer capacity and secondary drop lead current. However, there are some other practical factors need to be consider when EV charging is planned. One of the most important factors is transformer life cycle. Transformer ageing depends highly on the state of internal insulation materials, which is impacted by internal transformer temperatures, specially the hottest spot temperature [44]. High level EV penetration in hours will cause transformer overloading and temperature rise. In this section the transformer ageing analysis is conducted for the investigated transformer.

\subsubsection{Transformer Ageing Model}

Transformer temperature rise is caused by the transformer losses including load losses and no-load losses. The load losses depend on the load current in the transformer windings. Core losses are sometimes referred to as iron losses and are commonly referred to as no-load losses, because core losses do not require load currents. Transformer thermal capability is the load capacity generating the hottest area of the windings, which is winding hot spot. The hot spot decides the transformer life, which is a cumulative effect.

According to [44], the estimated life of a transformer is primarily a function of ageing within the transformer insulation because transformer insulation typically fails prior to other transformer components. Acceleration ageing is a measure of how quickly the transformer insulation degrades under actual conditions, relative to degradation at related loading and rated ambient temperature conditions. The detailed transformer 
ageing model is described in [44] and [45]. Two indices, Factor of Aging Acceleration factor $\left(F_{A A}\right)$ and Factor of Equivalent Aging $\left(F_{E Q A}\right)$ [45], are defined as follows to determine transformer insulation life:

$$
\begin{aligned}
& F_{A A}=e^{\left[\frac{15000}{383}-\frac{15000}{T_{H S}+273}\right]} \\
& F_{E Q A}=\frac{\sum_{n=1}^{N} F_{A A n} \Delta t_{n}}{\sum_{n=1}^{N} \Delta t_{n}}
\end{aligned}
$$

where

$T_{H S} \quad$ is the transformer winding hottest-spot temperature $\left({ }^{\circ} \mathrm{C}\right)$

$n \quad$ is index of time interval, $t$

$N \quad$ is total number of time intervals

$F_{A A n} \quad$ is $F_{A A}$ for the temperature which exists during the time interval, $\Delta t_{n}$

$\Delta t_{n} \quad$ is time interval, hours

$F_{A A}$ indicates the instantaneous accelerated aging of transformer. It has a value greater than 1 for winding hottest-spot temperatures greater than the reference temperature $110^{\circ} \mathrm{C}$ and less than 1 for temperatures below $110^{\circ} \mathrm{C}$. The transformer winding hottest-spot temperature is calculated based on transformer load and ambient temperature by using the method given in [45]. $F_{E Q A}$ is the average value of $F_{A A}$ over a time period, e.g., 24 hours. The use of the life of transformer will accelerate if $F_{E Q A}$ is above 1.0 [45].

The transformer per unit insulation life is defined as equation (5) [45]. 


$$
\text { Per unit life }=9.80 \times 10^{-18} e^{\left[\frac{15000}{T_{H S}+273}\right]}
$$

where

$T_{H S} \quad$ is the transformer winding hottest-spot temperature $\left({ }^{\circ} \mathrm{C}\right)$

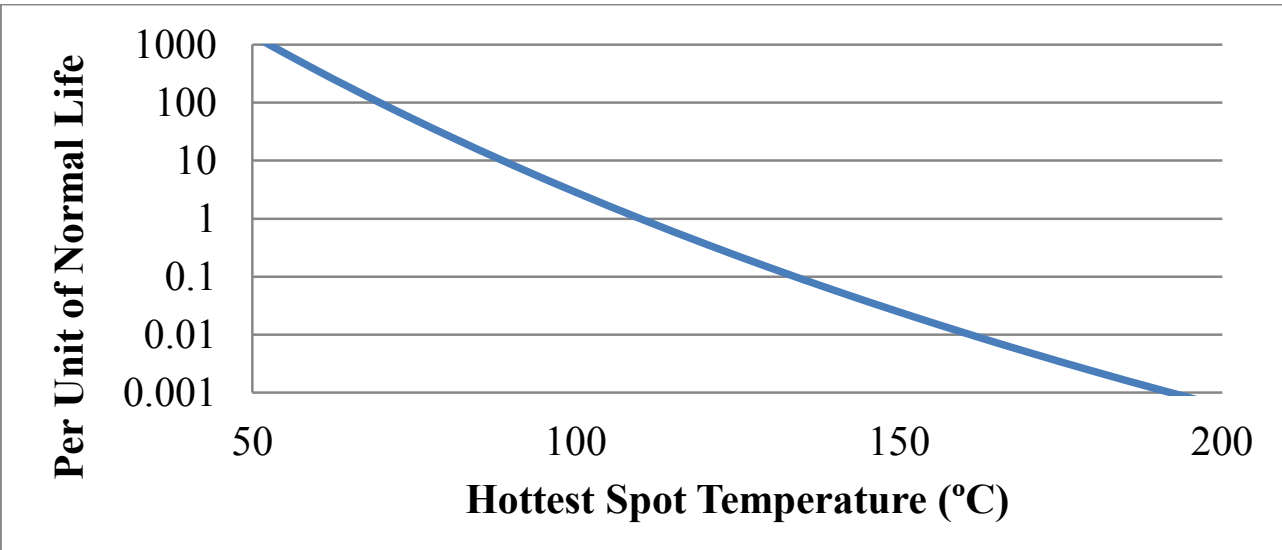

Figure 3.8 Transformer Insulation Life

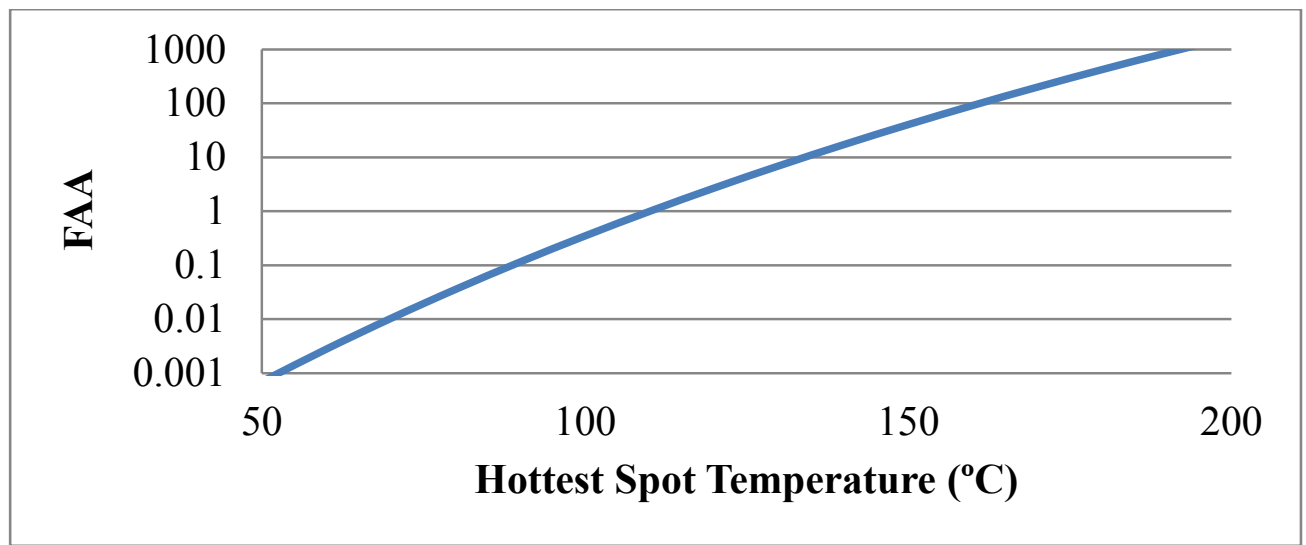

Figure 3.9 Factor of Aging Acceleration Factor

The relation between the transformer insulation life and $F_{A A}$ can be observed from Figure 3.8 and Figure 3.9 [45]. When the $F_{A A}$ increases, the transformer insulation life will decrease. 


\subsubsection{Transformer Ageing Analysis for EV Charging}

This sub-section presents the ageing analysis results for the transformer shown in Figure 3.1(a) when different EV penetration levels are tested. The transformer parameters used to calculate the transformer temperature are listed in Table 3.16. Figure 3.10(a) shows the transformer temperature curve for the base scenario on the warmest day (peak load time), i.e., no EV charging. Figure 3.10(b) shows the base load profile for that day.

Table 3.16 Transformer Parameters

\begin{tabular}{|c|c|}
\hline Description & Value \\
\hline Rated kVA of the transformer (kVA) & 50 \\
\hline No-load loss (W) & 140 \\
\hline Load loss (W) & 330 \\
\hline Total loss (W) & 470 \\
\hline Top oil temperature rise above ambient $\left({ }^{\circ} \mathrm{C}\right)$ & 65 \\
\hline Mass of core and coils (lbs) & 617 \\
\hline Mass of core (lbs) & 478 \\
\hline Mass of windings (lbs) & 139 \\
\hline Gallons of oil in the tank (gallon) & 50.46 \\
\hline
\end{tabular}

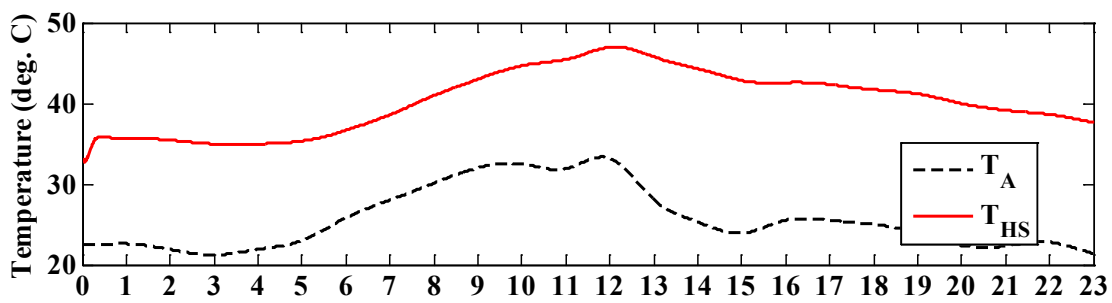

(a)

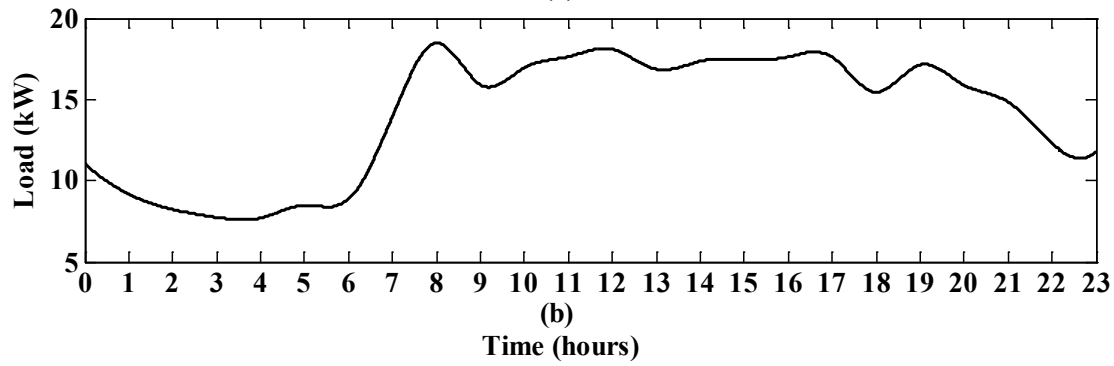

Figure 3.10 Transformer temperature without EV charging (warmest day) 
The transformer temperature abbreviations are as follows:

$T_{A}$ : Ambient temperature, ${ }^{\circ} \mathrm{C}$

$T_{H S}$ : Winding hottest-spot temperature, ${ }^{\circ} \mathrm{C}$

The ambient temperatures on the studied warmest day in Ottawa come from [38].

Figure 3.11 shows the $F_{A A}$ curve for the base scenario. From this figure one can see that the maximum value of $F_{A A}$ in 24 hours of the warmest day is smaller than 0.01 (the transformer ageing threshold value recommended in [45] is 1) under normal loading condition, i.e., without EV load.

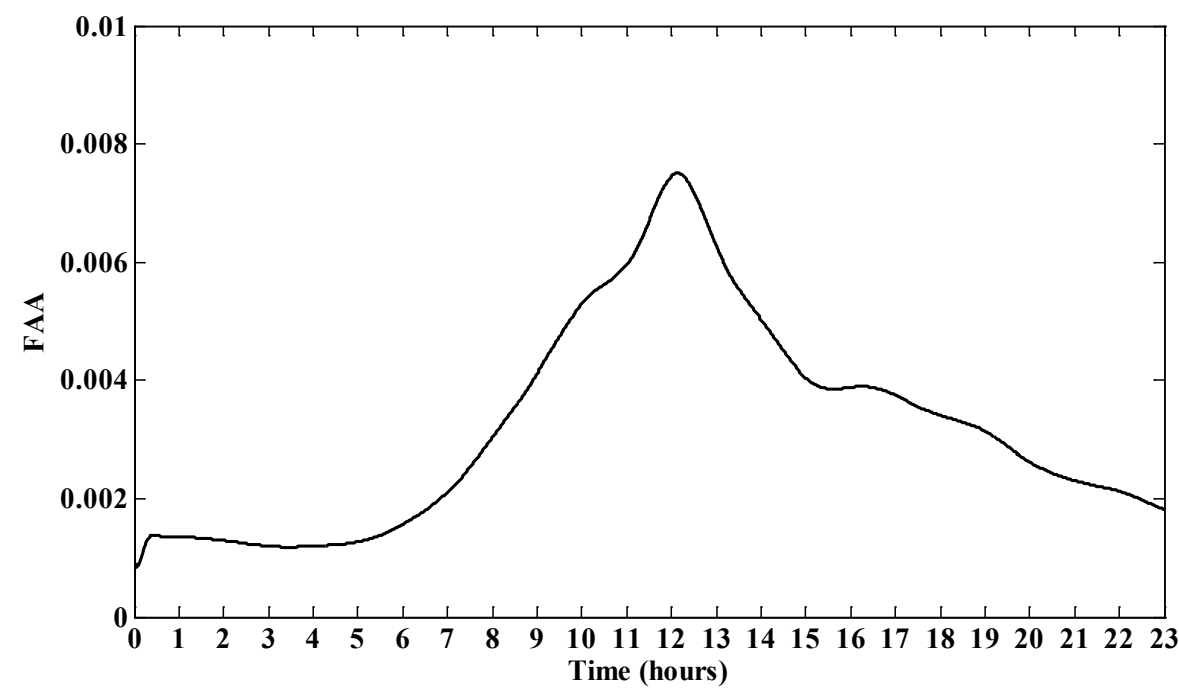

Figure 3.11 Transformer FAA without EV charging (warmest day)

Figure 3.12 displays the $F_{A A}$ curves for different number of the $6.6 \mathrm{~kW}$ charger connected to the transformer. Figure 3.13 reveals the corresponding $F_{E Q A}$ curve for the situations shown in Figure 3.12. The time period Figure 3.13 of the $F_{E Q A}$ value calculation in (4) is 24 hours. The thresholds for $F_{A A}$ and $F_{E Q A}$ are all set as 1 in Figure 
3.12 and Figure 3.13 [45]. From Figure 3.12, 6 EVs can be charged at the same time on that day without accelerate the transformer ageing. From Figure 3.13, 7 EVs can be charged at the same time on that day without accelerating the transformer ageing. Keep in mind that 4 EVs are allowed for charging if the rated transformer capacity is used as the assessment criteria.

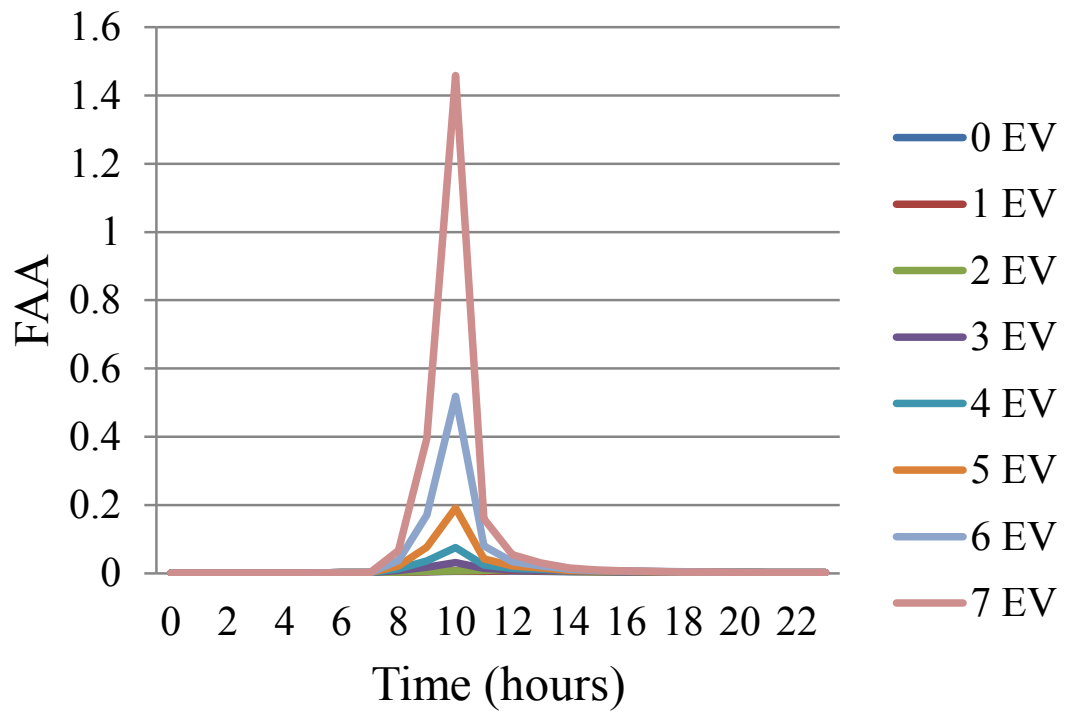

Figure 3.12 Transformer $F_{A A}$ with $\mathrm{EV}$ charging (6.6kW charger, warmest day)

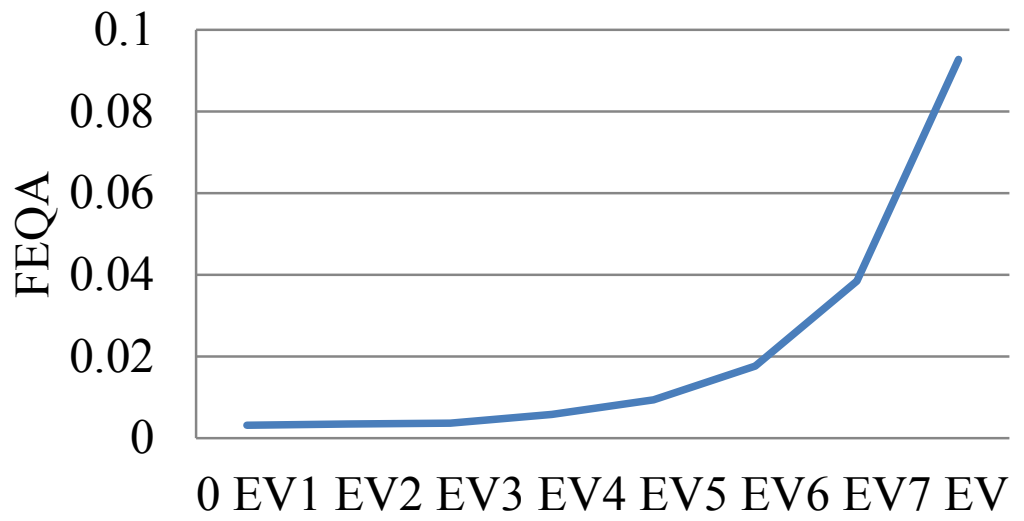

Figure 3.13 Transformer $F_{E Q A}$ with $\mathrm{EV}$ charging (6.6 $\mathrm{kW}$ charger, warmest day) 


\subsubsection{Transformer Ageing Analysis on the Warmest Day}

EVs are connected to the grid at 8:00am which is the peak load time on the warmest day. To observe the entire $F_{A A}$ and $F_{E Q A}$ situation, the $1 \mathrm{~kW}$ charger, $3.3 \mathrm{~kW}$ charger, $6.6 \mathrm{~kW}$ charger, and $20 \mathrm{~kW}$ charger are connected. Figure 3.14 displays the $F_{A A}$ curves for different number of the $1.0 \mathrm{~kW}$ charger connected to the transformer. Figure 3.15 reveals the corresponding $F_{E Q A}$ curve for the situations shown in Figure 3.14. The two figures show that $7 \mathrm{EVs}$ can be charged at the same time.

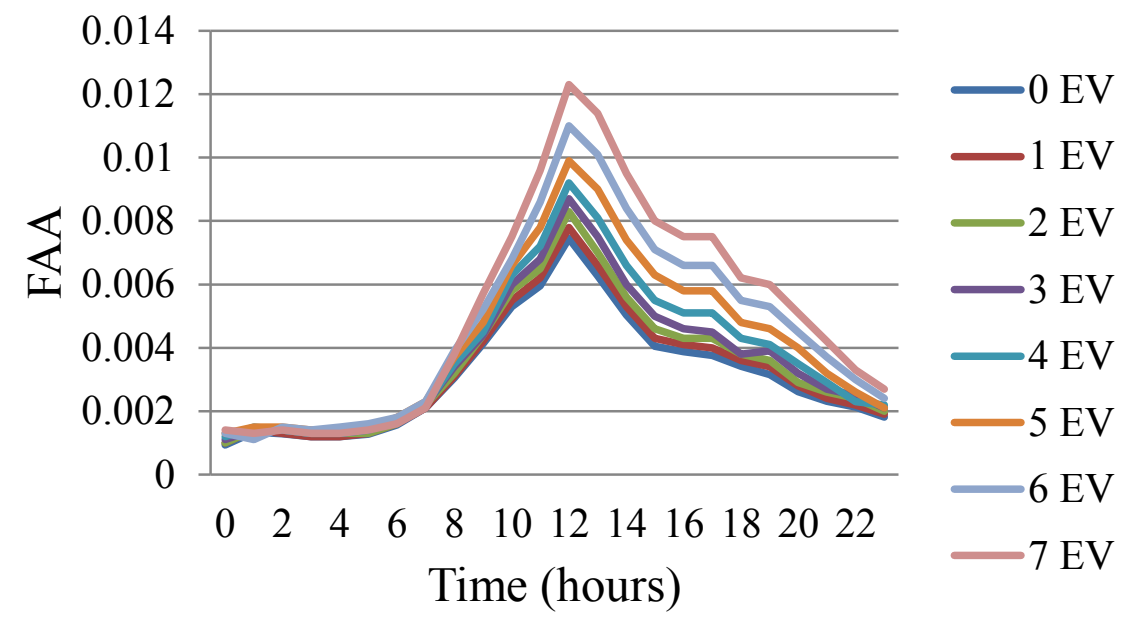

Figure 3.14 Transformer $F_{A A}$ with $\mathrm{EV}$ charging (1.0kW charger, warmest day)

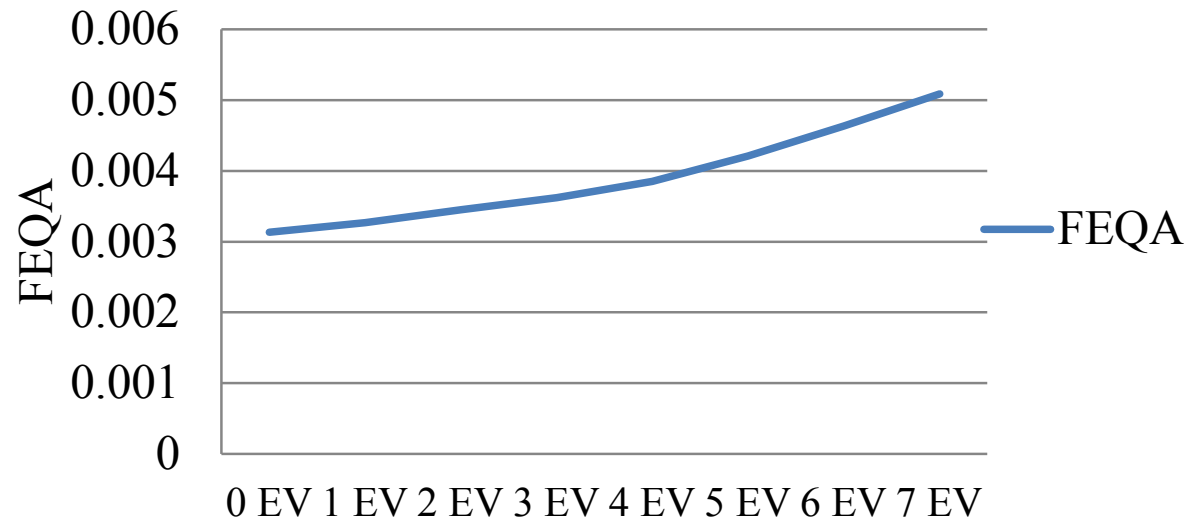

Figure 3.15 Transformer $F_{E Q A}$ with EV charging (1.0kW charger, warmest day) 
Figure 3.16 displays the $F_{A A}$ curves for different number of the $3.3 \mathrm{~kW}$ charger connected to the transformer. Figure 3.17 reveals the corresponding $F_{E Q A}$ curve for the situations shown in Figure 3.16. The two figures show that 7 EVs can be charged at the same time.

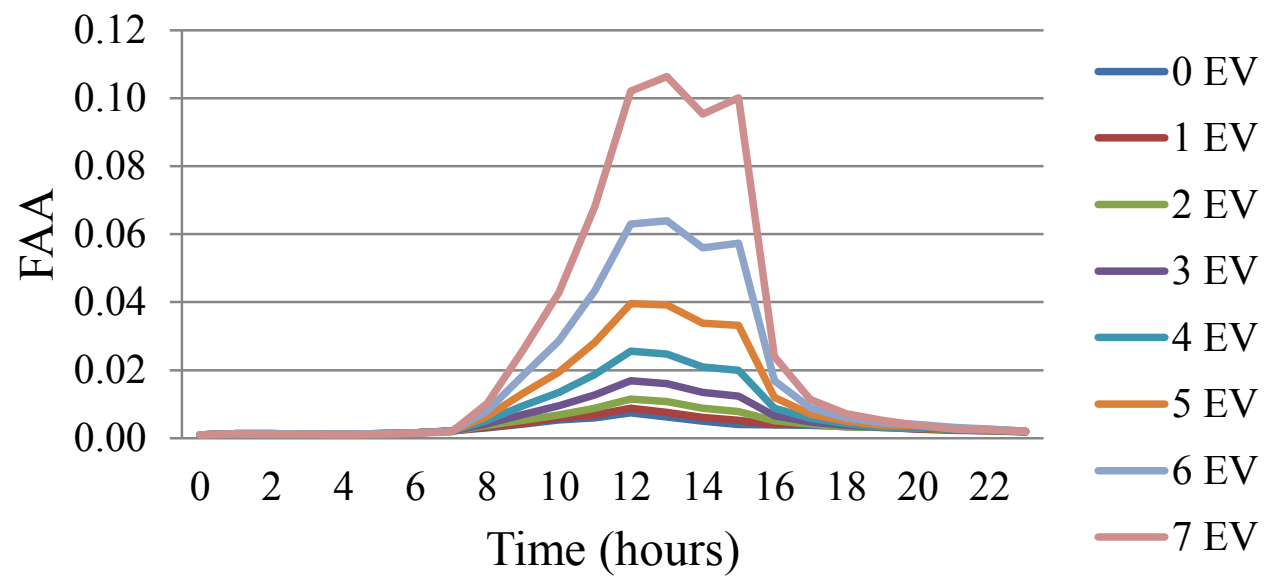

Figure 3.16 Transformer $F_{A A}$ with EV charging (3.3kW charger, warmest day)

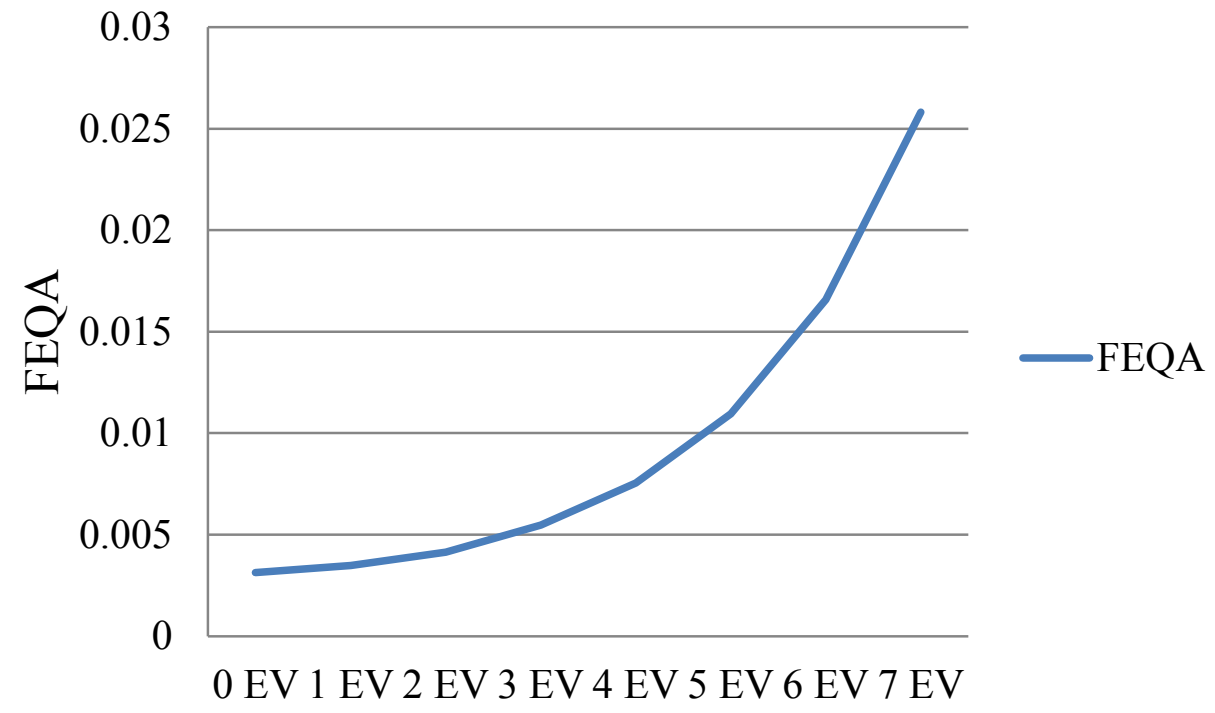

Figure 3.17 Transformer $F_{E Q A}$ with EV charging (3.3kW charger, warmest day) 
Figure 3.18 displays the $F_{A A}$ curves for different number of the $6.6 \mathrm{~kW}$ charger connected to the transformer. Figure 3.19 reveals the corresponding $F_{E Q A}$ curve for the situations shown in Figure 3.18. Figure 3.18 shows that 6 EVs can be charged at the same time. Figure 3.19 shows that 7 EVs can be charged at the same time.

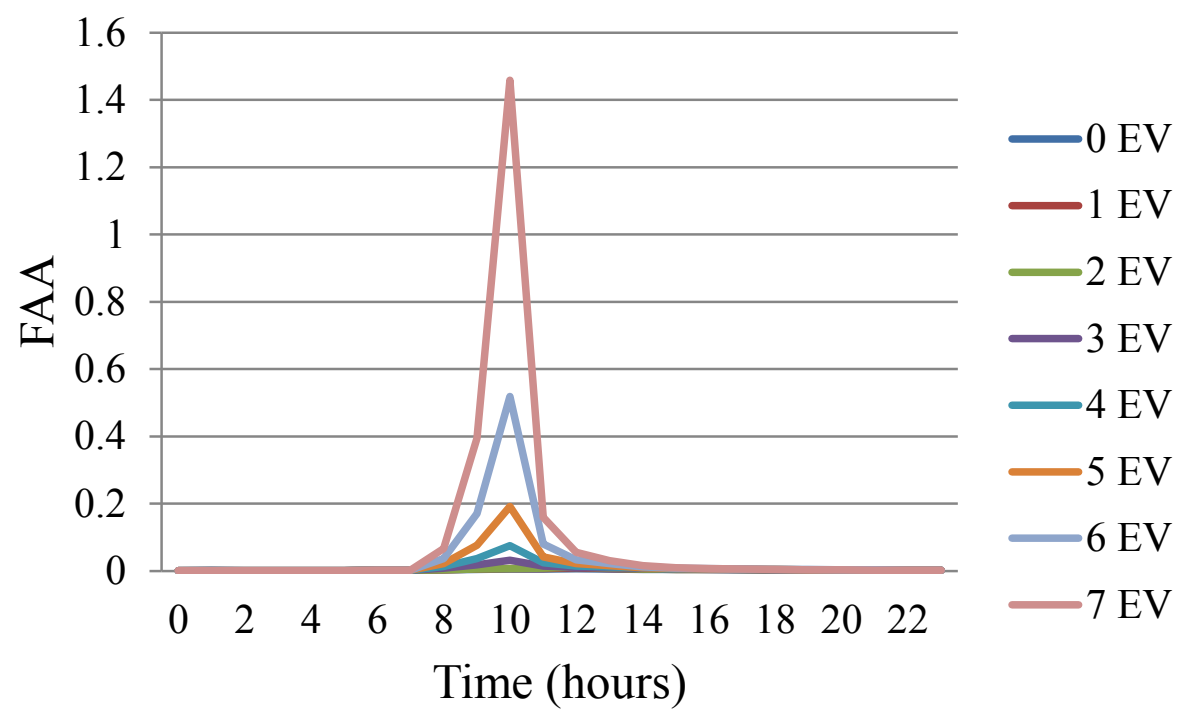

Figure 3.18 Transformer $F_{A A}$ with $\mathrm{EV}$ charging (6.6kW charger, warmest day)

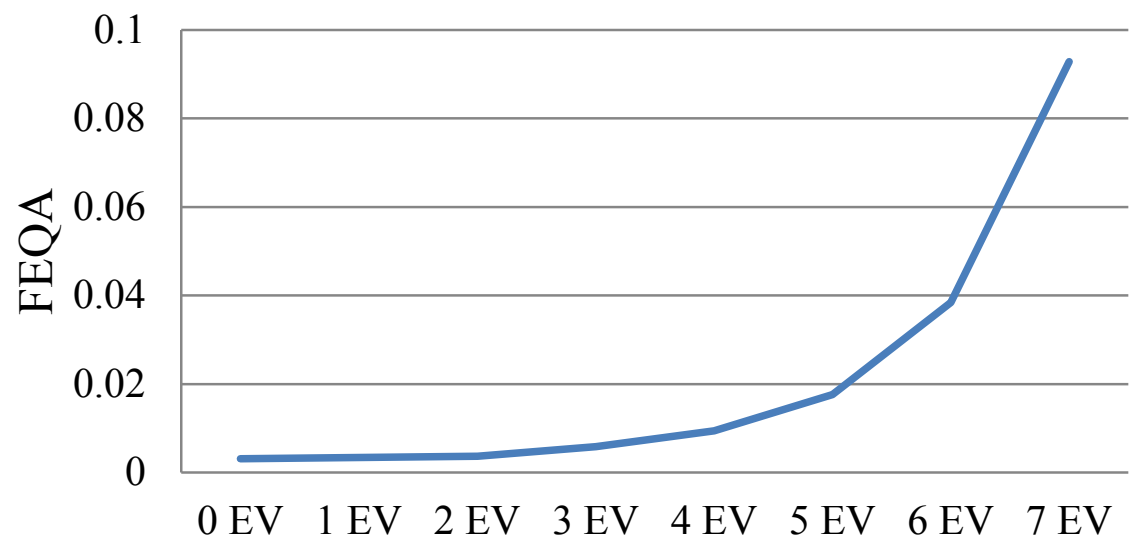

Figure 3.19 Transformer $F_{E Q A}$ with EV charging (6.6kW charger, warmest day)

Figure 3.20 and Figure 3.21 displays the $F_{A A}$ curves for different number of the 20 $\mathrm{kW}$ charger connected to the transformer. The number of EVs that can be connected is 
not clear from the Figure 3.20. Figure 3.21 shows the threshold limit and the number of EVs that can be connected. Figure 3.21 gives information when all 7 EVs are connected. From Figure 3.21 it is observed that $1 \mathrm{EV}$ can be connected. When $2 \mathrm{EVs}$ are connected, it is crossing the threshold limit.

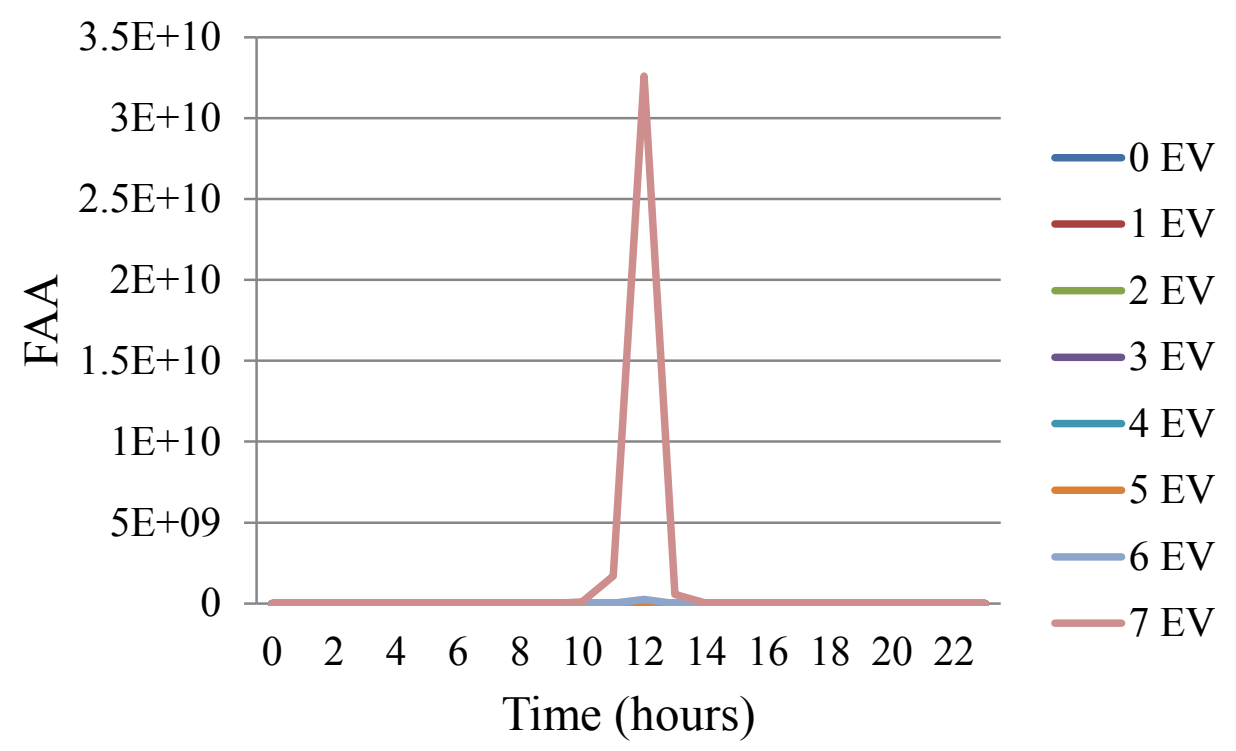

Figure 3.20 Transformer $F_{A A}$ with EV charging (20kW charger, warmest day)

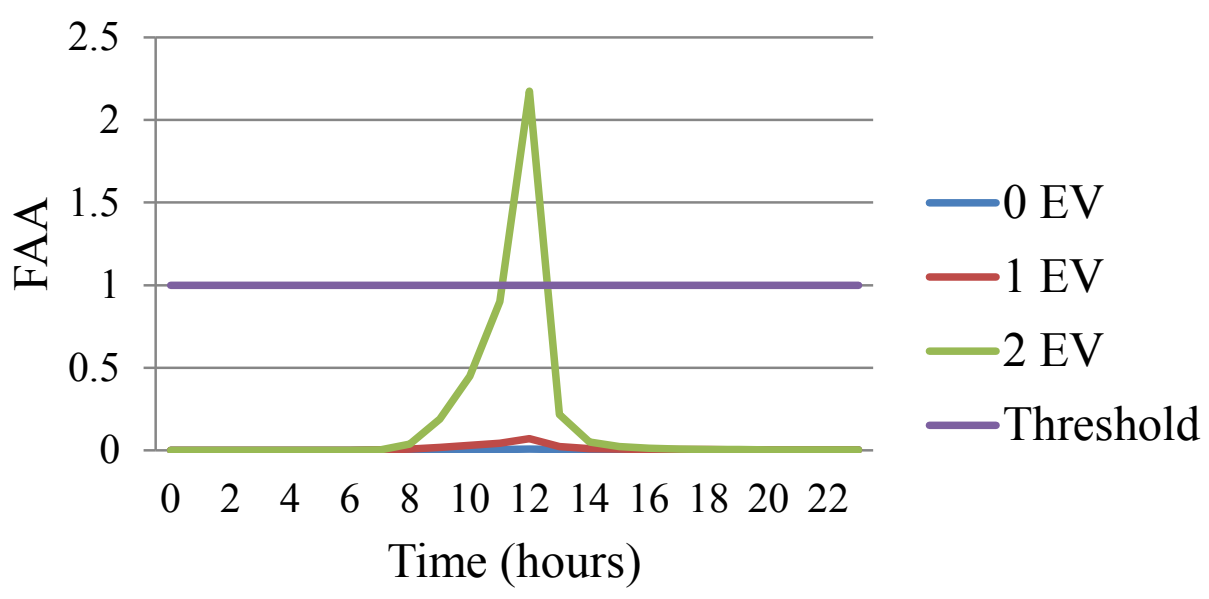

Figure 3.21 Transformer $F_{A A}$ with EV charging and threshold limit (20kW charger, warmest day) 
Figure 3.22 and Figure 3.23 reveals the corresponding $F_{E Q A}$ curve for the situations shown in Figure 3.20. Figure 3.21 shows that $1 \mathrm{EV}$ can be charged at the same time. Figure 3.23 shows that 2 EVs can be charged at the same time. This conclusion is not the same as that drawn from the transformer capacity assessment.

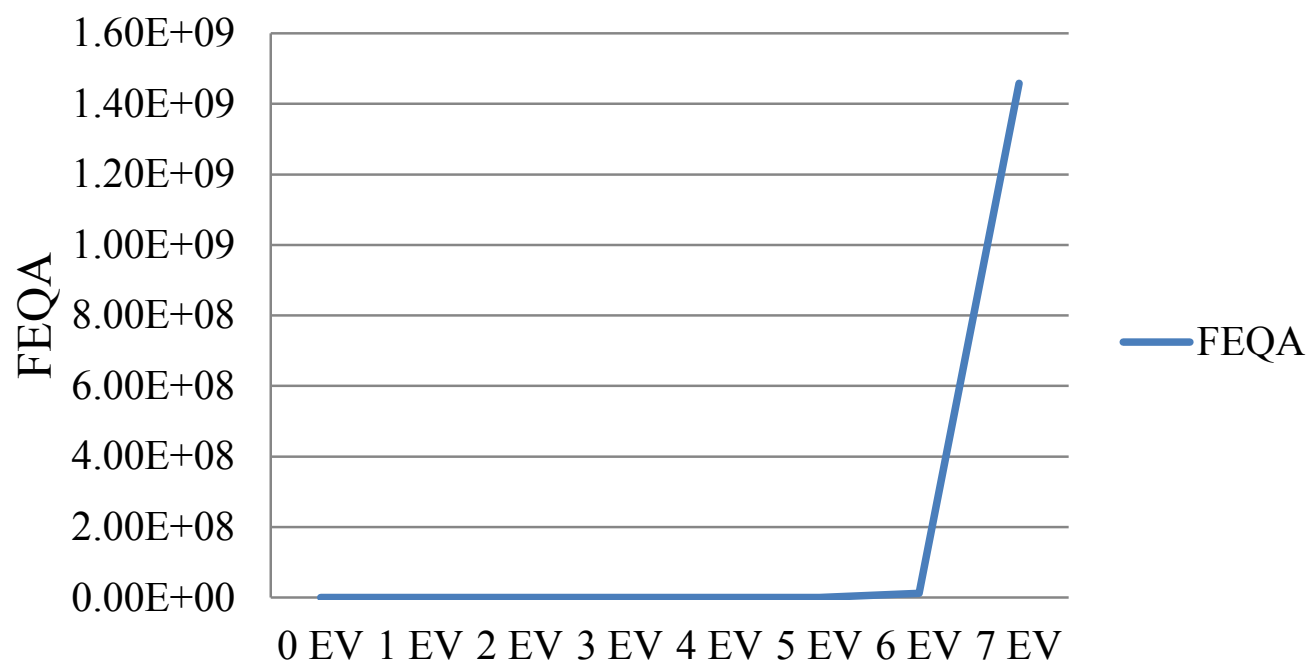

Figure 3.22 Transformer $\boldsymbol{F}_{E Q A}$ with EV charging (20kW charger, warmest day)

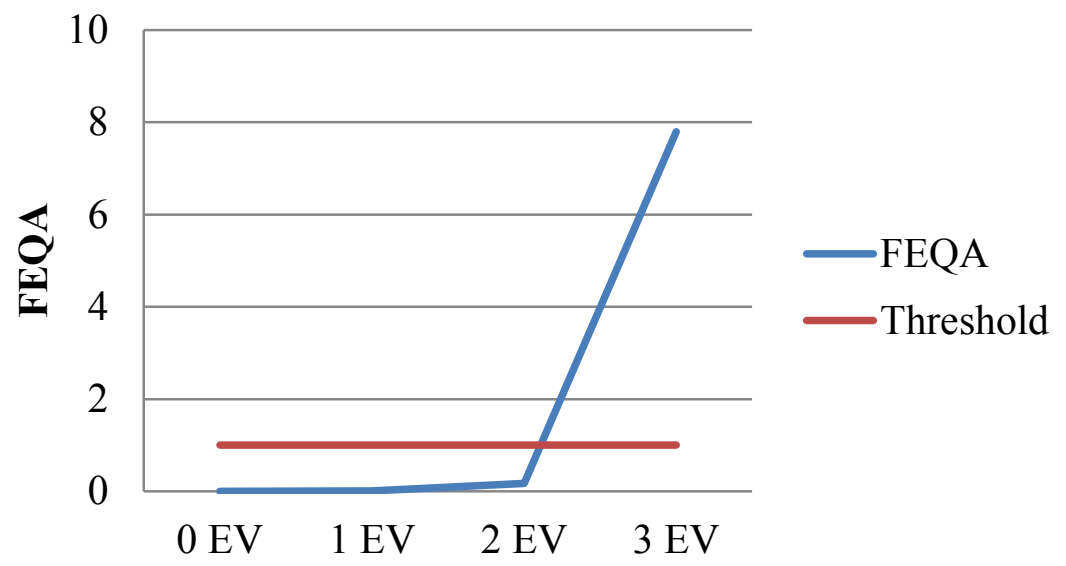

Figure 3.23 Transformer $F_{E Q A}$ with EV charging and threshold limit (20kW charger, warmest day) 
Table 3.17 gives information about the number of EVs that can be connected to the grid at the peak load time on the warmest day by taking different criteria into consideration. For the $20 \mathrm{~kW}$ charger if the rated transformer capacity is taken as the criterion then $1 \mathrm{EV}$ can be connected to the grid and, similarly if $F_{A A}$ is taken as the criterion then $1 \mathrm{EV}$ can be connected to the grid, but if $F_{E Q A}$ is taken as the criterion then 2 EVs can be connected to the grid.

Table 3.17 Summary of Transformer Ageing Analysis on the Warmest Day (Peak Load Time)

\begin{tabular}{|c|c|c|c|c|c|}
\hline \multicolumn{2}{|c|}{ EV Model } & $\begin{array}{l}2013 \text { Fiat } \\
\text { 500e 120V }\end{array}$ & $\begin{array}{l}\text { Nissan Leaf } \\
240 \mathrm{~V}\end{array}$ & $\begin{array}{l}2014 \text { Honda } \\
\text { fit EV 240V }\end{array}$ & $\begin{array}{c}\text { TESLA } \\
\text { Model S 240V }\end{array}$ \\
\hline \multicolumn{2}{|c|}{ EV Charger } & $1.0 \mathrm{~kW}$ & $3.3 \mathrm{~kW}$ & $6.6 \mathrm{~kW}$ & $20 \mathrm{~kW}$ \\
\hline \multicolumn{2}{|c|}{$\begin{array}{c}\text { Rated Transformer } \\
\text { Capacity(50kVA) }\end{array}$} & 7 & 7 & 4 & 1 \\
\hline \multirow{2}{*}{$\begin{array}{c}\text { Current } \\
\text { Limit }\end{array}$} & $\begin{array}{c}\text { Old } \\
\text { Standard } \\
\text { Current } \\
\text { Limit } \\
(185 \mathrm{~A})\end{array}$ & 7 & 7 & 3 & 1 \\
\hline & $\begin{array}{c}\text { New } \\
\text { Standard } \\
\text { Current } \\
\text { Limit } \\
(325 \mathrm{~A})\end{array}$ & 7 & 7 & 7 & 2 \\
\hline \multicolumn{2}{|c|}{$F_{A A}$} & 7 & 7 & 6 & 1 \\
\hline \multicolumn{2}{|c|}{$F_{E Q A}$} & 7 & 7 & 7 & 2 \\
\hline
\end{tabular}

\subsubsection{Transformer Ageing Analysis on the Coldest Day}

Similar transformer ageing analysis on the warmest day has also been done for the coldest day when the EVs are charging at the peak load time. Table 3.18 gives information about the number of EVs that can be connected to the grid for winter peak load time by taking different criteria into consideration. For the $20 \mathrm{~kW}$ charger if the rated transformer capacity is taken as the criterion then $1 \mathrm{EV}$ can be connected to the grid and, 
similarly if $F_{A A}$ is taken as the criterion then $3 \mathrm{EVs}$ can be connected to the grid, and if $F_{E Q A}$ is taken as the criteria then $4 \mathrm{EVs}$ can be connected to the grid.

Table 3.18 Summary of Transformer Ageing Analysis on the Coldest Day (Peak Load Time)

\begin{tabular}{|c|c|c|c|c|c|}
\hline \multicolumn{2}{|c|}{ EV Model } & $\begin{array}{l}2013 \text { Fiat } \\
\text { 500e 120V }\end{array}$ & $\begin{array}{l}\text { Nissan Leaf } \\
240 \mathrm{~V}\end{array}$ & $\begin{array}{l}2014 \text { Honda } \\
\text { fit EV 240V }\end{array}$ & $\begin{array}{c}\text { TESLA } \\
\text { Model S 240V }\end{array}$ \\
\hline \multirow{2}{*}{\multicolumn{2}{|c|}{$\begin{array}{c}\text { EV Charger } \\
\text { Rated Transformer } \\
\text { Capacity }(50 \mathrm{kVA})\end{array}$}} & $1.0 \mathrm{~kW}$ & $3.3 \mathrm{~kW}$ & $6.6 \mathrm{~kW}$ & $20 \mathrm{~kW}$ \\
\hline & & 7 & 7 & 5 & 1 \\
\hline \multirow{2}{*}{$\begin{array}{c}\text { Current } \\
\text { Limit }\end{array}$} & \begin{tabular}{|c|} 
Old \\
Standard \\
Current \\
Limit \\
$(185 \mathrm{~A})$ \\
\end{tabular} & 7 & 7 & 4 & 1 \\
\hline & $\begin{array}{c}\text { New } \\
\text { Standard } \\
\text { Current } \\
\text { Limit } \\
\text { (325A) }\end{array}$ & 7 & 7 & 7 & 3 \\
\hline \multicolumn{2}{|c|}{$F_{A A}$} & 7 & 7 & 7 & 3 \\
\hline \multicolumn{2}{|c|}{$F_{E Q A}$} & 7 & 7 & 7 & 4 \\
\hline
\end{tabular}

\subsection{EV Charging Optimization}

From the grid assessment results in the previous sections one can see that the number of the EVs that can be connected to the grid in a neighborhood is small when the EVs are with relatively large charger and are charged simultaneously. This section developed an EV optimal charging strategy for an example scenario to understand how to maximize the number of EVs charging while at the same time creating the least possible burden for the transformer. Whereas the majority of the previous grid assessment scenarios looked at the worst possible case, this optimal charging strategy sought to better understand the best case assuming key variables such as time of charge could be managed. The optimal charging strategy would require some element of control, likely 
on the part of the local distribution company, to flow the electricity to charge an EV at those times when it would least impact the electricity distribution system.

The optimal charging strategy uses $6.6 \mathrm{~kW}$ charger (Honda Fit EV) for the neighborhood shown in Figure 3.1(a). Although many papers have discussed different optimization methods like the literature review has mentioned, this thesis uses adjustable charger with residences driving habits such as driving distance, return home time, and leaving home time to increase the charging EV numbers. The optimization nomenclatures are in Table 3.19.

Table 3.19 EV Charging Optimization Nomenclature

\begin{tabular}{|c|c|}
\hline Nomenclature & Description \\
\hline SOC & EV battery state of charge \\
\hline SOCi & EV battery initial state of charge \\
\hline TL & Total load power consumption \\
\hline BL & Base load power consumption in each house \\
\hline CL & Charging load power consumption in each house \\
\hline CT & Charging time control \\
\hline k & Represent different house, $\mathrm{k}=\{0,1,2, \ldots 6\}$ \\
\hline RT & Represent different hour, $1=\{0,1,2, \ldots 23\}$ \\
\hline LT & Driver returning time \\
\hline DD & Driver leaving time \\
\hline
\end{tabular}

\subsubsection{Optimization Objective}

In this scenario, we assume each house has a $6.6 \mathrm{~kW} \mathrm{EV} \mathrm{to} \mathrm{be} \mathrm{charged,} \mathrm{the}$ optimization objective is to minimize the total peak load power if all the 7 EVs need to be charged in a time segment. It will take 3 hours to charge the Honda Fit EV from empty to full. The total load power can be expressed as (6) and it is smaller than the rated transformer capacity $50 \mathrm{~kW}$, as shown in (7). 


$$
T L=\sum_{k=0}^{6}(B L[k]+C L[k])
$$

$$
T L \leq 50 \mathrm{~kW}
$$

In order to get the optimal charging results, we assume the EV charger is not a fixed $6.6 \mathrm{~kW}$ charger and the charging level $C L$ can be controlled to vary between 0 and $6.6 \mathrm{~kW}$. The reason for doing so is to obtain the minimum peak power being supplied. To decrease this peak power supplying, the power less than $6.6 \mathrm{~kW}$ still could be used to charge the EV battery. The charging time control CT is $\{0,6.6\}$. When CT is 0 , it means the $\mathrm{EV}$ is leaving. When $\mathrm{CT}$ is 6.6 , the $\mathrm{EV}$ is charging but the charging power level is adjustable between 0 and $6.6 \mathrm{~kW}$. As a result, the following constraint can be obtained for the optimization:

$$
C L[k] \leq C T[k]
$$

The SOC of each house is calculated by (9) which is necessary to know in order to avoid EV battery overcharging. The SOC is set as less or equal $90 \%$ [46].

$$
\operatorname{SOC}[k]=\operatorname{SOC} i[k]+\frac{100}{6.6 \times 3} \sum_{l=0}^{23} C L[k][l]
$$

$$
\operatorname{SOC}[k] \leq 90
$$

The following factors of each EV will also be necessary to do the optimization, i.e., initial SOC (SOCi, (determining the total charging time), EV returning home time (determining the earliest beginning time of charging), EV leaving home time 
(determining the latest finishing time of charging). The initial SOC when charging begins can be calculated based on the driving distance (DD) per day of each EV by the following equation:

$$
S O C i=100\left(1-\frac{D D}{132}\right)-10
$$

According to the previous assumptions, an EV will leave home with the SOC $90 \%$ every day and will return home by driving the distance of DD. A $100 \%$ Honda Fit can drive $132 \mathrm{~km}$ [42]. So the SOC reduction of a Honda Fit will be 1-DD/132 per day. The values of DD and SOCi for each house is listed in Table 3.20. The DD values are obtained from a driving habit survey conducted in the City of Ottawa through the Electric Mobility Adoption and Prediction (EMAP) project in 2013 [47]. Table 3.21 and Table 3.22 shows the EV returning time (RT) and leaving time (LT) which are also obtained from the EMAP project.

Table 3.20 Driving Distance and Initial SOC

\begin{tabular}{|l|r|r|r|r|r|r|r|}
\hline House & 1 & 2 & 3 & 4 & 5 & 6 & 7 \\
\hline DD $(\mathrm{km})$ & 0.56 & 17.03 & 33.49 & 49.95 & 66.41 & 82.87 & 99.33 \\
\hline SOCi $(\%)$ & 89.57 & 77.10 & 64.63 & 52.16 & 39.69 & 27.22 & 14.75 \\
\hline
\end{tabular}

Table 3.21 EV Returning Time

\begin{tabular}{|l|l|l|l|l|l|l|l|}
\hline House & 1 & 2 & 3 & 4 & 5 & 6 & 7 \\
\hline RT (PM) & $2: 00$ & $3: 00$ & $4: 00$ & $5: 00$ & $6: 00$ & $8: 00$ & $9: 00$ \\
\hline
\end{tabular}

Table 3.22 EV Leaving Time

\begin{tabular}{|l|l|l|l|l|l|l|l|}
\hline House & 1 & 2 & 3 & 4 & 5 & 6 & 7 \\
\hline Designed LT (AM) & $6: 00$ & $7: 00$ & $8: 00$ & $8: 00$ & $9: 00$ & $10: 00$ & $11: 00$ \\
\hline
\end{tabular}




\subsubsection{Optimization Result}

The following optimal result is acquired by setting the optimization objective and constraints in the optimization software IBM ILOG CPLEX.

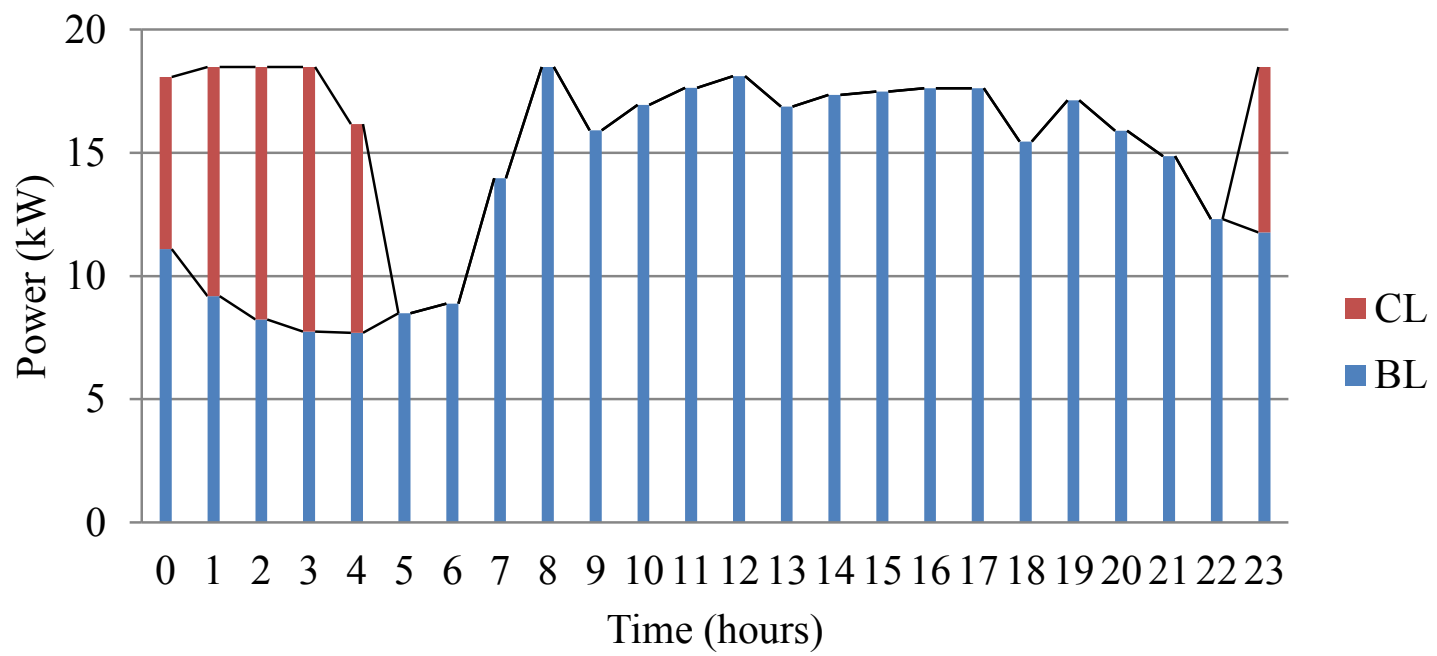

Figure 3.24 Optimal EV charging result

From Figure 3.24 one can see that the total load is not over $18.48 \mathrm{~kW}$ which is the peak value of the base load BL at 8:00AM. In other words, we arrange $76.6 \mathrm{~kW}$ EVs to charge between 22:00pm and 5:00am without adding the peak value of BL.

\subsection{Summary}

In this chapter, the EV charging scenarios at the neighborhood level of Hydro Ottawa are developed and the grid assessment of EV charging are conducted for these scenarios. Different EV models are tested for the grid assessment and the factors of 
transformer capacity, secondary current limit, and transformer ageing are considered to get the EV penetration limit.

It is found that if the transformer ageing factors and the rated transformer capacity are taken as the criteria then the $F_{E Q A}$ analysis can be considered as the main criterion to determine the maximum EV number that can be charged simultaneously. The $F_{E Q A}$ is influenced by $F_{A A}$ and the rated transformer capacity.

By just choosing the transformer ageing analysis as the criteria, the maximum EV number that can be connected to the grid cannot be assessed correctly as the secondary drop lead current also influences the EV penetration limit. Thus, the secondary drop lead current and the transformer ageing analysis $\left(F_{E Q A}\right)$ must be taken into consideration for all scenarios.

This chapter also develops an optimal EV charging strategy that could minimize the total load power and increase the EV penetration limit without violating the above grid assessment criteria. 


\section{Chapter: Assessment of EV Charging at the Feeder Level}

In this chapter the impact of massive EV charging on the distribution system feeder is investigated. A representative residential feeder is selected for study from the distribution system Hydro Ottawa. Figure 4.1 shows the schematic diagram of the assessed feeder. There are 293 transformers that are connected to the feeder in three phase or single phase. The connection distribution of the transformers among three phases is shown in Table 4.1.

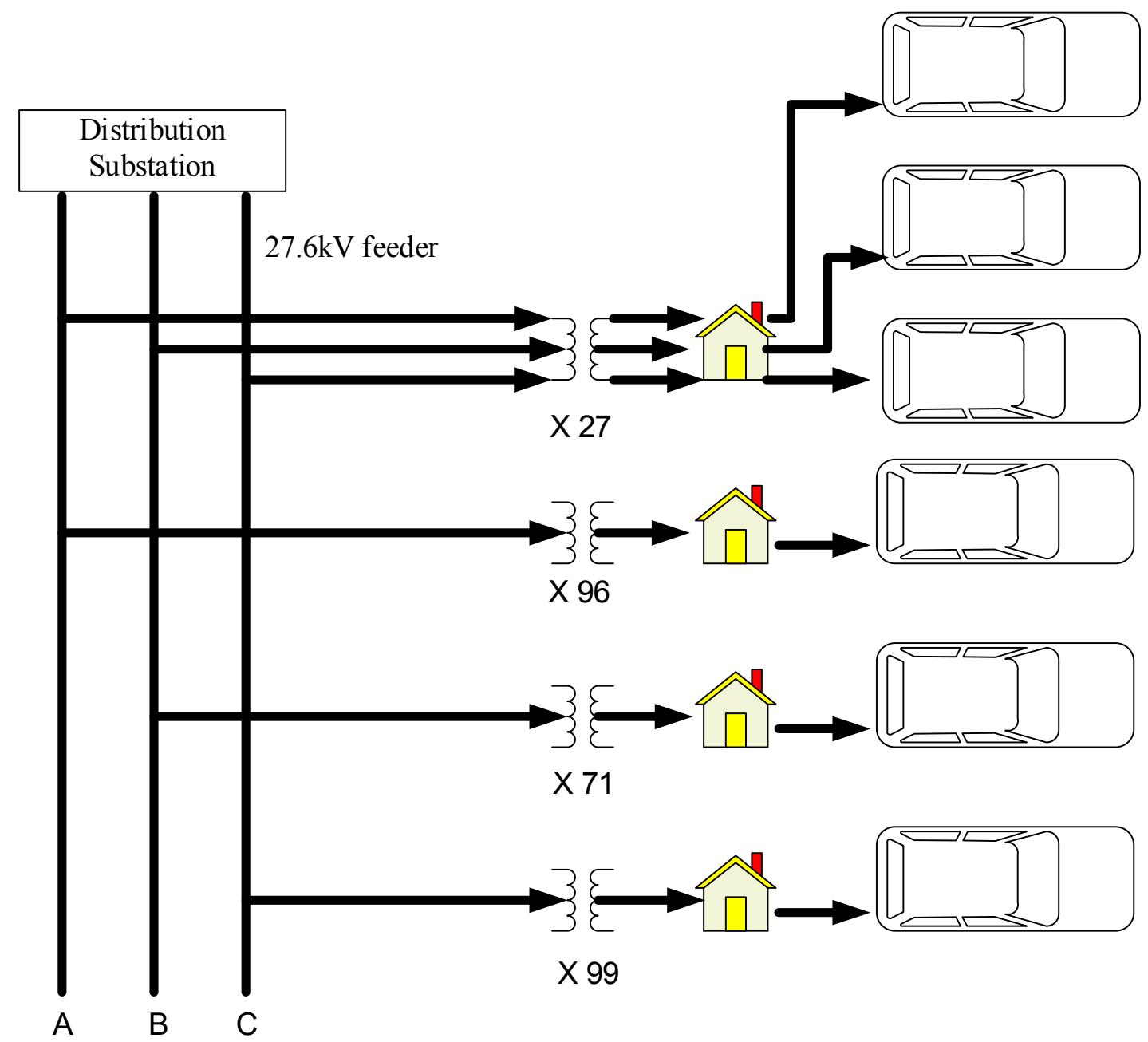

Figure 4.1 Schematic diagram of the investigated residential feeder for EV charging assessment 
Table 4.1 Transformer Connection Distribution

\begin{tabular}{|c|c|}
\hline Transformer & Numbers \\
\hline Three-phase & 27 \\
\hline Phase A & 96 \\
\hline Phase B & 71 \\
\hline Phase C & 99 \\
\hline Total & 293 \\
\hline
\end{tabular}

\subsection{Power and Current Impact}

In the assessment, each transformer is assumed to connect numbers of EVs to check the operation conditions of the feeder. Two main factors are considered for the operation conditions. One is the voltage and current unbalance of the feeder and the other is the power loss on the feeder when a large number of EVs are connected to the feeder. The feeder is simulated in the software CYMEDist.

Considering the EV charger investigated in this thesis is single-phase charger, each three-phase transformer is split into three single-phase transformers to connect EVs. As a result, Phase A will have $96+27=123$ single-phase transformers and each transformer is connected with numbers of EVs. The new transformer connection distribution in this way is shown in Table 4.2.

Table 4.2 New Transformer Connection Distribution

\begin{tabular}{|c|c|}
\hline Phase to Transformer & Numbers \\
\hline Phase A & 123 \\
\hline Phase B & 98 \\
\hline Phase C & 126 \\
\hline Total & 347 \\
\hline
\end{tabular}

On the feeder, each phase are connected with different number of residential loads (e.g., houses). To observe the EV charging effect on the feeder, the following equations is used to the power of each phase with EVs. 


$$
P_{p h}=P_{c h} \times\left(E V_{p t}\right) \times N_{p t}+P_{b}
$$

where

$P_{p h}:$ total power of each phase

$P_{c h}$ single EV charger power

$E V_{p t}$ number of EVs connected to each single-phase transformer

$N_{p t}:$ number of single-phase transformers

$P_{b}$ : basic power without $\mathrm{EV}$ connecting

Table 4.3 Feeder Load with EV Charging

\begin{tabular}{|c|c|c|c|c|c|c|}
\hline \multirow{2}{*}{$\begin{array}{c}\text { Number of } \\
\text { EVs in } \\
\text { addition to } \\
\text { transformer }\end{array}$} & \multicolumn{6}{|c|}{ Feeder Load (kW) } \\
\cline { 2 - 7 } & \multicolumn{7}{|c|}{$\mathbf{6 . 6 ~ k W}$} & $\mathbf{2 0} \mathbf{~ k W}$ \\
\hline 0 & 1220.7 & 1220.7 & 1218.7 & 1220.7 & 1220.7 & 1218.7 \\
\hline 1 & 2031.2 & 1868.5 & 2049.1 & 3679.5 & 3181.9 & 3737.4 \\
\hline 2 & 2842.9 & 2516 & 2880.3 & 6139.7 & 5141.8 & 6257.3 \\
\hline 3 & 3654.9 & 3162.3 & 3712.2 & 8599.8 & 7102.4 & 8776.6 \\
\hline 4 & 4466.6 & 3809.6 & 4543.4 & 11060.2 & 9061.5 & 11297.1 \\
\hline 5 & 5278.7 & 4455.6 & 5375.5 & 13520.6 & 11021.7 & 13816.6 \\
\hline 6 & 6090.5 & 5102.6 & 6206.9 & 15980.7 & 12980.9 & 16337.3 \\
\hline 7 & 6902.3 & 5749.6 & 7038.3 & 18441 & 14940.9 & 18857 \\
\hline
\end{tabular}

Table 4.3 shows the simulated feeder load when different types of EV charger and different number of EVs are connected to each single-phase transformer by using the software CYMEDist. The highlighted parts in the table means the load level is over the limit designed for the feeder. From this table it can be observed that the $6.6 \mathrm{~kW}$ charger will allow 7 EVs per transformer to be connected to Phase A, Phase B and Phase C. The 
20kW charger will allow 3 EVs per transformer to be connected to phase A and Phase C.

The $20 \mathrm{~kW}$ charger will allow only 4 EVs per transformer to be connected to phase B.

Table 4.4 Feeder Current with EV Charging

\begin{tabular}{|c|c|c|c|c|c|c|}
\hline \multirow{4}{*}{$\begin{array}{l}\text { Number of } \\
\text { EVs in } \\
\text { addition to } \\
\text { transformer }\end{array}$} & \multicolumn{6}{|c|}{ Feeder Current (A) } \\
\hline & \multicolumn{6}{|c|}{ EV Charger Capacity } \\
\hline & \multicolumn{3}{|c|}{$6.6 \mathrm{~kW}$} & \multicolumn{3}{|c|}{$20 \mathrm{~kW}$} \\
\hline & $\mathbf{A}$ & B & $\mathrm{C}$ & $\mathbf{A}$ & B & C \\
\hline 0 & 85.5 & 85.4 & 85.2 & 85.5 & 85.4 & 85.2 \\
\hline 1 & 133 & 123.1 & 133.9 & 234 & 203.2 & 237.5 \\
\hline 2 & 182.4 & 162.3 & 184.6 & 387.2 & 324.9 & 394.5 \\
\hline 3 & 232.5 & 202 & 236 & 541 & 447.3 & 552.1 \\
\hline 4 & 282.9 & 242 & 287.6 & 695.1 & 569.9 & 709.9 \\
\hline 5 & 333.4 & 282.1 & 339.4 & 849.3 & 692.7 & 867.9 \\
\hline 6 & 384.1 & 322.4 & 391.3 & 1003.6 & 815.5 & 1025.9 \\
\hline 7 & 434.8 & 362.8 & 443.3 & 1157.9 & 938.4 & 1184 \\
\hline
\end{tabular}

Table 4.4 shows the simulated feeder current when different types of EV charger and different number of EVs are connected to each single-phase transformer by using the software CYMEDist. The highlighted parts in the table means the current level is over the limit designed for the feeder. From this table it can be observed that the $6.6 \mathrm{~kW}$ charger will allow 7 EVs per transformer to be connected to Phase A, Phase B and Phase C. The $20 \mathrm{~kW}$ charger will allow $3 \mathrm{EVs}$ per transformer to be connected to phase A and Phase C. The $20 \mathrm{~kW}$ charger will allow only 4 EVs per transformer to be connected to phase B. From the simulation results in Table 4.3 and Table 4.4 one can see that the current feeder capacity is not large enough to accommodate large scale of EV interconnection.

\subsection{Unbalance Impact}

Since each phase of the feeder is connected with different number of transformers, unbalanced feeder current, feeder power and feeder voltage could be caused 
among the three phases, especially when the number of EVs increases. To observe the unbalance conditions, first we need to understand the basic situation. The basic situation means all the transformers are not connected with EVs. For this situation, the voltage, current, and power along the feeder are displayed in the Figure 4.2, Figure 4.3, and Figure 4.4, respectively. The estimated distance is from the map of CYMEDist.

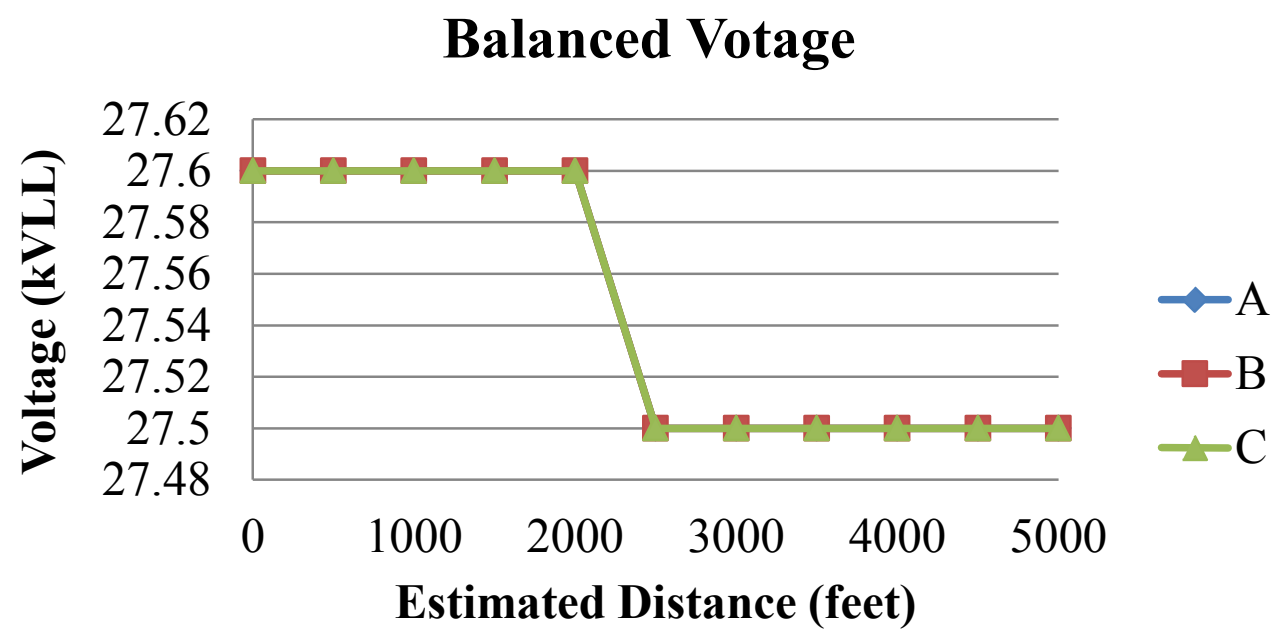

Figure 4.2 Feeder voltage without EVs

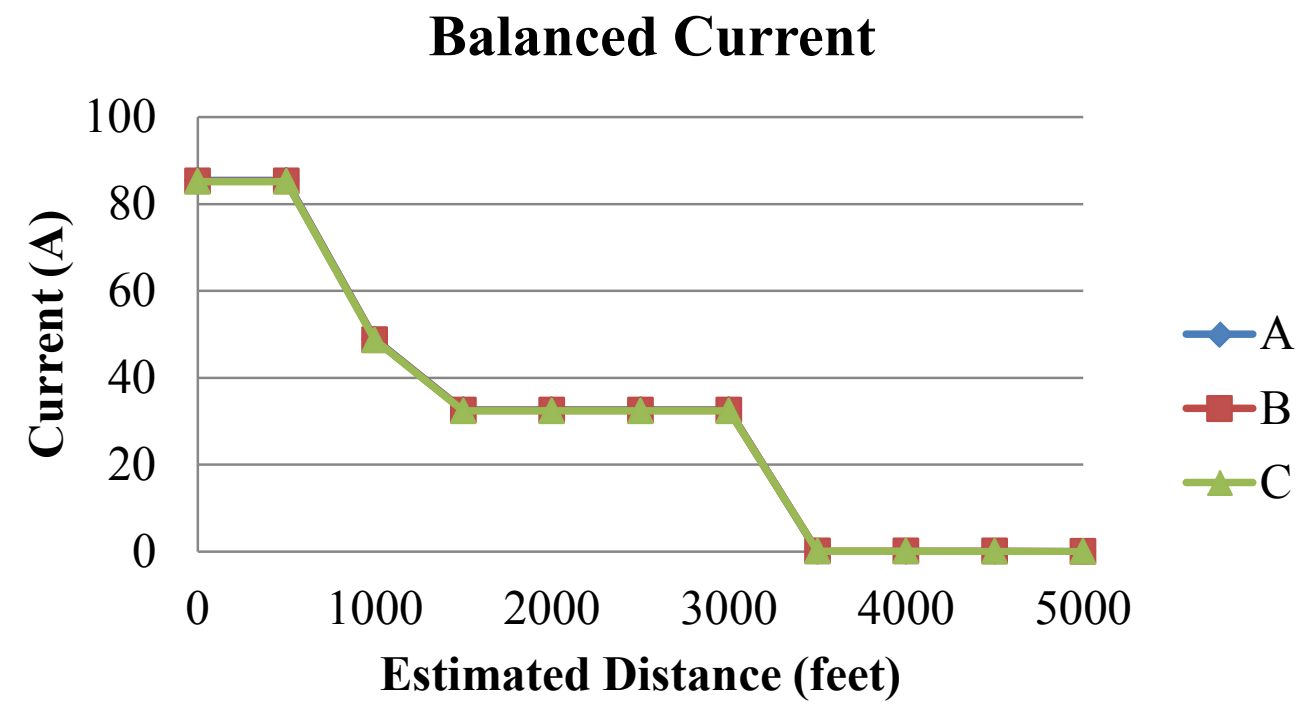

Figure 4.3 Feeder current without EVs 


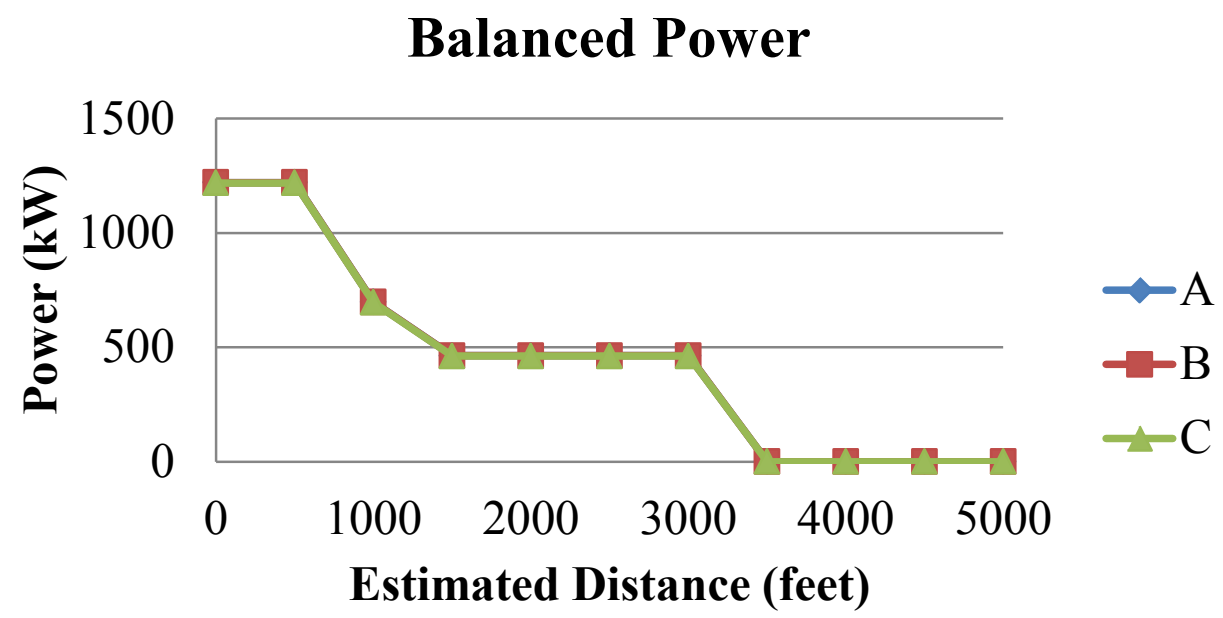

\section{Figure 4.4 Feeder Power without EVs}

The estimated distance in these figures means the distance between the distribution substation and the measured point on the feeder. From the above figures, it can be seen that the voltage, current and power are balanced in the basic situation. To observe the maximum unbalance situation of the distribution system, we consider 7 EVs on each transformer of Phase-C and no EVs are on the other two phases. The software CYMEDist does not accept this condition. So we add two EVs for each transformer of Phase A and Phase B phases in addition to 7 EVs for each transformer of Phase C. Under this situation, the three-phase voltage unbalance and current unbalance are shown in Figure 4.5 and Figure 4.6, respectively.

From Figure 4.5 one can see that the voltage unbalance becomes larger when the estimated distance is longer. This is because the feeder voltage regulator at the distribution station will try to balance the feeder voltage. However, such function of the feeder regulator will not be effective when it is close to the end of the feeder due to the increasing feeder impedance. The voltage unbalance and the current unbalance of the 
feeder are calculated according to (13)-(14) [48]. The unbalance results are shown in Figure 4.7 and Figure 4.8.

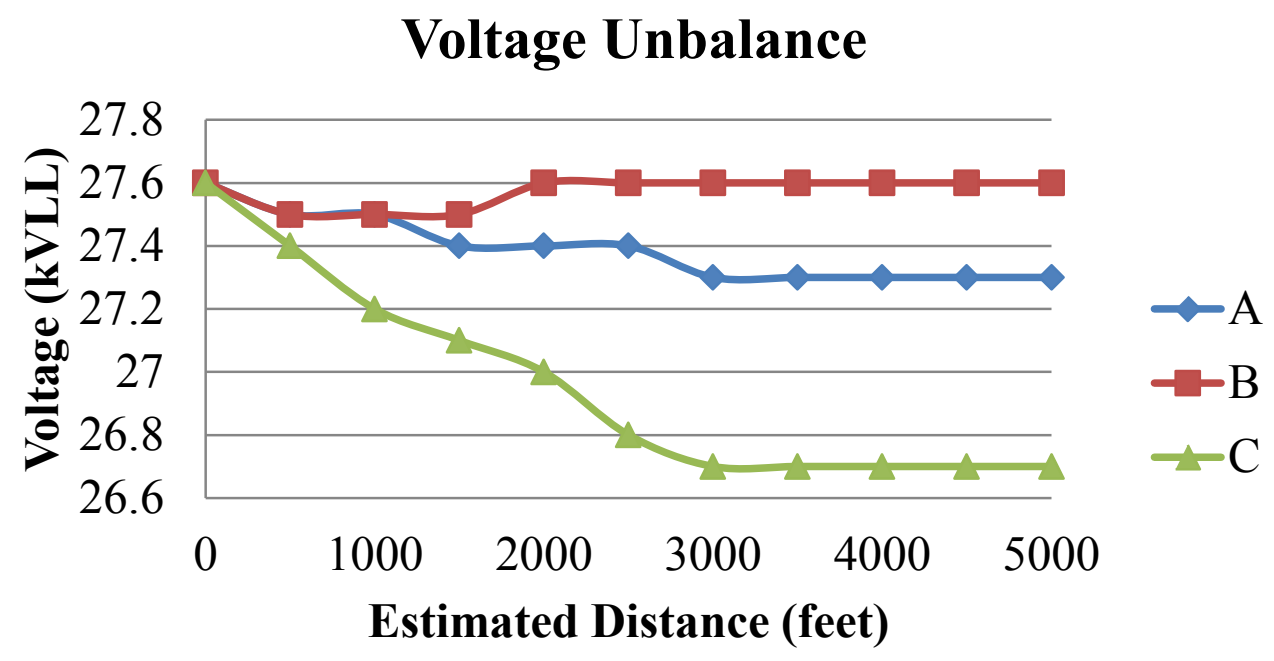

Figure 4.5 Feeder voltage with EVs

\section{Current Unbalance}

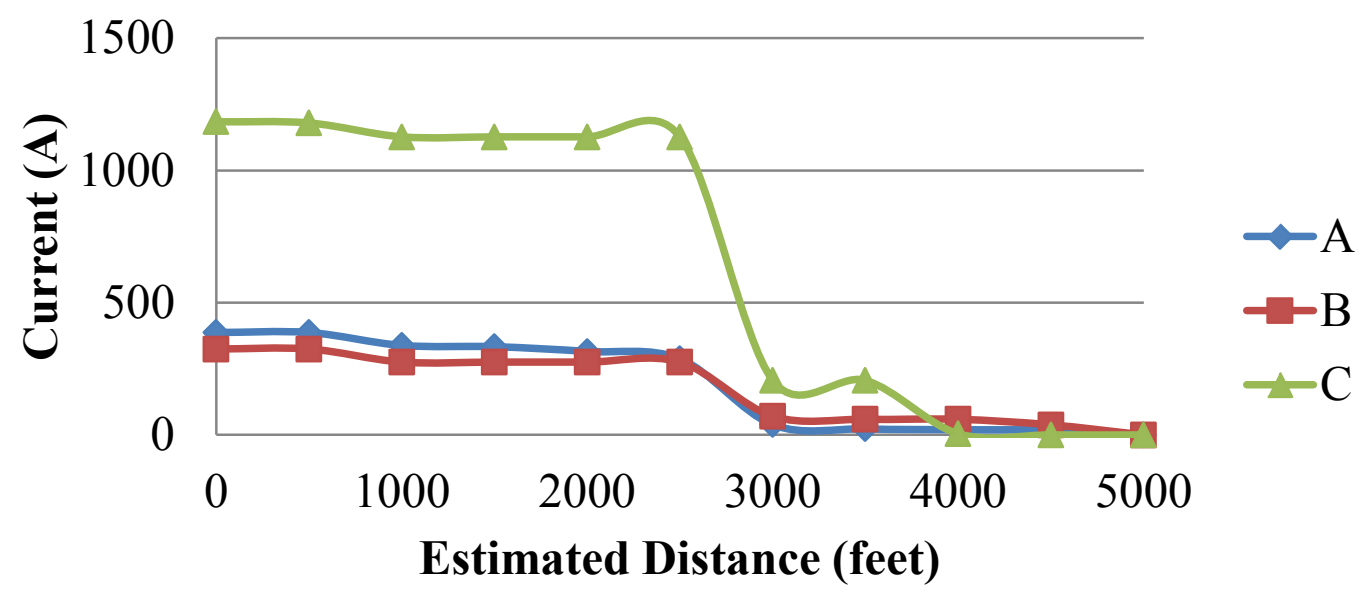

Figure 4.6 Feeder current with EVs

$$
\% \text { Voltage Unbalance }=\frac{\text { Max.Volt.Deviation From Avg.Volt. }}{\text { Average Volts }} \times 100 \%
$$


$\%$ Current Unbalance $=\frac{\text { Max.Current.Deviation From Avg.Current. }}{\text { Average Currents }} \times 100 \%$

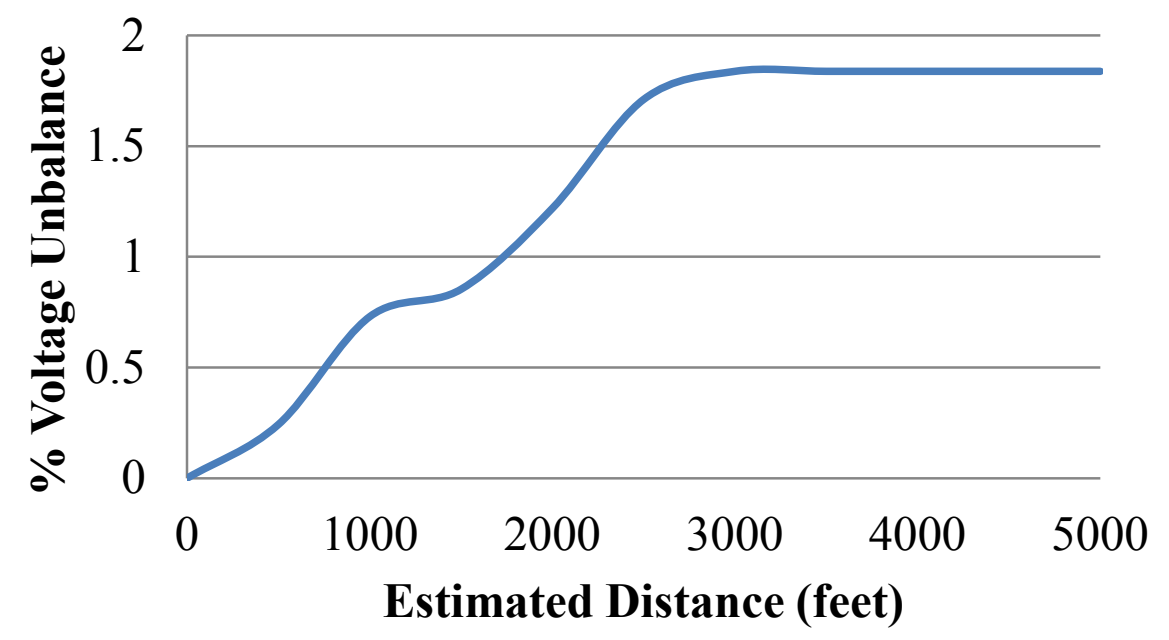

Figure 4.7 Percent of feeder voltage unbalance

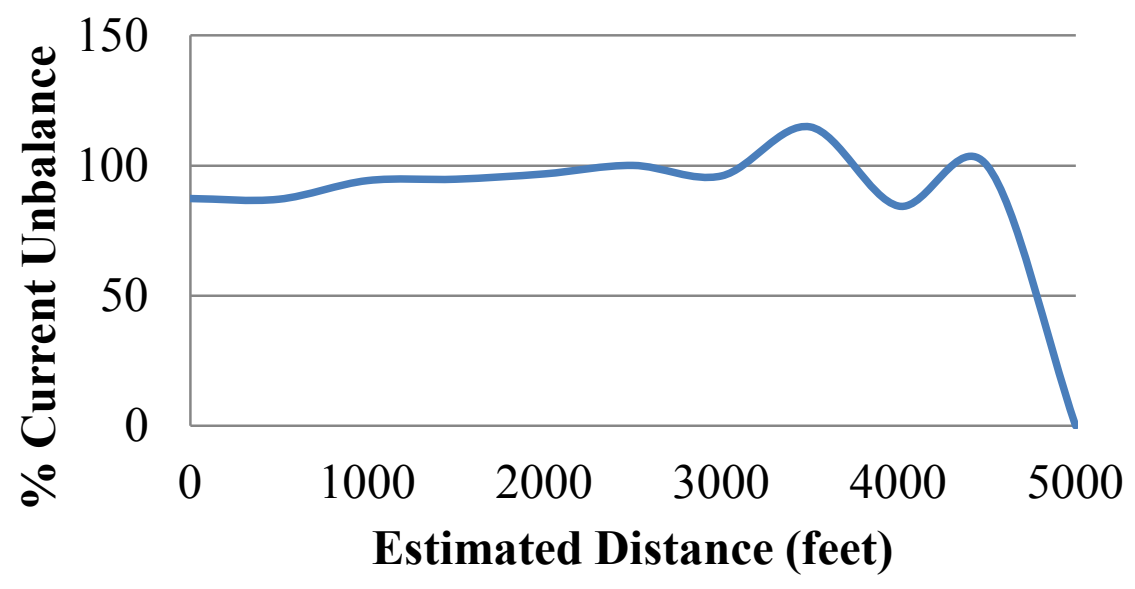

Figure 4.8 Percent of feeder current unbalance

From Figure 4.7 one can see that large scale of grid-connected EV could cause voltage unbalance at the feeder level in the City of Ottawa.

\subsection{Power Loss Impact}

The feeder power loss is also calculated for large EV integration into the distribution system of Hydro Ottawa. The electric power distribution losses include the 
line losses, cable losses and transformer load losses between the feeder and the residences. The losses are divided into two parts to discuss. The first part is about the basic situation, which means the losses are caused by normal electric power consuming without any EV chargers. The second part is about the heavy unbalance situation, which means the losses are caused by EV interconnection (each transformer connects two EVs on Phase A or Phase B phase but seven EVs on Phase C). The basic power generation and losses are in Table 4.5 and the total losses for EV interconnection are in Table 4.6. From these tables one can see that the unbalance situation will cause more distribution losses due to the feeder voltage regulators working to reach a stable and balanced output.

Table 4.5 Basic Electric Power Generation and Losses

\begin{tabular}{|c|c|c|c|c|}
\hline Summary & kW & kvar & kVA & Power Factor (\%) \\
\hline Sources (Swing) & 3658.74 & 1798.97 & 4077.1 & 89.74 \\
\hline Generators & 0 & 0 & 0 & 0 \\
\hline Total Generation & $\mathbf{3 6 5 8 . 7 4}$ & $\mathbf{1 7 9 8 . 9 7}$ & $\mathbf{4 0 7 7 . 1}$ & $\mathbf{8 9 . 7 4}$ \\
\hline Line Losses & 1.71 & 5.79 & 6.03 & 28.27 \\
\hline Cable Losses & 2.63 & 2.16 & 3.4 & 77.29 \\
\hline Transformer Load Losses & 5.41 & 33.64 & 34.07 & 15.88 \\
\hline Transformer No-Load Losses & 0 & 0 & 0 & 0 \\
\hline Total Losses & $\mathbf{9 . 7 4}$ & $\mathbf{4 1 . 5 8}$ & $\mathbf{4 2 . 7 1}$ & $\mathbf{2 2 . 8 2}$ \\
\hline
\end{tabular}

Table 4.6 Electric Power Generation and Losses with EV Charging

\begin{tabular}{|c|c|c|c|c|}
\hline Summary & kW & kvar & kVA & Power Factor (\%) \\
\hline Sources (Swing) & 30138.88 & 1800.81 & 30192.63 & 99.82 \\
\hline Generators & 0 & 0 & 0 & 0 \\
\hline Total Generation & $\mathbf{3 0 1 3 8 . 8 8}$ & $\mathbf{1 8 0 0 . 8 1}$ & $\mathbf{3 0 1 9 2 . 6 3}$ & $\mathbf{9 9 . 8 2}$ \\
\hline Line Losses & 544.24 & 1990.41 & 2063.47 & 26.38 \\
\hline Cable Losses & 216.92 & 152.21 & 264.99 & 81.86 \\
\hline Transformer Load Losses & 690.8 & 3393.97 & 3463.56 & 19.94 \\
\hline Transformer No-Load Losses & 0 & 0 & 0 & 0 \\
\hline Total Losses & $\mathbf{1 4 5 1 . 9 7}$ & $\mathbf{5 5 3 6 . 5 9}$ & $\mathbf{5 7 2 3 . 8 1}$ & $\mathbf{2 5 . 3 7}$ \\
\hline
\end{tabular}




\subsection{Summary}

The impact of large scale EV charging on the feeder unbalance and power losses for the distribution system of Hydro Ottawa is investigated in this Chapter. On the tested feeder the three phases connect different number of transformers, which mean there are different residences on each phase. Here, we assume each transformer has the same number of household load. If the number of EVs under each transformer is increased at the same time, the entire system will be unbalanced. Therefore, to maintain a balanced system we should adjust the transformer numbers to each phase when the number of EVs increases. To observe the unbalance situation, we connected seven EV chargers to the Cphase transformers. In this situation, the distribution loss increases due to the cables and line impedances. 


\section{Chapter: Conclusions and Future Work}

The purpose of this thesis is to investigate the EV charging impact on the Hydro Ottawa distribution systems and provide optimization solution for the future EV charging strategies without updating the power basic infrastructure such as secondary drop leads, transformers, and feeders. Following conclusions are drawn from the investigation results of the thesis.

- It is observed that the transformer becomes the main limitation to charge the neighborhood EVs. Although the transformer power capacity and the base load could limit the penetration level of EV charging, the ambient temperature also would influence it. Here the factor of acceleration aging and the factor of equivalent aging of transformer are used to assess the charging capacity of the dump charging pattern (simultaneous charging pattern).

- To increase the capacity of neighborhood EV charging, an optimal EV charging strategy is designed. Based on the driver habits and the transformer limitation, flexible charging rate is used for the optimization. The charging capacity is greatly increased when using the Honda Fit $6.6 \mathrm{~kW}$ charger as the representative charger without updating the basic infrastructure.

- On the feeder load simulation, the unbalance charging situation would cause more power losses than the balance charging situation.

The future work should include following aspects:

- Develop advanced energy management systems to optimal EV charging both at the neighborhood level and the distribution system level by considering the key 
factors investigated in this thesis, i.e., transformer capacity, secondary current limit, transformer ageing, voltage unbalance, power losses, etc.

- More accurate stochastic model should be studied for different pattern of EV charging, e.g., week days, weekend days, and holidays.

- Investigate the vehicle-to-grid (V2G) applications and develop advanced V2G strategies by considering the above the effect of the above factors. 


\section{References}

[1] Natural Resources Canada. (2013, Apr.). Electric Vehicle Technology Roadmap for Canada: A Strategic Vision for Highway-Capable Battery-Electric, Plug-in and Other Hybrid-Electric Vehicles. Natural Resources Canada Public Inquiries, Ottawa, Ontario. [Online]. Available: http://publications.gc.ca/site/eng/399694/publication.html

[2] Durham Strategic Energy Alliance. (2012, Jul.). Electric Vehicle Charging Equipment Demonstration Project Final Report. Durham Strategic Energy Alliance, Oshawa, Ontario. [Online]. Available: https://secure2.mearie.ca/imis15/CMDownload.aspx?ContentKey=f4e598fb-fb86$\underline{\text { 46e6-b01f-1a43d2fb6ee9\&ContentItemKey=d93073e4-74c9-40e3-816e- }}$ $\underline{95897 \mathrm{c} 2 \mathrm{aa} 4 \mathrm{a} 6}$

[3] S. Hadley and A. Tsvetkova. (2008, Jan.). Potential Impacts of Plug-in Hybrid Electric Vehicles on Regional Power Generation. OAK RIDGE NATIONAL LABORATORY, Oak Ridge, Tennessee. [Online]. Available: http://web.ornl.gov/info/ornlreview/v41_1_08/regional_phev_analysis.pdf

[4] T. Ida, K. Murakami, M. Tanaka, and L. Friedman. (2013, Jan.). Consumers' willingness to pay for alternative fuel vehicles: A comparative analysis between the US and Japan. Goldman School of Public Policy, University of California, Berkeley, CA.

[Online]. Available: http://gspp.berkeley.edu/assets/uploads/research/pdf/GSPP13-001 Tanaka_Ida_Murakami_Friedman_Alternative_Fuel_Vehicles_011313.pdf 
[5] European Association for Battery, Hybrid and Fuel Cell Electric Vehicles (AVERE). (2012, Sep.). Norwegian Parliament extends electric car iniatives until 2018. AVERE. [Online].

Available: http://www.avere.org/www/newsMgr.php?action=view\&frmNewsId=611\&section= $\underline{\text { \&type }}=\&$ SGLSESSID $=$ phhp $3 \mathrm{v} 7 \mathrm{n} 4 \mathrm{cs} 275 \mathrm{~g} 46 \mathrm{piss} 4 \mathrm{bv} 71$

[6] K. Clement, E. Haesen, and J. Driesen, "Stochastic analysis of the impact of plug-in hybrid electric vehicles on the distribution grid," in Proc. 2009 The 20th International Conference and Exhibition on Electricity Distribution - Part 2, pp.1-1.

[7] S. W. Hadley. (2006, Oct.). Impact of Plug-in Hybrid Vehicles on the Electric Grid. OAK RIDGE NATIONAL LABORATORY, Oak Ridge, Tennessee. [Online]. Available: http://web.ornl.gov/info/ornlreview/v40 2 07/2007 plug-in paper.pdf

[8] K. Parks, P. Denholm and T. Markel. (2007, May). Costs and emissions associated with plug-in hybrid electric vehicle charging in the Xcel Energy Colorado Service Territory. National Renewable Energy Laboratory, Golden, Colorado. [Online]. Available: http://www.nrel.gov/vehiclesandfuels/pdfs/41410.pdf

[9] J. Taylor, A. Maitra, M. Alexander, D Brooks, and M. Duvall, "Evaluation of the impact of plug-in electric vehicle loading on distribution system operations," in Proc. 2009 Power \& Energy Society General Meeting, pp.1-6.

[10] K. Qian, C. Zhou, M. Allan, Y. Yuan, "Modeling of Load Demand Due to EV Battery Charging in Distribution Systems," IEEE Trans. Power Systems, vol. 26, pp. 802-810, May 2011. 
[11] S. Shao, M. Pipattanasomporn, and S. Rahman, "Challenges of PHEV penetration to the residential distribution network," In Proc. 2009 Power \& Energy Society General Meeting, pp. 1-8.

[12] New York ISO. (2009, Jun.). Alternate route: electrifying the transportation sector. New York ISO. [Online]. Available: http://s3.amazonaws.com/zanran_storage/www.nyiso.com/ContentPages/19214547.p $\underline{\mathrm{df}}$

[13] S. W. Hadley. (2006, Oct.). Impact of plug-in hybrid vehicles on the electric grid. Oak Ridge National Laboratory, Oak Ridge, Tennessee. [Online]. Available: http://web.ornl.gov/info/ornlreview/v40_2_07/2007_plug-in_paper.pdf

[14] S. L. Judd, and T. J. Overbye, "An evaluation of PHEV contributions to power system disturbances and economics," in Proc. $200840^{\text {th }}$ North American Power Symposium, pp.1-8.

[15] X. Yu, "Impacts assessment of PHEV charge profiles on generation expansion using national energy modeling system," in Proc. 2008 IEEE Power and Energy Society General Meeting - Conversion and Delivery of Electrical Energy in the 21st Century, pp.1-5.

[16] K. Morrow, D. Karner, and J. Francfort. (2008, Nov.). U.S. Department of Energy Vehicle Technologies Program-Advanced Vehicle Testing Activity: Plug-in Hybrid Electric Vehicle Charging Infrastructure Review Final Report. Battelle Energy Alliance. [Online]. Available: http://www1.eere.energy.gov/vehiclesandfuels/avta/pdfs/phev/phev_infrastructure_re port 08.pdf 
[17] K. Clement, E. Haesen, and J. Driesen, “The impact of charging plug-in hybrid electric vehicles on the distribution grid," IEEE Trans. Power Systems, vol. 25, pp. 371-380, Feb. 2010.

[18] P. Denholm and W. Short. (2006, Oct.). An evaluation of utility system impacts and benefits of optimally dispatched plug-in hybrid electric vehicles. National Renewable Energy Laboratory, Golden, Colorado. [Online]. Available: http://www.lifepo4.info/Battery_study/Reports/An_Evaluation_of_Utility_System_I mpacts_and_Benefits_of_Optimally_Dispatched_PlugIn_Hybrid_Electric_Vehicles.pdf

[19] G. Putrus, P. Suwanapingkarl, D. Johnston, E. Bentley, and M. Narayana, "Impact of electric vehicles on power distribution networks," in Proc. 2009 IEEE Vehicle Power and Propulsion Conf., pp.827-831.

[20] R. Liu, L. Dow, and E. Liu, "A survey of PEV impacts on electric utilities," in Proc. 2011 IEEE PES Innovative Smart Grid Technologies (ISGT), pp. 1-8.

[21] G. A. Putrus, P. Suwanapingkarl, D. Johnston, E. C. Bentley, and M. Narayana, "Impact of electric vehicles on power distribution networks," in Proc. 2009 IEEE Vehicle Power and Propulsion Conf., pp. 827-831.

[22] J. A. Orr, A. E. Emanuel, and D. J. Pileggi, “Current Harmonics, Voltage Distortion, and Powers Associated with Electric Vehicle Battery Chargers Distributed on the Residential Power System," IEEE Trans. Industry Applications, vol. IA-20, pp.727734. Jul, 1984.

[23] California Public Utilities Commission. (2009, Aug.). Order Instituting Rulemaking on the Commission's own motion to consider alternative-fueled vehicle 
tariffs, infrastructure and policies to support California's greenhouse gas emissions reduction goals. Filed Public Utilities Commission, San Francisco, CA. [Online]. Available: http://docs.cpuc.ca.gov/PUBLISHED/FINAL_DECISION/106042-02.htm

[24] K. Schneider, C. Gerkensmeyer, M. Kintner-Meyer, and R Fletcher, "Impact assessment of plug-in hybrid vehicles on Pacific Northwest distribution systems," in Proc. 2008 IEEE Power and Energy Society General Meeting, pp. 1-6.

[25] S. Rahman and G.B. Shrestha, "An investigation into the impact of EV load on the electric utility distribution system," IEEE Trans. Power Delivery, vol. 8, pp. 591-597, Apr. 1993.

[26] J. de Hoog, T. Alpcan, M. Brazil, D. A. Thomas, and I. Mareels, "Optimal Charging of Electric Vehicles Taking Distribution Network Constraints Into Account," IEEE Trans. Power Systems, vol. PP, pp. 1-11, May, 2014.

[27] P. Richardson, D. Flynn, and A. Keane, "Optimal charging of electric vehicles in low-voltage distribution systems," IEEE Trans. Power Systems, vol. 27, pp. 268-279. Feb. 2012.

[28] J. de Hoog, D. A. Thomas, V. Muenzel, D. C. Jayasuriya, T. Alpcan, M. Brazil, and I. Mareels, "Electric vehicle charging and grid constraints: Comparing distributed and centralized approaches," in Proc. 2013 IEEE Power and Energy Society General Meeting, pp. 1-5.

[29] Pollution Probe. (2013) Electric Mobility Adoption and Prediction (EMAP) Toronto $\begin{array}{lll}\text { Report. } & \text { [Online]. Available: }\end{array}$ http://www.pollutionprobe.org/EMAP/EMAP_Report_Sample.pdf 
[30] Pollution Probe. (2014) Electric Mobility Adoption and Prediction (EMAP): Developing a strategic approach to enabling electric vehicle technology in the City of Ottawa.

[31] A. Arancibia, K. Strunz, and F. Mancilla-David, "A unified single- and three-phase control for grid connected electric vehicles," IEEE trans. Smart Grid, vol. 4, pp. 1780-1790, Dec. 2013.

[32] Sony Corporation. Lithium Ion Rechargeable Batteries Technical Handbook. [Online]. Available: http://www.sony.com.cn/products/ed/battery/download.pdf

[33] The Mathworks, Inc. (2014, Feb.). Matlab R2014a Help Document: Battery Implement Generic Battery Model, version 8.3.0.532 (R2014a). The Mathworks, Inc., $\begin{array}{llll}\text { Natick, } & \text { MA. } & \text { [Online]. }\end{array}$ http://www.mathworks.com/help/physmod/sps/powersys/ref/battery.html?searchHigh $\underline{\text { light }=\text { Implement }+ \text { Generic }+ \text { Battery }+ \text { Model }}$

[34] O. Tremblay and L. A. Dessaint, "Experimental validation of a battery dynamic model for EV applications," in Proc, 2009 EVS24 World Electric Vehicle Journal, vol. 3, p.p. 1-10.

[35] F. Musavi, M. Edington, W. Eberle, and W. G. Dunford, "Evaluation and efficiency comparison of front end AC-DC plug-in hybrid charger topologies," IEEE Trans. Smart Grid, vol. 3, pp. 413-421, Mar. 2012.

[36] M. Yilmaz and P. T. Krein, "Review of battery charger topologies, charging power levels, and infrastructure for plug-in electric and hybrid vehicles," IEEE Trans. Power Electronics, vol. 28, pp.2151-2169, May, 2013. 
[37] SAE Electric Vehicle and Plug-in Hybrid Electric Vehicle Conductive Charge Coupler, SAE J1772, Oct. 2012. [Online]. Available: http://standards.sae.org/j1772_201210/

[38] Government of Canada. (2014, Jul.). Climate: Hourly Data Report for July 17, 2013. Environment Canada, National Inquiry Response Team, Fredericton, New $\begin{array}{lll}\text { Brunswick. } & \text { [Online]. Available: }\end{array}$ http://climate.weather.gc.ca/climateData/hourlydata_e.html?StationID=49568\&Mont $\underline{\mathrm{h}=7 \& \text { Day }=17 \& \text { Year }=2013 \& \text { timeframe }=1}$

[39] FIAT. 500e. Fiat S.p.A. Turin, Italy. [Online]. Available: http://www.fiatusa.com/en/2013/500e/

[40] E. Loveday. (2011, Mar.). Report: Nissan to equip Leaf with uprated onboard charger in 2012. [Online]. Available: http://green.autoblog.com/2011/03/07/reportnissan-to-equip-leaf-with-uprated-onboard-charger-in-201/

[41] Nissan. 2015 leaf features. Nissan Canada Inc., Orillia, Ontario. [Online]. Available: http://www.nissan.ca/en/electric-cars/leaf/features/

[42] HONDA. (2014). 2014 Accord Plug-in. American Honda Motor Co., Inc., Torrance, CA. [Online]. Available: http://automobiles.honda.com/accord-plug-in/charging-anelectric-vehicle.aspx

[43] TESLA. (2014). 85 kWh Battery. Tesla Motors, Palo Alto, CA. [Online]. Available: http://www.teslamotors.com/models/design

[44] A. D. Hilshey, P. D. H. Hines, P. Rezaei, and J. R. Dowds, "Estimating the Impact of EV Smart Charging on Distribution Transformer Aging," IEEE Trans. Smart Grid, vol. 4, pp. 905-913, Jun. 2013. 
[45] IEEE Guide for Loading Mineral-Oil-Immersed Transformers, IEEE Std C57.911995, Mar. 2012.

[46] O. Sundstroem and C. Binding, "Flexible charging optimization for electric vehicles considering distribution grid constraints," IEEE Trans. Smart Grid, vol. 3, pp. 26-37, Mar. 2012.

[47] B. Oliver, P. Probe, and M. Flores. EMAP: Informing the development of an EV deployment strategy in the City of Ottawa. Presented at Evve Conference and Trade Show, Gatineau, Canada, Oct. 21-23, 2013. [Online]. Available: http://emcmec.ca/evve2013/pdfs/22OCT/TS8/3 Oliver_Flores.pdf

[48] T. Gonen, Electric Power Distribution System Engineering, $2^{\text {nd }}$ Ed. Boca Raton, FL: Taylor \& Francis Group, 2008, p. 630 